\title{
Counting on COVID-19 vaccine: Insights into the current strat- egies, progress and future challenges
}

\author{
Ramesh Kandimalla ${ }^{1,2,}$, Pratik Chakraborty ${ }^{3}$, Jayalakshmi Vallamkondu ${ }^{4}$, Anupama Chaudhary ${ }^{5}$, Sonalinandini \\ Samanta ${ }^{6}$, P. Hemachandra Reddy ${ }^{7-11}$, Vincenzo De Feo ${ }^{12, *}$ and Saikat Dewanjee ${ }^{1, *}$
}

\author{
${ }^{1}$ Applied Biology, CSIR-Indian Institute of Technology, Uppal Road, Tarnaka, Hydera- \\ bad 50000, Telangana, India \\ ${ }^{2}$ Department of Biochemistry, Kakatiya Medical College, Warangal 506007, Telangana, \\ India \\ ${ }^{3}$ Advanced Pharmacognosy Research Laboratory, Department of Pharmaceutical Tech- \\ nology, Jadavpur University, Kolkata 700032, India \\ ${ }^{4}$ National Institute of Technology, Warangal 506004, Telangana, India \\ ${ }^{5}$ Orinin-BioSystems, LE-52, Lotus Road 4, CHD City, Karnal, Karnal, Haryana -132001, \\ India \\ ${ }^{6}$ Department of Dermatology (Skin \& Venereology), ESIC Medical College \& Hospital, \\ Bihar, Patna 801103, India. \\ ${ }^{7}$ Texas Tech University Health Sciences Center, Lubbock, TX, USA \\ ${ }^{8}$ Neuroscience \& Pharmacology, Texas Tech University Health Sciences Center, Lub- \\ bock, TX, USA \\ 9Departments of Neurology, School of Medicine, Texas Tech University Health Sciences \\ Center, Lubbock, TX, USA \\ ${ }^{10}$ Public Health Department of Graduate School of Biomedical Sciences, Texas Tech Uni- \\ versity Health Sciences Center, Lubbock, TX, USA \\ ${ }^{11}$ Department of Speech, Language and Hearing Sciences, School Health Professions, \\ Texas Tech University Health Sciences Center, Lubbock, TX, USA \\ ${ }^{12}$ Department of Pharmacy, University of Salerno, 84084 Fisciano, Italy \\ * Correspondence: ramesh.kandimalla@gmail.com; defeo@unisa.it; saikat.de- \\ wanjee@jadavpuruniversity.in
}

\begin{abstract}
Emergence of a novel coronavirus viz., severe acute respiratory syndrome coronavirus (SARS-CoV-2) in late 2019 and its subsequent substantial spread, produced coronavirus disease 2019 (COVID-19) pandemic worldwide. Given its unprecedented infectivity and pathogenicity, COVID-19 pandemic had a devastating impact on human health and its clinical management. It led to development and speedy trials of several vaccine candidates against SARS-CoV-2 at an exceptional pace; as a result, several COVID-19 vaccines were made commercially available in the 2021 first half. Although, several COVID-19 vaccines showed promising results, crucial insights into their epidemiology, protective mechanism and propensity of reinfection are not largely reviewed. In the present report, we provided insights into the prospects of vaccination against COVID-19 and assessed diverse vaccination strategies including DNA, mRNA, protein subunits, vector-based, live attenuated, and inactivated whole/viral particle-based vaccines, imitating COVID-19 infection. Next, we reviewed major aspects of various available vaccines approved by the WHO and by local administration to use against COVID-19. Moreover, we comprehensively assessed the success of these approved vaccines and also their untoward effects including the possibility of reinfection. We also provided an update on the vaccines that are under development and could be the promising candidate. Conclusively, we provided insights into the COVID-19 vaccine epidemiology, their potency and propensity for SARS-CoV-2 reinfection, while a careful review of their current status, strategies, success and future challenges was also presented.
\end{abstract}


Keywords: Coronavirus disease 2019 (COVID-19); SARS-CoV-2; vaccine; coronaviruses; reinfection; epidemiology; spike protein; ACE2 receptor; antigenicity; immunity

\section{Introduction}

Coronavirus disease 2019 (COVID-19) outbreak was first identified reported in Wuhan, China in December 2019 and was found to cause by severe acute respiratory syndrome coronavirus 2 (SARS-CoV-2) which that is a novel pleomorphic, positive- stranded RNA virus belonging to the Coronaviridae family. Quickly, it has become a global pandemic infecting more than 176 million population and causing the death of more than 3.8 million individuals and we are yet to get over it. Thus, an ongoing quest is being carried out for prophylactics/therapeutics to prevent the transition from infection into serious forms of COVID-19 [1]. Though measures like physical distancing, use of masks, frequent sterilization, repurposing of existing drugs, etc. are being undertaken, the development of herd immunity through vaccination seems to be the most instrumental one.

Many therapeutic strategies which can prove useful in the management of COVID19 disease are underway and are being currently studied, such as blocking the virus from binding cell receptors, preventing synthesis and replication of viral RNA, restoring innate immunity, and modulating specific receptors/enzymes of the host [2-6]. However, amongst all such strategies to control the pandemic; the role of vaccines in preventing coronavirus $(\mathrm{CoV})$ disease has been the most promising approach. The viral genome encodes several non-structural and structural proteins e.g., spike (S), envelope (E), membrane $(\mathrm{M})$, and nucleocapsid $(\mathrm{N})$ proteins which may play potentially instrumental roles to develop antigenic responses against the virus [7].

Scientists worldwide are in a race to develop safe and efficacious vaccine candidates against SARS-CoV-2 to curb the pandemic of COVID-19. Overwhelming attention has been paid to the spike $(S)$ protein of the virus. $S$ protein makes up the studs outside the virus and is responsible for viral anchoring onto human cells through interaction with angiotensin-converting enzyme 2 (ACE2) receptors [8]. Hence, a vaccine expressing the spike protein should induce a protective immune response without exposure to the whole virus in killed or attenuated form, i.e., spike itself is capable enough to act as the target antigen. Newer platforms use only the genetic material coding for spike protein. Viral vectors with altered genetic payload (weakened viruses carrying sequences for the antigenic spike protein) are also among the frontrunners in the race. Previously none of the adenovirus vectors, DNA vaccines, and mRNA vaccines had been approved by USFDA but the current pandemic has changed the trend. Other candidates in the race for vaccines include protein subunit vaccines, whole virus vaccines and some of them have displayed very promising results.

As of 06 August 2021, 15.3\% of the global population have been fully vaccinated against COVID-19 and 29.7\% have received at least one dose. Perturbations have been raised for the vaccines especially regarding their efficacy and about the possibility of SARS-CoV-2 reinfection after being vaccinated. Mutation of an RNA virus is a matter of grave concern as it gives rise to newer strains, posing apprehensions that a vaccine developed for one strain might not be effective against a mutated strain. In this review, we provided insights into the epidemiology, mechanism of action, and propensity for reinfection with coronavirus for the different vaccines administered worldwide.

\section{Prospects of vaccination against COVID-19}

During the initial stages of SARS-COV-2 infection, glycoprotein $S$ of the virus (protruding out from the surface) binds with ACE2 receptor of host (human) cell. S1 subunit interacts with the ACE2 receptor via the receptor binding domain (RDB) while the S2 subunit is responsible for the fusion of the two cell membranes into a six-helix bundle core 
[9]. In the lower respiratory tract (LRT), viral spike proteins lock themselves with epithelial cells of LRT including the alveolar epithelial cells- type 2. By utilizing the S2 subunit, virus gains entry into lung cells. It seems that SARS-COV-2 has some in-built mechanism to withstand the antiviral activity of interferons [10]. On spotting the viral antigens, the immune system kick-starts the production of antibodies against them. Further, cytokines and chemokines production is triggered by the antibodies which in turn cause fluid buildup within the lungs. This fluid contains T- cells to kill viral particles. CD8+ T cells, in combination with NK cells, destroy the virus-affected epithelial cells. With increasing accumulation of the fluid, lungs find it difficult to extract oxygen from air; as a result, dry cough (one of the preliminary symptoms of COVID-19 infection) starts as an attempt to exhale the fluids. $97 \%$ of patients show up symptoms like fever, dry cough, breathlessness, headache, joint pain, dizziness, diarrhea, nausea, etc. within 11.5 days of acquiring an infection while the median incubation time for the virus is around 4-5 days [11]. Oestrogen can modulate the immune system to fight this infection more effectively, hence men are more likely to succumb to COVID-19 than women [12]. Clearly, overdrive of the immune system in the form of cytokine storm leads to severe conditions amongst COVID-19 patients.

To cope up with the uncontrolled replication of the virus, killer cells e.g., monocytes, neutrophils are recruited leading to overproduction of pro-inflammatory cytokines like IL-6, IL-8, IL-12, TNF- $\alpha$, etc. (cytokine storm). Affected cells may present the viral antigens to $\mathrm{CD} 8+\mathrm{T}$ cells while dendritic cells can present the antigens to CD4+ $\mathrm{T}$ cells. As a result of CD4+ $\mathrm{T}$ cell differentiation, memory $\mathrm{T}$ cells are produced to protect the human body from reinfection by similar strains. Plasma B cells also get into action by producing IgA, IgM, IgG, and other virus-specific antibodies. In a patient infected with COVID-19 for the second time, serum neutralizing antibodies and IgG were spotted within 8 days of hospitalization while IgM was absent [13].

Between SARS-CoV-2 and SARS-CoV, there are 27 amino acid replacements in the S protein whereas 102 and 61 amino acid substitutions are found in the NSP3 and NSP2 respectively [14]. To enter into the cell, SARS-CoV-2 binds with the human ACE2 receptor with higher affinity than the SARS-CoV. MERS-CoV uses an entirely different receptor, DPP4 [15]. As mentioned earlier, SARS-CoV-2 contains four structural proteins namely, spike (S), nucleocapsid (N), envelope (E), and membrane (M) and these are encoded by the 3 '-end of the viral genome [16]. S glycoprotein, a large multi-functional trans-membrane protein plays a vital role in the attachment, fusion, and entry of the virus into the host cell. The S protein consists of S1 and S2 subunits. The S1 subunit has two functional domains viz. N-terminal domain and RDB. The $\mathrm{S} 2$ subunit has three operational domains i.e., fusion peptide, heptad repeat 1 , and heptad repeat 2 . The stalk of the immune-dominant S protein is formed by the trimeric S2 subunit whereupon the S1 sits at the top. The high pathogenicity of the virus may be attributed to a furin cleavage site within the spike protein. Conformational masking and glycan shielding has been hypothesized to let the spike protein circumvent host immune cells [17].

Immunotherapy, since long has been considered to be effective prophylaxis of infectious diseases involving artificial triggering of host immune system to elicit an immune response [18]. Development of a vaccine that elicits the production of neutralizing antibodies to $S$ protein is the primary aim of the researchers amongst the various COVID-19 vaccines (in use and trial). Many full-length genomes of SARS-CoV-2, isolated from various countries are now available for delineating polymorphisms in S protein and other important proteins with regard to vaccine development [19]. Epidemiological studies conducted in China have estimated that the reproduction number $\left(\mathrm{R}_{0}\right)$ used as a measure of how many susceptible persons an infected person can potentially infect is 3 , which is on the higher side [20]. Developing herd immunity against COVID-19 seems to be the only way out to get rid of the ongoing pandemic. However, infection of more than $60 \%$ of the global population to generate this herd immunity poses an immense risk of fatality and other losses. Hence, constituting an effective vaccine is crucial and considered the only 
practical way to establish herd immunity. Numerous government and non-government agencies have come up with funding for vaccine development against COVID-19. To develop a safe and effective vaccine, it is critical that before every/any vaccine is released for public use; all pre-clinical and clinical trials are done with vigilance to avoid severe adverse effects. Before the advent of coronavirus, the fastest developed vaccine was the mumps vaccine which also took about 5 years to make the cut. Within more or less a year of release of the genome sequence of SARS-CoV-2 in January 2020, multiple vaccines have been approved for public use worldwide. Clearly, uncontrolled haste would possibly worsen the situation. Fast-tracking vaccine development by combining various phases involves trials being conducted on smaller groups. Cooperation among various international organizations is critical at this point regarding the emergence of unwanted effects in various demographic groups, especially for the newer platforms being used. Exorbitant vigilance must be continued to prevent public use of any suspicious candidate vaccine under any kind of pressure. SARS-CoV-2 is an RNA virus, generally having a high mutation rate. Genetic instability has long been considered to represent a challenge to develop long-lasting protection against RNA viruses due to the emergence of newer and resistant variants with time [21]. Protective effect of a candidate vaccine is highly attributed to antibodies against the spike protein, against the RDB of the $S$ protein to be more precise. Often, healed patients display high titers of SARS-CoV-2 neutralizing antibodies [22]. Effective vaccination may not only significantly reduce the occurrence and severity of illness but also prevent disease spread.

\section{Strategies to imitate COVID-19 infection regarding vaccination}

Since the initial years of the current century, CoVs were thought to cause mild flulike symptoms. Serial outbreaks of SARS in 2002, MERS in 2012, and COVID-19 from 2019 onwards have demonstrated their pathogenicity globally. Global losses of human resources and economy due to the ongoing COVID-19 pandemic make vaccines highly desirable, as presently no definite drug is available against coronavirus. Vaccine research targeting SARS-CoV-2 worldwide is exploring various strategies in search of a safe and effective vaccine. The various candidates identified in the search done so far include inactivated virus vaccines, recombinant viral vaccines, subunit vaccines, nucleic acid vaccines, and attenuated vaccines (Table 1). Nucleic acid vaccines are relatively newer candidates in the process of vaccine development. Of note, DNA vaccines need to reach the nucleolus of the cell while RNA vaccines can act from within the cytoplasm. They express desirable antigens inside the cell to induce an immune response.

Table 1. Strategies in use to imitate SARS-COV-2 infection regarding vaccination.

\begin{tabular}{|c|c|c|c|c|}
\hline S. No. & Stategies & Advantages & Limitations & Leading candidates \\
\hline \multirow[t]{3}{*}{1} & DNA vaccine & Stable, cost effective, induces & Immunogenicity & Zycov-D, INO-4800 \\
\hline & & cellular, humoral and & lower than viral & \\
\hline & & neutralizing antibody response & vaccines & \\
\hline \multirow[t]{3}{*}{2} & mRNA vaccine & Easy to design, lower risk of & Carrier required to & BNT162b2, mRNA- \\
\hline & & accidental infection than viral & stabilize and pack & 1273, ARCoV, \\
\hline & & vaccines & naked RNA & CureVac \\
\hline \multirow[t]{5}{*}{3} & Protein subunit & Non-infectious, pure antigens & Comparatively & Corbevax, Sanofi, \\
\hline & & easily elicit immunogenic & costlier & NVX-CoV2373, \\
\hline & & response & & UB612, SCB-2019, \\
\hline & & & & EpiVacCorona, \\
\hline & & & & Nanocovax \\
\hline
\end{tabular}




\begin{tabular}{|c|c|c|c|c|}
\hline 4 & $\begin{array}{l}\text { Recombinant } \\
\text { viral vector }\end{array}$ & $\begin{array}{l}\text { Efficient design easily elicits } \\
\text { immunogenicity to desired level, } \\
\text { fast and reusable platform }\end{array}$ & $\begin{array}{c}\text { Possibility of } \\
\text { undesirable reactions, } \\
\text { possibility of Th2 bias }\end{array}$ & $\begin{array}{c}\text { AZD1222, Janssen } \\
\text { Immunoty Bio, } \\
\text { GRAd-COV2, } \\
\text { Sputnik V, } \\
\text { Convidicea }\end{array}$ \\
\hline 5 & $\begin{array}{l}\text { Live attenuated } \\
\text { vaccine }\end{array}$ & $\begin{array}{c}\text { Presents entire viral antigen to } \\
\text { immune system, strong and long } \\
\text { lasting immune response }\end{array}$ & $\begin{array}{c}\text { Risk of infection } \\
\text { going out of control, } \\
\text { not suitable for } \\
\text { immunocompromised } \\
\text { individuals } \\
\end{array}$ & $\begin{array}{l}\text { CoviVac, BCG } \\
\text { (repurposing) }\end{array}$ \\
\hline 6 & $\begin{array}{l}\text { Whole killed } \\
\text { vaccine }\end{array}$ & $\begin{array}{l}\text { Rapid development, can elicit } \\
\text { very good immunogenic } \\
\text { response, broad antigenic profile }\end{array}$ & Th2 bias & $\begin{array}{c}\text { BBIBP-CorV, } \\
\text { CoronaVac, } \\
\text { VLA2001, BBV152 }\end{array}$ \\
\hline 7 & $\begin{array}{l}\text { Virus like } \\
\text { particles }\end{array}$ & $\begin{array}{c}\text { Non-infectious, broad antigenic } \\
\text { profile }\end{array}$ & $\begin{array}{c}\text { Weaker } \\
\text { immunogenicity }\end{array}$ & Medicago \\
\hline
\end{tabular}

Nanotechnology can play a vital role in vaccine development as both nanoparticles and viruses operate at similar size scales. The ability of nanoparticles to enter cells, to enable expression of nucleic acids and/or directly target immune cells for co-delivery of antigens and adjuvants make them attractive platforms for vaccine design.

\subsection{DNA vaccine}

In 1986, the US patent was granted for a cDNA-based vaccine against the canine coronavirus [23]. DNA vaccines are attractive candidates for research owing to their simplicity, stability, and ease of production. The S, M, and N proteins of coronavirus have been reported to induce cellular and humoral responses making them essential components to be included for various DNA vaccine-candidates. In a mouse model experiment conducted way back in 2004, DNA vaccine-associated expression of S protein has generated both T-cell and neutralizing antibody responses besides lowering replication of SARS$\mathrm{CoV}$ in the respiratory tract [24].

DNA vaccines deliver coronavirus genes to the human cells mostly through recombinant plasmid DNA. The plasmid contains mammalian promoter along with transgene sequence coding for the desired antigen, $S$ protein in this case. The principle relies on DNA translocation within the nucleus of the cell. Once in the nucleus, using the host cell machinery antigenic proteins are expressed by the delivered viral genetic material. Thus, they are much safer than a live attenuated virus or inactivated virus regarding chances of pathogenicity. Moreover, these vaccines use human cells as production houses to increase the antigenic load, thus decreasing individual dose requirements. Antigen-presenting cells can be transfected directly with the delivered genetic material. Expressed antigens are loaded onto MHC I and MHC II molecules due to the cross-priming potential [25]. The antigens are either released by exosomes or apoptotic bodies which lead to recognition by antigen-presenting cells and further evolvement of humoral or cytotoxic immune responses. However, a low risk of viral mutation still coexists by integration of transfected DNA with host somatic DNA leading to irregularities in genetic expressions.

Devices like electroporators, gene guns can be used to improve the delivery and uptake of the genetic material by antigen-presenting cells. Antigen-presenting cells will, in turn, present the antigens to naive CD4+ and CD8+ T cells of the secondary lymphatic system thereby generating cellular immune responses. Further, antigens produced later 
in the body will also reach secondary lymph organs and activate B cells to produce antibodies. Suitable adjuvants may also be co-administered to boost adaptive immunity.

\section{2. $m R N A$ vaccine}

To combat a rapidly spreading virus, using mRNA instead of protein is a faster approach as a vaccination strategy. This approach is arguably the most rapid and flexible amongst different vaccination strategies being taken up worldwide. The mRNA vaccines deliver a short viral mRNA sequence to express the antigenic protein inside the host cell. This way, the foreign antigenic protein is produced within the host cell to induce adaptive immunity. Since it does not involve genetic recombination, there stands no chance of dysregulation in host genetic expressions, unlike the DNA vaccines. The immunogenicity of these mRNA vaccines is comparable to that of the inactivated viruses while at the same time these are devoid of the risks of accidental virulence associated with whole viral vaccines. It is also superior to protein subunit vaccines as it does not pose the risk of protein contamination besides bypassing the time taking and laborious steps of purification and standardization of viral proteins. However, the requirement of very low temperatures $(\leq$ $-20^{\circ} \mathrm{C}$ ) for long term storage of RNA vaccines makes them difficult to use at the community scale.

Generation of RNA vaccine involves reactions between a DNA plasmid template and a recombinant RNA polymerase. A sequence analogous to capping and a poly(A) tail is added at $5^{\prime}$ and $3^{\prime}$ ends respectively to form a mature and stable RNA sequence. The hydrophilic nature and strongly negative charge of mRNA pose difficulty in cellular uptake of mRNA in vivo. Further, naked mRNA is highly susceptible to ribonuclease in the cytoplasm. Thus, efficient carriers preferably lipidic nanoparticles are required to pack the mRNA in a stable injectable form. Self-amplifying mRNA vaccines contain both the genes encoding desired antigen and the genes required for self-replication enzymes. The main difference between these two types of RNA vaccines lies in the time taken for the onset of action. The conventional one presents with prompt antigen production within the host cell and therefore humoral and cellular immune responses are induced quickly. On the other hand, while delayed antigenic production is seen with the self-amplifying ones; these produce higher yield and confer equivalent protection in the long run with a much lower dose. RNA, being the minimally immunogenic genetic vector, circumvents the risk of anti-vector immunity to a large extent even on repeated administrations. The mRNA vaccines also have the capability to induce both antibody production and T-cell responses, since the protein antigen i.e. the $S$ protein in most cases is produced using host machinery [26]. However, antigenic expression after mRNA vaccination is transient, limiting its persistence in the human body and thus calling for repeated administrations at certain intervals.

\subsection{Protein subunit vaccine}

Subunit vaccines are made up of either synthetic peptides or recombinant proteins responsible for eliciting immunogenicity. Since these vaccines consist of only certain immunogenic fragments instead of the whole viruses, they are quite efficacious as well as safer. Further, small defined peptide fragments are easy to scale up and pose fewer risks of side effects. As already mentioned, a number of structural proteins e.g. spike (S), envelope (E), membrane (M), and nucleocapsid (N); expressed by SARS-CoV may act as antigens to activate the immune response. Generally, either booster doses or co-administration of suitable adjuvants are required along with peptide subunits to elicit an immunogenic response to the desired level. Currently, the highest number of vaccine candidates against SARS-CoV-2 are using this strategy [27].

Amongst the various structural proteins expressed by SARS-CoV; S proteins are the most suitable candidates as vaccines since they contain sites for both binding of the receptor (S1) and membrane fusion (S2). Subunit vaccines based on S protein are expected to 
generate antibodies preventing the binding of virus and later fusion of membranes thus conferring double-layer protection against entry of the virus. Interestingly, the infectivity of SARS-CoV is counteracted by human $\mathrm{mAb}$ that binds to $\mathrm{S}$ protein through $\mathrm{N}$-terminal thereby preventing binding of receptor through syncytia formation. On the contrary, few epitopes of S protein of SARS-CoV can elicit potentially harmful immune responses. Hence, it is a must to identify and eliminate such epitopes beforehand. $S$ protein has been reported to protect mice and monkeys from SARS-CoV challenge by inducing serum neutralizing antibodies [28]. S protein is also shown to be responsible for eliciting responses by CD4+ and CD8+ T-cells [29]. RDB is a 193-amino acid segment in the center of the S1 subunit; responsible for binding to receptors present on the target cells. It has been reported that vaccines based on RDB can produce antibodies in mice and rabbits displaying $50 \%$ neutralizing titres at $>1: 10,000$ serum dilution [30]. RDBs are advantageous over complete S protein in that, unlike S protein it produces only neutralizing antibodies owing to the absence of immunodominant regions responsible for non-neutralizing antibody formation. However, the absence of some potentially important epitopes may also make it inferior to $S$ protein as far as an immunogenic response is concerned [31]. Recombinant sequences comprising peptides from different variants can be used to protect against multiple viral strains. Counteracting antibodies have also been produced using $\mathrm{M}$ proteins which are generally responsible for the proper configuration of the viral envelope [32]. $\mathrm{N}$ proteins have demonstrated elevated $\mathrm{T}$ cell response and when used in conjunction with adjuvants, have also produced IgG antibodies but these antibodies fail to protect from subsequent infection [33,34]. As a general rule, prefusion-stabilized viral glycoproteins are usually more immunogenic, thus being more attractive vaccine targets. Delivered antigen must maintain its surface chemistry and profile of the original pre-fusion spike protein to preserve the epitopes for inducing proper antibody responses [35]. Further, using receptor binding motif as antigen would enhance the neutralizing antibody response.

\subsection{Viral vector vaccine}

Viral vector vaccines consist of a less virulent, actively dividing virus recombined with a gene of interest encoding desired antigenic protein. Replication of this recombinant virus inside the host cell would produce coronavirus proteins leading to activation of the immune system. Viral vectors are selected in such a way that they can infect human cells easily and can be detected by antigen-presenting cells. To minimize chances of pre-existing host immunity, non-human viruses or rare serotype viruses are usually selected as vectors [36]. Accidental integration of viral genome with host genome may lead to uncontrolled replication resulting in disaster. In some cases, the viral vector proteins may also serve as adjuvants to elicit an immune response against the highly pathogenic antigen [37]. Genetically engineered viral vectors expressing SARS-CoV-2 proteins have been at the center of attraction right from the start of the COVID-19 vaccine development. Increasing interests have been focused on this type as vector-based vaccines can be constructed relatively fast and used even without an adjuvant. The spike $S$ protein, specifically the RDB of S-protein has been identified as neutralizing epitope which could be actively pursued for the development of viral vector-based vaccines [38]. Replication-competent vectors are required at lower-dose to elicit strong responses as the multiplying vectors can result in enhanced antigen presentation whereas replication-defective vectors need to be administered in higher doses.

To serve as a viral vector, adenovirus comes up with advantages like ease of administration along with non-pathogenicity to human being. Back in 2003, an adenovirus vector containing genes for $\mathrm{N}, \mathrm{S}$, and M protein of SARS-CoV successfully induced antibody response to $\mathrm{S} 1$ fragment and $\mathrm{T}$ cell response to $\mathrm{N}$ protein in Rhesus macaques monkeys [39]. Poxvirus is another potential vector candidate owing to greater insert size, cytoplasmic gene expression, and long-lasting immune response in the human. Newcastle disease virus could have been another possible vector candidate, but a higher risk of pathogenesis and probable carcinogenicity is holding it back in the race. 


\subsection{Live attenuated vaccine}

Historically, live attenuated vaccines have been most successful against intracellular pathogens [40]. Attenuated live virus, mimics natural infection to elicit long-lasting immune response but with a lower risk of pathogenicity. Generally, though this type of vaccine is highly efficacious, safety is a paramount concern in its usage. Live attenuated vaccines present the entire viral antigens to the host immune system, deliver antigens to respective cell compartments, and are easily presented through antigen-presenting cells similar to natural infection thus generating cytotoxic $\mathrm{T}$ cell responses, antigen-specific effectors, and also memory cells. Thus, this type of vaccines can generate $\mathrm{T}$ cell responses as well as antibody responses with long-lasting immune memory. The most critical step during their development is the optimization of balance between high immunogenicity and low virulence. Reversal of virulence inside the host becomes a concern in few cases. In the case of coronavirus, deletion of genes encoding E protein has successfully developed non-virulent mutants [41, 42]. Hamsters vaccinated with the mutant under discussion have raised the level of serum neutralizing antibodies and protected from clinical symptoms and replication of SARS-CoV in the respiratory tract [43]. Some other mutations are also under research. Due to the large genome size of coronavirus, it takes a longer time to prepare a non-virulent clone. Reversal to virulent form may effectively be prevented through gene replacement knockout strategy more effectively than chemical treatment or irradiation [44]. For attenuation, exhaustive long-term repetitive cultures are required. Generally, via repeated replication in the host, wild-type pathogen is allowed to accumulate mutations that adapt it to the new host progressively lowering the virulence to humans. Even after that, the attenuated strain might revert to the wild genotype. Coronaviruses are known to frequently recombine in nature, further complicating the development of the live attenuated vaccines. These types of vaccines are therefore generally not recommended for immunocompromised individuals considering the risks.

\subsection{Whole killed vaccinel inactivated virus vaccine}

Whole killed virus vaccine refers to a virus devoid of its ability to infect and replicate within host cell but retaining its immunogenicity. Generally, the whole virus is neutralized by heat, radiation, or chemical treatment thus requiring considerably fewer efforts than live attenuated vaccines. Inactivated viral vaccine presents the same epitopes to the immune system as natural infection by the virus rather than only the spike protein in case of some other technologies discussed earlier. Formaldehyde and $\beta$-propionolactone are the most popular chemical agents used for inactivation. Successful sterilization of SARS$\mathrm{CoV}$, in bulk, has been demonstrated by ultraviolet radiation [45]. Inactivated SARS-CoV has been observed to induce neutralizing antibodies in mice models in the past [46]. Generally, administration of booster dose and co-administration of adjuvants help to generate better, long-lasting adaptive cellular immunity responses. Since dead pathogens are administered, this traditional vaccine technology is comparatively safer for immunocompromised patients.

\subsection{Virus-like particles}

Virus-like particles are composed of only the capsid layer without any infectious nucleic acid. They effectively present different surface antigens and/or multiple copies of one antigen mimicking virus structures thereby invoking immune responses [47]. The clustering of antigenic epitopes on the surface of the non-infective particles provides scopes for cognate activation of $B$ cells and enhanced antibody response. Once administered, the antisense RNA inhibits virus expression whereas viral nucleic acid activates pattern recognition receptors to trigger immune responses against the virus characterized by elevated interferons and some proinflammatory cytokines [48]. The safety profile is almost unquestionable since they are devoid of any genetic material. Figure 1 schematically depicts the different vaccination strategies. 


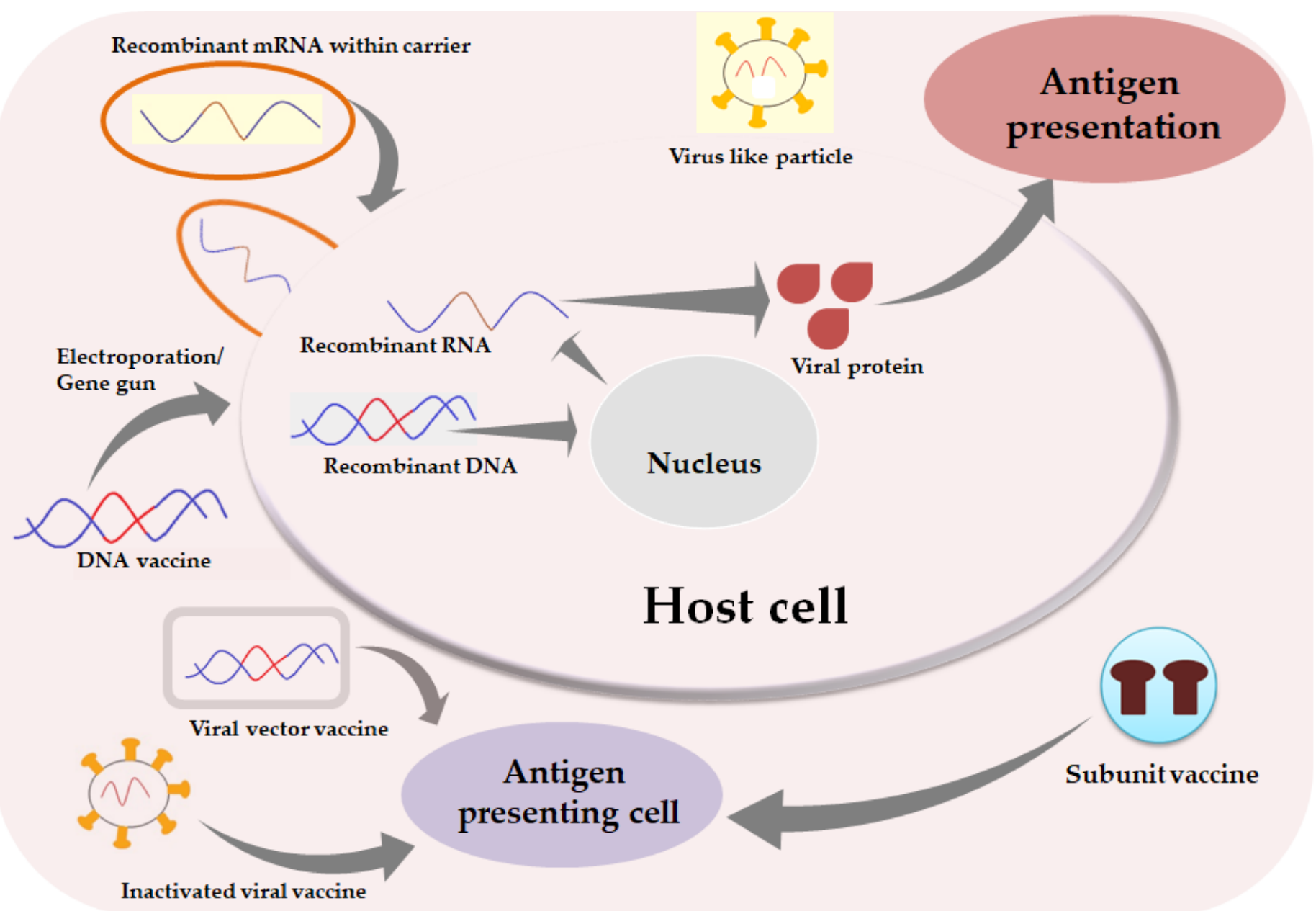

Figure 1. Schematic representation of different vaccines strategies- Recombinant viral vector, live attenuated, inactivated, and mRNA.

\section{Vaccines approved for public use}

Within a year of the emergence of novel coronavirus, the distribution of the first vaccines to protect against it began. Many governments and non-government agencies have spent havoc across the globe on an effective vaccine. Clinical approval is broadly a threephase process. During Phase I, small groups of people receive the candidate under trial. In Phase II, the scope is expanded, and vaccine candidate is administered to people who have characteristics (such as age and physical health) similar to those for whom the new vaccine is intended. In Phase III, the vaccine is given to thousands of people in a multicentric approach and tested for efficacy and safety. After approval, post-marketing surveillance continues as the fourth phase. Regulatory authorities continue to ensure safety through regular/periodic monitoring. Currently, we are on a verge of a very critical step of immunization of the majority of the global population through approved vaccine products. Till date, all the approved vaccines belong to either of the five types i.e. mRNA vaccine, viral vector vaccine, protein subunit vaccine, inactivated virus, and DNA vaccine (Figure 2). 


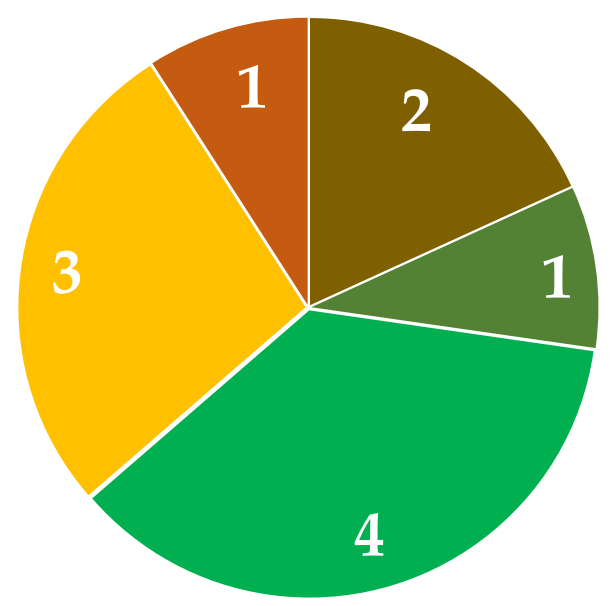

mRNA Vaccine

Protein subunit vaccine

Recombinant viral vector vaccine

Inactivated vaccine

DNA vaccine

Figure 2. Distribution of approved vaccines based on vaccine type. Recombinant viral vector vaccines dominates the list. 1. Protein subunit vaccine; 2 . mRNA vaccine; 3 . inactivated vaccine; 4 . Recombinant viral vector vaccine; and 5 . DNA vaccine

\subsection{Vaccines approved by WHO for global application}

The World Health Organization (WHO), in collaboration with other agencies is aiming to work with vaccine manufacturers to offer low-cost vaccines to countries under the COVAX initiative. So far, WHO has approved six vaccines against COVID-19 (Table 2).

Table 2. A summary table of the vaccines approved by WHO.

\begin{tabular}{ccccc}
\hline S. No. & Vaccines & Types & Carriers & Doses \\
\hline 1 & Oxford-AstraZeneca & Viral vector, & Modified Chimpanzee & 2 doses 8 to 12 \\
& (ChAdOx1nCoV-19, & targeted towards & Adenovirus ChAdOx1 & weeks apart, i.m. \\
& AZD1222) & spike protein & & \\
2 & Pucleoside & Lipid nanoparticle & 2 doses 21 to 28 \\
& (BNT162b2) & modified mRNA & & days apart, i.m. \\
3 & Johnson and Johnson & Spike protein of & Recombinant, replication & Single dose, i.m. \\
& (Ad26.COV2.S, Janssen) & SARS-COV-2 & incompetent adenovirus & \\
& & WA1/2020 strain & Ad26 & \\
4 & Moderna (mRNA-1273) & Nucleoside & Lipid nanoparticles & 2 doses, 4 to 6 \\
& & modified mRNA & weeks apart, i.m. \\
5 & Sinopharm (BBIBP-CorV) & Inactivated virus & Inactivated virus + adjuvant & 2 doses, 3-4 weeks \\
& & (2019-CoV) & apart, i.m. \\
6 & CoronaVac (Sinovac) & Inactivated virus & Inactivated virus + adjuvant & 2 doses, 2-4 weeks \\
& & & & apart, i.m. \\
\hline
\end{tabular}

i.m., intramuscular

\subsubsection{Pfizer-BioNTech (mRNA vaccine)}

This is the first COVID-19 vaccine granted by WHO on 31 December 2020. This is an mRNA-based vaccine developed collaboratively by three pharmaceutical companies of Germany, USA, and China. The vaccine BNT162b2 is composed of nucleoside-modified mRNA (4284 nucleotides long sequence) encoding a mutated form of the full-length spike 
protein of SARS-CoV-2 delivered in the form of lipid nanoparticles encapsulating the nucleic acid. The mRNA BNT162 codes for the RDB of S protein of SARS-CoV-2 besides including T4 fibritin-derived trimerization domain to elicit an immune response. The RNA sequence consists of a $5^{\prime}$ cap, a 48-base signal peptide, and two proline substitutions, $\mathrm{K} 986 \mathrm{P}$ and V987P, allowing the spike to adopt a prefusion-stabilized conformation reducing the membrane fusion ability, increasing expression, and stimulating neutralizing antibodies. The $2 \mathrm{P}$ proline substitutions in the spike proteins were originally developed at the University of Texas at Austin for a vaccine against camel-flu, predominant in the Middle East. WHO recommends a two-dose schedule of BNT162b2 three to four weeks apart. The vaccine BNT162b2 (Comirnaty) has demonstrated 95\% efficacy against symptomatic SARS-COV-2 infection [49]. In some countries, BNT162b2 is recommended for minors $(\geq 12$ years) also. Lustig and colleagues [50] highlighted the requirement of the timely administration of the second dose, particularly in the elderly and immunosuppressed population. An Italian survey on anti-SARS-COV-2 IgA response in baseline seropositive and seronegative individuals receiving BNT162b2 suggested the possibility of considering delaying/dropping the second dose of the vaccine in baseline seropositive individuals [51]. However further detailed study is required to conclude anything regarding this concern. In a press release dated 08July 2021, Pfizer-BioNTech has ignited the possibility of a third booster dose of the vaccine (https://www.pfizer.com/news/press-release/press-releasesarchive). In line with most of the pre-existing vaccines, the efficacy of BNT162b2 has been found to decrease with the increasing age of the recipient $[52,53]$.

\subsubsection{Astrazeneca/University of Oxford (Viral vector vaccine)}

The vaccine prepared by Oxford-AstraZeneca is available in the market as Covishield or Vaxzevria. In February 2021, WHO recommended the use of this vaccine in all adults. It is currently approved in more than 130 countries. It is a monovalent vaccine that consists of a chimpanzee adenovirus DNA vector i.e., a recombinant and replication-deficient (ChAdOx1) vector and encodes the S glycoprotein of SARS-CoV-2 [54, 55]. The non-replicating viral vector vaccine is currently designated as AZD1222. L-Histidine analogs are also present in the formulation. The vaccine expresses SARS-CoV-2 $\mathrm{S}$ immunogen in a trimeric pre-fusion conformation; to stabilize the expressed S-protein in the pre-fusion conformation the code sequence was not modified in the pre-fusion conformation [54,55]. Two separate doses of $0.5 \mathrm{ml}$ each are provided in the ChAdOx1nCoV-19 vaccination course. After the first dose, the second dose should be given after 4-12 weeks [56]. Persons who receive the first dose of this vaccine should receive the second vaccine dose to complete the course of vaccination. Each dose of this vaccine consists of more than $2.5 \times 10^{8}$ infectious units of ChAdOx1-S [56]. The vaccine is given in the form of suspension for injection through intramuscular injection. According to a review of findings on the dosing interval of ChAdOx1nCoV-19 vaccine, it has been found that the most important factor for vaccine efficacy is the dosing interval, and not the dosing level [57]. This is consistent with previous research which supports greater effectiveness over a longer period of time in other vaccines such as those for influenza and Ebola [57]. After a gap of 12 or more weeks between the first and second dose, the study found that vaccine efficacy reached $82.4 \%$ (95\% CI $62.7 \%$ to $91.7 \%$ ). The efficacy was only $54.9 \%$ when the two doses were given less than six weeks apart [58].

According to a report published in British Medical Journal, after a study of 2000 healthy and young volunteer workers, the rollout of Oxford-AstraZeneca Covid-19 in South Africa was stopped, reporting that it did not protect from mild and moderate disease owing to the new variant (501Y.V2) that emerged there [59]. In a cohort study in the UK, both BNT162b2 and ChAdOx1nCoV-19 have been found to demonstrate comparable efficacies against B.1.1.7 variant of SARS-COV-2 [60].

\subsubsection{Johnson and Johnson (Viral vector vaccine)}


Janssen is a non-replicating viral vector vaccine (Ad26.COV2.S) to fight the menace of COVID-19. Ad26.COV2.S is a recombinant, replication-incompetent adenovirus serotype 26 vector encoding a full-length, stabilized spike protein of SARS-CoV-2 WA1/2020 strain. It uses the same systems AdVac and PER.C6 earlier successfully used for developing Ebola vaccine by the same sponsor company. The vaccine is recommended as a single intramuscular injection of $0.5 \mathrm{ml}$ to adults. Due to insufficient data on vaccine co-administration, a minimum gap of 14 days is recommended with any other kind of vaccination for other disorders. According to an update by WHO on 25 June 2021, Ad26.COV2.S is safe and effective at protecting people from extremely serious risks of COVID-19, including death, hospitalization, and severe disease. 28 days after inoculation Ad26.CoV2.S displayed an efficacy of $85.4 \%$ against severe disease and $93.1 \%$ against hospitalization [61]. A single dose of Ad26.COV2.S demonstrated the efficacy of $66.9 \%$ against symptomatic moderate and severe SARS-CoV-2 infection in the clinical trials [61]. In search of design elements for coronavirus $S$ protein; replacing Ad26 vector encoding for a membranebound stabilized S protein with a wild-type signal peptide (Ad26.COV2.S) elicited potent neutralizing humoral immunity and cellular immunity that was polarized towards Th1 IFN- $\gamma$ in mice [62]. In a comparative study by Mukhopadhyay et al, Ad26.COV2.S ranked second to the rapid elicitation of immunogenicity and protective efficiency in non-human primates among six vaccine candidates based on data available till October 2020 [63]. During preclinical developments, Ad26.COV2.S was found to protect Rhesus macaques monkeys from SARS-COV-2 after single immunization [64]. Recently, a G614 spike SARSCoV-2 virus variant Syrian hamster model has proven the success of Ad26.COV2.S in preventing COVID-19 and associated LRT infections [65]. A second dose of the vaccine to Syrian hamsters was found to be beneficial for G614 spike SARS-COV-2 variant with optimum immunogenicity without vaccine associated enhanced respiratory diseases. Low dose Ad26.COV2.S has been demonstrated to impart protection of SARS-COV-2 in Rhesus macaques [66].

\subsubsection{Moderna (mRNA vaccine)}

This vaccine is an mRNA vaccine (mRNA-1273). The vaccine comprises lipid nanoparticle-encapsulated, nucleoside-modified mRNA encoding the stabilized prefusion spike glycoprotein S-2P of SARS-CoV-2 [67]. The mRNA encodes spike protein in such a way that when the vaccine is injected, immune cells processing the mRNA, and the subsequent protein would be marked for destruction [68]. The dosage regimen includes two doses of $0.5 \mathrm{ml}(100 \mu \mathrm{g})$ each to be administered through the intramuscular route $28-42$ days weeks apart. The vaccine is about $94.1 \%$ effective against COVID-19, starting 14 days after the first dose [69]. Storage at $-20^{\circ} \mathrm{C}$ is recommended for long term. However, after thawing it is stable at cold conditions for up to 30 days thus making it very suitable for widespread community use [70]. Corbett et al (2020) noticed robust SARS-COV-2 neutralizing activity with mRNA-1273 in non-human primates without any pathogenic change in the respiratory system [71]. It has been observed that mRNA-1273 induces both potent neutralizing antibody and CD8 $+\mathrm{T}$ cell responses for protection against SARS-COV-2 infection in lungs and noses of mice without any immunopathology [72]. In addition to that, a high pseudovirus neutralizing antibody response was noticed in mice expressing a mutated form of the spike protein, D614G [72].

\subsubsection{Sinopharm (Inactivated virus vaccine)}

This is an inactivated novel coronavirus (2019-CoV) vaccine (BBIBP-CorV/verocell) developed in China against SARS-COV-2 to stimulate the immune system. Virus on exposure to $\beta$-propionolactone, bonded with the genes in such a manner that the virus cannot replicate but its spike proteins remained intact. Two doses of $0.5 \mathrm{ml}$ each through intramuscular route is recommended by WHO, 3-4 weeks apart. Vaccine efficacy was found to be $79 \%$ and $79 \%$ respectively against symptomatic COVID-19 infection $14^{\text {th }}$ day 
onwards after $2^{\text {nd }}$ dose and COVID-19 associated hospitalization [73]. Phase III clinical trial data are insufficient to determine vaccine efficacy against persons with comorbidities. It can be stored under cold temperature conditions making it suitable for widespread community use. Sinopharm, coronavac, and covaxin use similar technologies to prepare inac-

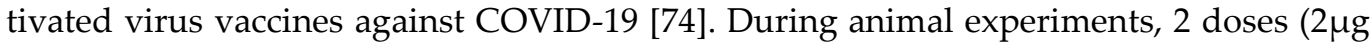
each) of BBIBP-CorV successfully induced high titer values of neutralizing antibodies against SARS-COV-2 in mice, rats, guinea pigs, rabbits, Cynomolgus monkeys and Rhesus monkeys [75].

\subsubsection{Sinovac Biotech (Inactivated virus vaccine)}

CoronaVac (formerly PiCoVacc) is an inactivated virus (formalin treated) vaccine using alum as an adjuvant, developed by Sinovac Biotech, China. CoronaVac is recommended in 2 doses of $0.5 \mathrm{ml}$ each (intramuscular injection) 2-4 weeks apart. CoronaVac has been claimed to be 51\% effective against symptomatic COVID-19 infection and 100\% effective against severe COVID-19 infection and hospitalization according to a phase III clinical trial in Brazil from day 14 onwards after the $2^{\text {nd }}$ dose [76]. In a phase I/II study in China involving 144 and 600 participants respectively in phase I and phase II between 16

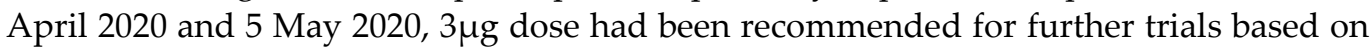
safety, immunogenicity, and production capacity [77]. Pain at the injection site is the most reported adverse effect post-vaccination. Though it is recommended for the adult population, only limited safety data for individuals $\geq 60$ years is currently available. WHO granted an emergency use listing for CoronaVac on 01 June, 2021.

\subsection{Vaccines approved regionally}

Many countries have approved one or more vaccines based on outcomes. Some have been approved by WHO later. Still, some vaccines are there which have succeeded to satisfy the regulatory bodies of few countries but have yet to obtain global acceptance.

\subsubsection{Sputnik V (Viral vector vaccine)}

Sputnik V (Formerly, Gam-COVID-Vac) is a recombinant adenovirus vaccine rAd26 and rAd5 developed in Russia. This adenovirus vaccine is the World's first registered combination vector vaccine against COVID-19, the ' $\mathrm{V}$ ' standing for 'Victory' over COVID19. Based on phase I and phase II clinical trial data only, it was approved for use in Russia in August 2020. According to an interim analysis published later, the efficacy of Sputnik $\mathrm{V}$ is $91.6 \%$ [78]. It is to be administered through intramuscular injection in two doses, first dose rAd26 and after 21 days, second dose rAd5. A cold chain of subzero temperature is not required for storage of the lyophilized powder which paves way for easier community use. Sputnik light is a single-dose of rAd26 to be used as a third booster dose if needed after at least six months. Adenovirus 26 and adenovirus 5 are used as vectors for the expression of SARS-COV-2 spike protein. The heterologous recombinant adenovirus approach with two varying serotypes aims to overcome any pre-existing adenovirus immunity [79]. Initially, Sputnik V has faced lots of criticism for unseemingly haste with low transparency, the outcome and interim analysis reports published in Lancet has attempted to do away with the allegations of non-transparency [78, 80-84]. On 29 June 2021, Gamaleya research Institute claimed Sputnik V to be $90 \%$ effective against the B.1.617.2 (delta) variant of coronavirus.

\subsubsection{EpiVacCorona (Protein subunit vaccine)}

EpivacVacCorona is a peptide vaccine developed in Russia. The vaccine comprises three synthetic peptides mimicking viral spike protein. These peptides are conjugated to a carrier protein, a fusion product of viral nucleocapsid protein, and a bacterial maltosebinding site protein. The viral portion of the chimeric protein is responsible for immunization, aluminium hydroxide serves as an adjuvant. It is to be injected in two doses 21 to 
28 days apart through the intramuscular route. Currently, it is approved for emergency use in Russia, Belarus, and Turkmenistan. Immunogenicity and protectivity of the peptide candidate were assessed in a preclinical study [85]. EpiVacCorona was administered in

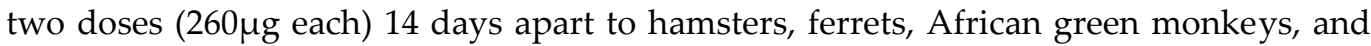
Rhesus macaques monkeys. The vaccine was $100 \%$ successful to generate virus-specific antibodies in animals. In hamsters, dose-dependent immunogenicity was observed along with prevention from pneumonia, in ferrets, EpiVacCorona speeded up clearance of coronavirus from the upper respiratory tract (URT); COVID-associated pneumonia was prevented in non-human primates. Two clinical trials (NCT04780035 and NCT04527575) aiming to assess the tolerability, safety, immunogenicity, prevention efficacy, and reactogenicity of EpiVacCorona comprising of 3000 and 100 volunteers respectively are yet to post the results. Currently, the vaccine has been approved in Russia, Turkmekistan, and Belarus.

\subsubsection{Bharat Biotech (Inactivated virus vaccine)}

BBV152 (Covaxin) is a complete ineffective SARS-CoV-2 viral particle that contains the RNA surrounded by a protein shell but the genetic material is chemically modified so that it cannot replicate [86]. The vaccine consists of one of the two different adjuvants and a single inactivated whole SARS-CoV-2 virion. The adjuvant is either an aluminum hydroxide gel (Algel) or a novel TLR7/8 agonist adsorbed Algel [87]. A separate T-helpercell 1 (Th1) antibody response with increased levels of SARS-CoV-2-specific IFN- $\gamma$ and $\mathrm{CD} 4$ cells was further induced by the formulation containing the TLR7/8 agonist [87]. The dosing regimen of Covaxin consists of two doses given at a 28 days interval [86]. In a study, the inactivated virus vaccine was formulated with two adjuvants i.e. aluminum hydroxide gel (Algel) and a novel TLR7/8 agonist absorbed Algel, the immunogenicity was determined in rabbits, mice, and rats using three concentrations $(3 \mu \mathrm{g}, 6 \mu \mathrm{g}$ and $9 \mu \mathrm{g})$ [87]. The results show that in all the three species, BBV152 formulations produce significantly high antigen binding and neutralizing antibody titers at concentrations of $3 \mu \mathrm{g}$ and $6 \mu \mathrm{g}$ while maintaining excellent safety profiles [87].

\subsubsection{Cansino Biologics (Viral vector vaccine)}

Convidicea (Ad5-nCoV), also known as PakVac is a recombinant vaccine against COVID-19 using adenovirus type 5 vector encoding SARS-COV-2 spike protein. Ad5$\mathrm{nCoV}$ is based on replication-defective adenovirus type 5 as the vector to express the spike protein of SARS-COV-2. The vaccine has displayed an efficacy of $65.7 \%$ against moderate symptoms of COVID-19 and $91 \%$ efficacy to protect from severe disease [88]. Comfortable storage conditions of $2-8^{\circ} \mathrm{C}$ and single dosing requirements make it a potentially popular vaccine candidate. During preclinical studies, Ad5-nCOV single dose was found to completely protect BALB/c mice from URT and LRT infection by mouse-adapted SARS-COV2 and to protect ferrets from URT infection by SARS-COV-2 wild variant [89]. Currently, it is authorized for emergency use in 9 countries.

\subsubsection{Zydus Cadila (Plasmid-DNA vaccine)}

The DNA plasmid based COVID-19 vaccine, $\mathrm{ZyCoV-D}$ is the first DNA vaccine approved for emergency use in India by CDSCO on 20 August 2021. In an indigenous collaborative venture by Cadila Healthcare and Biotechnology Industry Research Assistance Council, India the vaccine comprises of a plasmid vector carrying genetic material encoding the spike (S) protein of SARS-CoV-2 to interfere with viral entry through membrane protein. The recombinant plasmid acts as vector to carry the genetic material coding for $\mathrm{S} 1$ protein of corona virus into the cell to generate immune response [90]. On interim analysis of phase III trial data, Cadila Healthcare announced the efficacy of ZyCoV-D to be $66.6 \%$ against symptomatic COVID-19 and $100.0 \%$ against moderate to severe disease in 
a press release dated 01 July 2021. Manufacturers have also claimed the vaccine to be useful for individuals $>12$ years, making it an option for adolescents of India. The plasmid constructs have been transformed into E. coli to boost production [91]. Immunogenicity potential have been evaluated in mice, guinea pigs and rabbits at different doses intradermally while preclinical toxicology was studied in rats and rabbits [91]. ZyCoV-D, in preclinical studies induced neutralizing antibody response along with Th-1 response and elevated interferon- $\gamma$ levels. Yadav et al evaluated immunogenicity and protective efficacy of $\mathrm{ZyCoV}-\mathrm{D}$ formulations at varying doses in Rhesus macaques [92]. The vaccine at $2 \mathrm{mg}$ dose (needle free injection system) successfully induced S1 specific IgG and neutralizing antibody titers which increased gradually on viral challenge for upto 2 weeks protecting from lung disease. Evaluation of nasal swab, throat swab and bronchoalveolar fluid also confirmed viral clearance. Enhanced proliferation of lymphocytes and production of IL-5 and IL-6 were also evidenced.

Open label, non-randomized phase I trial was conducted between July and October 2020 on 48 healthy volunteers ranging from 18-55 years of age [93]. Intra-dermal administration of three doses at day 0, day 28 and day 56 concluded ZyCoV-D to be safe, welltolerated and immunogenic. No deaths and serious adverse events were reported in phase I study. Phase II (CTRI/2020/07/026352) and phase III trial (CTRI/2021/01/030416) have reportedly been on the way from July 2020 and January 2021 respectively, however the results are not publicly available yet.

\subsection{Success of approved vaccines}

In a clinical trial consisting of 43448 volunteers ( $\geq 16$ years), BNT162b2 was given in

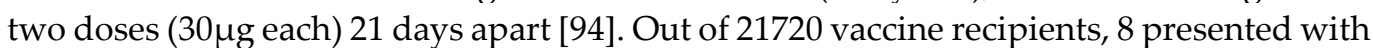
the onset of COVID-19 after 7 or more days of the second dose while 1 from the vaccine group presented with severe COVID-19 infection after the first dose. Overall, BNT162b2 was $95 \%$ effective in preventing Covid-19 (95\% credible interval, 90.3 to 97.6 ). To be precise, vaccine efficacy of $52.4 \%$ and $94.8 \%$ was observed after a single-dose and at least 7 days after 2 doses. Emerging evidence revealed that BNT162b2 can efficiently neutralize both N501 and Y501 variants (having mutated RDBs) of SARS-COV-2 [95,96]. In an observational study in Israel among healthcare workers from December 2020 to January 2021, vaccine efficacy of $89-91 \%$ was reported after $15-28$ days of the first dose [97]. Adjusted rate reductions of COVID-19 disease were $47 \%$ (95\% CI 17-66) and 85\% (71-92) for days 1-14 and days 15-28 after the first-dose, respectively. These early reductions of COVID19 rates provide support for delaying the administration of the second dose in countries facing vaccine shortages [97]. According to a real-world dataset assessment, inoculation with BNT162b2; reduced viral load substantially between 12-37 days of the first dose indicating the lower grade of infection and lesser possibility of virus spread after vaccination [98]. Another study on this concern revealed single-dose vaccination to be protective starting from day 14 onwards and reaching a peak at day 21, though scientists are yet to accept the interpretation unanimously and some interpret the same results in a not so encouraging conclusion [99]. Persons previously infected with COVID-19 develop stronger T cell and B cell immune responses after a single-dose of BNT162b2 than unaffected individuals [52]. Higher titres of neutralizing antibodies have also been observed in vitro in those individuals compared to the unaffected ones after a single-dose of BNT162b2 [52]. Two-dose schedule of BNT162b2 could successfully neutralize engineered variants of SARS-COV-2 with mutations in spike protein (69/70 deletion) and E484K [100]. Although vaccination yielded more or less similar neutralizing antibody titers for the engineered mutated variants compared to the parental strains, these kinds of deliberate engineering situations may prove highly dangerous. BNT162b2 has been found to remain effective against a SARS-COV-2 pseudovirus bearing mutation in B.1.1.7 spike protein [101]. Among the 40 sera tested, neutralization was only slightly decreased against the B.1.1.7 lineage pseudovirus, more evident in individuals aged below 55 years. A cohort study by Kustin and colleagues [102] suggests reduced efficacy of BNT162b2 against 
B.1.1.7 and B.1.351 variants of SARS-COV-2. In an attempt to evaluate the effectiveness of a three-dose schedule for hemodialysis patients [103] it was observed that $93 \%$ of the naive patients yielded a antibody titer $>50 \mathrm{UA} / \mathrm{ml}$ after 2 doses while its value increased to $93 \%$ after the $3^{\text {rd }}$ dose. Among the 10 non-responders after the $2^{\text {nd }}$ dose, 2 responded significantly after the $3^{\text {rd }}$ dose (17 to $568 \mathrm{UA} / \mathrm{ml}$ and 35 to $923 \mathrm{UA} / \mathrm{ml}$ ); 3 patients demonstrated no change in antibody titers after the $3^{\text {rd }}$ dose, 2 demonstrated significant decrease while 5 denied taking $3^{\text {rd }}$ dose. Morales-Núñez and peers [104] reported the production of neutralizing antibodies in $100 \%$ cases in both naive and previously infected individuals after 2 doses with tolerable adverse events and the possibility of immunosenescence. Results from a real-life study in Italy discovered the emergence of IgG directed towards the spike protein of SARS-COV-2 in $99.88 \%$ of the vaccinated population (1765 healthcare workers) 3 weeks after the $2^{\text {nd }}$ dose of BNT126b2 [105]. Younger recipients and those with the previous history of COVID-19 infection came up with better immunogenic responses than others. In a population of patients suffering from mast cell disorders $(n=26), B N T 162 b 2$ vaccine was well-tolerated without any serious adverse events despite the generally increased possibility of anaphylaxis [106]. No significant increase in serum STL level was observed after either of the doses nor was any clinical symptom of mast cell mediator release observed. Given the acute vaccine shortage worldwide, Ramos and colleagues [107] investigated the antibody response after a single-dose of BNT162b2 to examine probable benefits of fast administration of the vaccine to a large population to protect from COVID-19. Findings suggest that before the second dose inoculation, $95.3 \%$ already had anti-SARS-CoV-2 IgG, half of them even had antibody concentrations against RDB of the virus; however further studies are needed to conclude on a mass scale. From a retrospective cohort study, no increased risk was apprehended regarding vaccination for patients of inflammatory bowel disorder being treated with immunosuppressive agents, vaccine effectiveness in such patients was found to be highly comparable with that in the reference population [108]. Pottegård et al [109] reported lower incidences of thrombohaemorrhaegic adverse events with BNT162b2 than with ChAdOx1nCoV-19. Ram and colleagues [110] examined the effect of BNT162b2 on patients undergoing immune cell therapy. 66 patients after allogeneic HCT treatment and 14 patients after CD-19 based CART therapy were vaccinated with BNT162b2. Impressive immunogenicity was observed; $57 \%$ of individuals after CART infusion and 75\% after allogenic HCT demonstrated humoral and/or cellular immune response on vaccination. $12 \%$ after $1^{\text {st }}$ dose and $10 \%$ after $2^{\text {nd }}$ dose developed cytopenia while three developed GVHD exacerbation after each dose. One graft rejection, later on, was thought to be related to vaccination. Recent evidences suggest BNT162b2 to be effective against newer variants of coronavirus like B.1.526, B.1.1.7, B.1.429, and B.1.617.2 [111-113].

Lower immunogenicity of BNT162b2 has been reported in liver transplant patients than regular individuals while the results in liver transplant cases remain superior to other organ transplant cases [114]. Haemodialysis patients above 60 years of age have demonstrated lower antibody responses than healthy individuals [115]. Strengert et al [116] reported variable humoral and cellular immune response on vaccination with BNT162b2 in haemodialysis patients. In such patients, both anti-SARS-CoV-2 IgG and neutralization efficacy were reduced compared to healthy individuals; T-cell mediated IFN- $\gamma$ release after stimulation with SARS-CoV-2 spike peptides was also reduced. In Lithuania, patients with hematological malignancy depicted lower median anti-S1 IgG responses after 2 doses of vaccination than healthy individuals [117]. Among the patient population, patients actively treated with Bruton-tyrosine kinase inhibitors, ruxolitinib, venetoclax, antiCD20 antibody therapy displayed poorer antibody response than the untreated patients. Elderly patients with myeloma demonstrated lower neutralizing antibody response against SARS-COV-2 than healthy individuals [118]. Mucosal sites represent the primary entrance route for SARS-COV-2 to the human body. Anti S protein IgG and IgA total antibody titer and presence of neutralizing antibodies were assessed in serum and saliva of 60 healthcare workers after two weeks of both first and second doses of BNT162b2 [119]. 
From the results, it was evident that BNT162b2 can trigger neutralizing antibodies in serum, but not in saliva. Thus, this vaccine may not be very useful to stop the spreading of the virus from one human to another, however, is likely to protect vaccinated individuals via the systemic immune response.

Results of interim efficacy for two of the four ongoing studies with ChAdOx1nCoV19 from the UK and Brazil in 11636 participants between 18-55 years [120] are available. The ChAdOx1nCoV-19 recipients were not admitted with COVID-19-related complications, while 10 hospital admissions (2 of them serious) took place from control teams [120]. The vaccine efficacy, after primary dose analysis (combining dose groups), was $70 \cdot 4 \%$ ( $95 \cdot 8 \%$ CI $54 \cdot 8 \%-80.6 \%$ ) [120]. 30 of the 5807 participants in ChAdOx1 nCoV-19 Group and $101(1.7 \%)$ of the 5,829-control group were found to be infected with COVID-19, over 14 days after the second dose. A study was undertaken in Denmark following the reports of thromboembolism associated with ChAdOx1nCoV-19 vaccine with 4,915,426 individuals of age group 18-99 (follow up time 38,449,703 person-years) and 3,963,153 individuals of age group 18-64 (follow up time 29,537,310 person years) [121]. In a test-negative casecontrol study in the UK, the national immunization management system successfully linked 156,930 adults aged 70 years and older, which reported COVID-19 symptoms between 8 December 2020 and 19 February 2021 with their data on vaccines [122]. Participants who were vaccinated with AZD1222 had underlying risks of COVID-19 infections to non-vaccinated people in the first 9 days. The occurrence of ChAdOx1-S (spike protein) was observed in blood between 14 to 20 days after vaccination [103]. The efficacy of the vaccine against COVID-19 infection was found to be $60 \%$ (41\% to $73 \%)$ after 28 to 34 days of vaccination, and from day 35 onwards, efficacy shot up to $73 \%$ (27\% to $90 \%$ ) [103]. The need for hospital admission reduced by 37\% (3\% to 59\%) after receiving the single-dose of the vaccine [122, 123]. An updated report of 17178 participants among whom 9696 $(56 \cdot 4 \%)$ are female, $12975(75 \%)$ are white and $14413(83.9 \%)$ are aged between $18-55$ years, $1792(90 \%)$ are aged between 56-69 years and $973(5.7 \%)$ are aged 70 years or older have been analyzed by [124-126]. Participants were divided into 2 groups one receiving two standard doses and the other group receiving a low dose followed by a standard dose. Results show an overall vaccine efficacy of $66 \cdot 7 \%$ (95\% CI 57.4\%-74.0\%) more than 14 days after the second dose of the vaccine against the appearance of COVID-19 symptoms. In the patients who received two standard doses, the efficacy of the vaccine was $63.1 \%$ and it was $80.7 \%$ in those who received a low dose along with the standard dose. The effect of vaccines after a standard single dose was particularly high in exploratory analyses at $76.0 \%$ between day 22 and day 90, with a minimum decrease in antibody levels during that time. [127]. The vaccine efficacy was significantly higher at $81.3 \%$ after two standard dose intervals given at 12 weeks, compared to $55.1 \%$ at less than 6 -week intervals supporting longer interval immunization strategy. These findings were supported by immunosupportive studies in participants under 55 years of age that showed anti-SARS-CoV-2 IgG spike two-fold higher responses in people with a dosing interval of 12 weeks compared to less than six weeks having a geometrical mean ratio of 2.32 (95\% CI 2.01-2.68) $[58,127]$. In a randomized controlled trial with healthcare workers for detecting IgG spike after vaccination, it was found that 864 out of 890 (97.1\%) were seropositive after 14 days of vaccination with ChAdOx1nCoV-19 [128]. Previously infected healthcare workers are more likely to be seropositive. All 470 healthcare workers tested after the second dose of vaccination were found to be seropositive. Quantitative antibody response in recipients of ChAdOx1nCoV-19 with infection and without infection were 10095 (5354-17096) and 435 (203-962) AU/ml respectively [128]. A Phase III interim analysis in Peru, Chile, and the US found that the Oxford University and AstraZeneca-produced vaccine was $79 \%$ effective in preventing Covid-19 symptoms and 100\% effective in preventing severe diseases and hospital admission [129]. In the trial, 141 symptomatic cases of COVID-19 were reported among 32449 participants, with 2:1 randomized to vaccine group and placebo group. Four weeks apart, they were given both doses of the vaccine [129]. 
A phase 1-2a trial was conducted with Ad26.COV2.S on 805 participants in two age groups (18-55 years and $\geq 65$ years [130]. Neutralizing antibody titer against wild-type of coronavirus was detected (geometric mean titer value 212-354) in 90\% or more of all participants on day 29 after the first dose. The antibody titers remained stable for at least 71 days besides a 2.6-2.9-fold increase after the second-dose. Spike binding antibodies also followed the trend of neutralizing antibodies. On day 15, CD4+ T-cell responses were detected in 76 to $83 \%$ of the participants receiving two doses and in 60 to $67 \%$ of those receiving single-dose, with a clear bias toward type 1 helper T cells. CD8+ T-cell responses were slightly lower in single dose recipients compared to double dose recipients. To evaluate the immunogenicity of Ad26.COV2.S, a trial on 25 participants within 22-52 years was conducted [131]. Binding and neutralizing antibodies emerged rapidly by day 8 after initial immunization in $90 \%$ and $25 \%$ of vaccine recipients, respectively. By day 57 , binding and neutralizing antibodies were detected in $100 \%$ of vaccine recipients after a single injection. On day 71 , the geometric mean titer of spike-specific binding antibodies were 2432 to 5729 and the geometric mean titer of neutralizing antibodies were 242 to 449 in the vaccinated groups. A variety of antibody subclasses, Fc receptor binding properties, and antiviral functions were induced along with CD4+ and CD8+ T-cell responses at the interim endpoint of day 71. Ad26.COV2.S elicited both humoral and cellular immune responses cross-reacting with B.1.351 variant thus protecting Rhesus macaques monkeys from B.1.351 challenge [132]. Ad26.COV2.S induced lower binding and neutralizing antibodies against B.1.351 than against WA1/2020 but elicited CD8 and CD4 T cell responses comparable to those against WA1/2020, B.1.351, B.1.1.7, P.1, and CAL.20C. Sera from the recipients of a single-dose of Ad26.COV2.S demonstrated susceptibility to Ad26.COV2.Sinduced serum neutralization for B.1.351 (beta) and P.1 (gamma) variants that contain similar mutations in the RDB while much lower efficacy as observed for B.1.617.2 (delta) variant [133]. In South Africa, D614G and 501Y.V2 strains of coronavirus demonstrated high levels of cross-reactivity in spike-binding assay $(n=120)$ at least 29 days post-vaccination [134]. Interestingly, in a population subset $(n=27), 82 \%$ of the tested sera showed no detectable neutralizing antibody against 501Y.V2. Thus, it has been suggested that even low levels of neutralizing antibodies can contribute to protection from moderate to severe disease in combination with roles played by $\mathrm{F}_{\mathrm{c}}$ effector function and $\mathrm{T}$ cells in protection against 501Y.V2 variant.

In a phase-I study on $\geq 56$ years old persons, $100 \mu \mathrm{g}$ dose of mRNA-1273 induced higher binding and neutralizing antibody titer than lower doses [135]. In another phase I study on 45 healthy participants between 18-55 years old, mRNA-1273 induced antiSARS-CoV-2 immune responses in all participants without any identifiable trial-limiting safety concerns [136]. During Phase III clinical trial of the mRNA-1273 vaccine, 30,420 participants were enrolled within the age group of $18-95$ years $[69,137]$. Among the participants, 7000 were aged over 65 years and 5000 below 65 population presented with highrisk chronic diseases. Around $63 \%$ of the trial subjects were white along with 6000 Hispanics and more than 3000 blacks. On 2 months follow-up, findings indicated 94.1\% (95\% confidence interval $=89.3 \%-96.8 \%$ ) vaccine efficacy in persons without previous history of SARS-COV-2 infection. Severe COVID-19 infection occurred in 30 participants (all placebo recipients) with one recorded death [69]. Among the subjects, 10 instances of hospitalization were documented for COVID-19 infection among which 9 were from the placebo group further supporting vaccine-mediated protection from COVID-19 complications. More than $86 \%$ efficacy has been observed across age, sex, race, and in subjects with underlying medical conditions. In both the vaccine and placebo groups, the frequency of serious adverse events was very low. In GRADE evidence assessment, the vaccine displayed high certainty regarding protection from symptomatic SARS-COV-2 infection, moderate certainty in preventing COVID associated hospitalization, and very low certainty regarding protection from asymptomatic SARS-COV-2 infection [67]. Tré-Hardy and colleagues [138] in an interim analysis of vaccination surveillance concluded that 
anti-SARS-COV-2 antibodies persisted for up to 3 months after vaccination onset, however, a significant decrease in antibody levels was observed in some seronegative cases even earlier than that; hence a third dose of vaccination may seem to be reality in future. Mustafa et al [139] attempted to administer graded doses of the vaccine to administer the $2^{\text {nd }}$ dose to patients reporting immediate hypersensitivity reactions after the $1^{\text {st }}$ dose. Both of the two subjects under study were female healthcare workers showing negative results in skin prick tests for hypersensitivity [140]. One of the two patients developed pruritis after administration of $0.05 \mathrm{ml}$ full-strength vaccine $\left(2^{\text {nd }}\right.$ graded dose) and $0.2 \mathrm{ml}$ fullstrength vaccine ( $5^{\text {th }}$ graded dose) which vanished without any medication. After 3-4 weeks, none of them had any adverse reactions and both of them had developed IgG directed against spike protein of SARS-COV-2 indicating a successful vaccination. Despite a decrease in titers of binding and neutralizing antibodies in the human with time, mRNA1273 has been proven to impart humoral immunity responses for at least 119 days [141]. Krammer and colleagues [142] observed that a single dose of mRNA -1273 elicited rapid immune responses in seropositive persons, with post-vaccination antibody titers similar to or more than that in seronegative persons receiving two doses.

Xia et al [143] conducted a phase I (96 participants, 18-59 years) and phase II (224 participants, 18-59 years) clinical trials with BBIBP-CoR-V between April 12, 2020 and July 27, 2020 in Henan province, China. Participants receiving 3 doses through 56 days in the phase I trial displayed only a little difference in neutralizing antibody titer values with similar confidence intervals compared to participants receiving 2 doses in phase II. In phase II again, participants receiving 2 doses 28 days apart showed higher neutralizing antibody titres than those receiving 2 doses 14 days apart. Beijing Institute of Biological Products conducted a phase I and phase II clinical trials with 192 volunteers between 1880 years and 448 adult volunteers between 18-59 years, respectively at Shangqiu City Liangyuan District Center for Disease Control and Prevention in Henan province, China [144]. BBIBP-Cor-V was able to elicit antibodies against SARS-COV-2 in all trial subjects

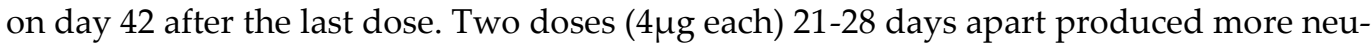
tralizing antibody titers than a single dose $(8 \mu \mathrm{g})$ or two doses $(4 \mu \mathrm{g}$ each) 14 days apart. UAE had claimed 86\% efficacy for the vaccine in December 2020 based on the phase III trial while within few days Sinopharm claimed it to be $79 \%$ based on phase I and phase II data [145]. A Wuhan-based phase III trial has claimed vaccine efficacy to be 72.5\% [146]. Phase III trials have also taken place in Peru, Egypt, Argentina, Bahrain, Jordan, and Pakistan [146, 147]. In a small-scale trial, 12 volunteers received BBIBP-CorV [116]. Based on serum neutralizing titer values, the vaccine was proven to provide immunity against two variants of SARS-COV-2 viz. 501Y.V2 and D614G (wild type). Geometric mean titer values were $110 \cdot 9(95 \%$ CI 76.7-160.2) and 71.5 (51.1-100.1) for D614G and 501Y.V2 respectively. In a cross-sectional survey in Jordan, $38.2 \%$ of the 2213 respondents received BBIBP-CorV and no life-threatening post-vaccination side effect was recorded [148]. According to Huang et al [149], BBIBP-Cor-V is effective against the South African variant of coronavirus. A Srilanka-based study concluded that BBIBP-Cor-V generates antibody response comparable to natural infection against B.1.351 (beta) and B.1.617.2 (delta) variants of coronavirus [150].

In a randomized, double-blind, placebo-controlled phase I/II trial with CoronaVac in Hebei, China on people aged $\geq 60$ years, 72 persons were enrolled for phase I between 22 May 2020 and 01 June 2020, and 350 persons were enrolled for phase II between 12 June 2020 and 15 June 2020 [151]. In phase 1, seroconversion after the second dose was observed in $100 \%$ of subjects in the $3 \mu \mathrm{g}$ group, $95.7 \%$ of participants in the $6 \mu \mathrm{g}$ group. In phase II, seroconversion was observed in $90.7 \%$ in $1.5 \mu$ g group, $98.0 \%$ in the $3 \mu \mathrm{g}$ group, and $99.0 \%$ in the $6 \mu \mathrm{g}$ group. Results also indicated optimum neutralized antibody titer with $3 \mu \mathrm{g}$ dose. In a study based in Nanjing, China, sera of 93 recipients of 2 doses were collected and assayed for neutralization activity against seven variants of SARS-COV-2 [152]. After 14 days of $2^{\text {nd }}$ dose, $82 \%$ serum samples could neutralize wild-type pseudovirus. Coronavac also proved effective against D614G, B.1.1.7, and B.1.429 variants. In a test-negative 
study in Brazil, a single-dose of CoronaVac was evidenced as more effective against symptomatic infection by gamma variant of coronavirus than the two-dose regimen [153]. Another test negative, case-control study was performed in Brazil from 17 January 2021 to 29 April 2021 on population aged $\geq 70$ years [154]. CoronaVac was found to be $42 \%$ effective against transmission of P.1 variant of coronavirus after 2 doses. A phase I/II clinical trial had been undertaken with CoronaVac at Hebei, China on a juvenile population aged 3-17 years in late 2020 [155]. Phase I included 72 participants in 3 age groups and 2 dosage regimes while phase 2 included 480 participants and 2 dosage regimens. Adverse events were mostly mild to moderate pain at the injection site $(13 \%)$. Humoral immune response was triggered by vaccination and results of neutralizing antibody titers supported the use of $3 \mu \mathrm{g}$ dose two times for further studies on the 3-17 years population. A cohort study on healthcare workers of Brazil concluded that CoronaVac (2 doses injected nearly 3 weeks apart) is $50.7 \%$ and $51.8 \%$ effective after 2 weeks and 3 weeks, respectively of $2^{\text {nd }}$ dose [156]. In a Turkey-based study, serum samples of 1072 healthcare workers were collected 28 days after $1^{\text {st }}$ dose and 21 days after $2^{\text {nd }}$ dose and assayed for SARS-COV-2 anti-spike antibody [157]. Antibodies of interest were detected in $77.8 \%$ of cases after $1^{\text {st }}$ dose and $99.6 \%$ cases after $2^{\text {nd }}$ dose. Persons previously infected with coronavirus before vaccination displayed significantly higher $(\mathrm{p}<0.001)$ antibody titer values than the rest. Persons with chronic disorders developed lesser antibody response than others. Seropositive response was more frequent in females than males and persons aged between 18-59 years presented with a higher frequency of humoral immunity. A case study in Brazil suggested that CoronaVac reduces the severity of illness after infection by P.1 variant of SARS-COV2 , however, argument may be raised on the sample size (2) being too small [158]. Single dose of CoronaVac to seropositive persons with a history of COVID-19 infection produced more antibodies than a double-dose of the vaccine to seronegative individuals in Indonesia [159]. In an interesting development, Calil and coworkers [160] claimed that CoronaVac can produce specific antibodies (IgA) against SARS-COV-2 in human milk. Reduced mortality rates have been reported among healthcare workers in Turkey after the introduction of the CoronaVac vaccine [161,162]. The ratio of COVID-19 associated deaths of doctors, dentists, pharmacists, and nurses to all COVID-associated deaths reduced from $0.9 \%$ to $0.1 \%$ after vaccination.

According to phase I/II trial data of Sputnik V, all (76) participants developed SARSCOV-2 antibodies without any serious adverse events [84]. Interim data of 19866 participants ( $(\geq 18$ years) of the phase III trial (September-November 2020 in Moscow) were published in Lancet [78]. The vaccine proved 91.6\% effective against symptomatic COVID-19 infection with zero cases of moderate to severe COVID-19; 21 days post-vaccination. $94 \%$ of the side effects reported were grade I while the 4 recorded deaths were concluded to be unrelated to vaccination. In an Argentine cohort study, among 707 health professionals, a response rate of Sputnik V was $96.6 \%$ while $71.3 \%$ reported one or more events supposedly attributed to vaccination and immunization during follow-up at 72 hours post first dose [163]. In studies regarding the efficacy of Sputnik V on variants of concern, it was observed that rAd26 and rAd5 successfully neutralized spike protein of B.1.1.7, showed moderate efficacy against variants with E484K mutation (also resistant to CoronaVac), and failed to neutralize spike protein of B.1.351 [164,165]. Currently, the vaccine is in use in nearly 59 countries; India is one of the latest countries to approve its emergency use. In July 2021, Sputnik V has been reported to maintain sera that neutralize B.1.1.7 (alpha), B.1.351 (beta), P.1 (gamma), and two versions of B.1.617 (delta) variant along with two more variants local to Moscow [166].

A phase I/II clinical trial regarding EpiVacCorona (NCT04527575) was conducted with 14 volunteers at stage 1 aged between 18-30 years and 86 volunteers in stage 2 aged between 18-60 years [85]. Participants were injected with two doses of EpiVacCorona 21 days apart. The injections induced specific antibody production in $100 \%$ of participants along with seroconversion with minimum neutralizing antibody titer of 1:20 after 21 days 
of $2^{\text {nd }}$ dose along with zero seroconversion in the placebo group. However, detection of antibodies in negative controls has not been discussed by the authors.

In a study, the efficacy of BBV152 against two newly developed strains of coronavirus was assessed [167]. The sera from vaccinated people, as well as sera of people who were infected with the newer strains (i.e., hCoV-19/India/20203522 and hCoV-19/India/2020Q111) were collected and cultured together to examine the neutralization in sera in vitro. The median ratio of neutralization of sera compared to mutant hCoV-19/India/20203522 strain was found to be 0.8 and it was found to be 0.9 for mutant strain hCoV19/India/2020Q111 [167]. This experimental data demonstrates that BBV152 is effective against the infection of these two mutant strains of coronavirus. In a phase II clinical trial, among 921 participants screened from 07 September to 13 September 2020, 380 participants were selected with respect to the safety and immunogenicity population [168]. After 56 days, the PRNT 50 seroconversion rates of neutralizing antibodies were found to be 92.9\% (88.2\%-96.2\%) in the $3 \mu \mathrm{g}$ with Algel-IMDG group and $98 \cdot 3 \%(95 \cdot 1 \%-99 \cdot 6 \%)$ in $6 \mu \mathrm{g}$ with Algel-IMDG group [168]. No significant difference or serious adverse events were reported in this study in any of the groups $[168,169]$. Another report from a tertiary care center in India suggested that Covaxin is safe and effective, and the adverse effects are minor in this vaccine appearing only in 15 people out of 1322 [170].

A non-randomized, open-label phase I trial was conducted in Wuhan, China with Ad5-nCOV on 108 participants [171]. Neutralizing antibodies increased after 14 days of vaccination reaching peak levels on day 28 . Antibody levels in phase I trial subjects have been claimed to remain high for six months post-vaccination according to the Chinese Centre for Disease Control and Prevention [172]. Following the trend from the phase I trial, RDB-specific antibodies increased after 14 days of vaccination reaching peak levels on day 28 during the phase II trial [173]. Seroconversion of neutralizing antibody to live SARS-COV-2 occurred in 59\% of cases of the middle dose group and $47 \%$ of cases of the low dose group. Relatively lower antibody response was observed in people aged $\geq 55$ years and people with pre-existing immunity. This study also suffers from the shortcoming of a low follow-up period of 28 days.

\subsection{Untoward effects}

As reported by Polack et al (2020), the occurrence of serious adverse events with BNT162b2 was low and evenly distributed between the vaccine group and placebo group, mild to moderate reactions included short-lasting pain at the injection site, fatigue and headache [94]. There have been reports of severe allergy-like reactions after vaccination with mRNA vaccines including BNT162b2 [174,175]. Investigations suggestively point fingers to polyethylene glycols used in the formulation which have the previous history of inducing anaphylactic reactions and therefore had never been a part of any vaccine formulation before [174,176]. An Italy-based cohort study consisting of 871 volunteers reported that blood levels of anti-SARS-COV-2 antibodies tend to decrease after 3 months of the first dose [51]. Bell's palsy has been suspected as an adverse event related to BNT162b2. A case-control study in Israel during the first two months of 2021 reported that $56.7 \%$ of the patients hospitalized for facial nerve palsy had a recent history of vaccination with BNT162b2, meantime after vaccination being 9.3 days after the first dose and 14.0 days after the second [177] dose. The number of hospitalizations regarding nerve palsy also falls out of trend from last 5-year data further adding fuel to the suspicion. Nevet from Israel has reported three cases of potentially life-threatening acute myocarditis within 2 days of the second dose [178]. On 9 July 2021, EMA enlisted myocarditis and pericarditis as side effects of BNT162b2.

In a study on AZD1222, for Danes between 18 and 99 years old, the incidence rate of venous thromboembolism was $1.76(95 \%$ CI $1.75-1 \cdot 78)$ per 1000 person-years and for Danes between 18 and 64 years old, it was $0.95(0 \cdot 94-0 \cdot 96)$ per 1000 person-years [121]. In a study based on Norway and Denmark over the thromboembolic incidents, the results observed were the same as expected for arterial events ( 83 observed events against 86 
expected), but more venous thromboembolic events were observed than expected in the vaccinated population (59 observed versus 30 expected) [109]. 7 of these occurrences were cerebral venous thrombosis, a life-threatening condition found to be a possible complication of ChAdOx1nCoV-19 vaccine in recent weeks [109]. Data analyzed indicated that from among the 281264 vaccinated individuals, 7 cases are low but still it is 20 times the general population rate and are an estimated 2.5 additional cases per 100000 vaccinated patients $[109,179]$. In total, reports of adverse effects after ChAdOx1-S in the EudraVigilance database were 54571 between 17 February 2021 and 12 March 2021. Initial adverse reactions most frequently reported were: tenderness of the injection site $(63.7 \%)$, pain at the injection site $(54.2 \%)$, exhaustion $(53.1 \%)$, headache $(52.6 \%)$, discomfort $(44.0 \%)$, myalgia (44.0\%), pyrexia including feverishness in $33.6 \%$ and fever $>38^{\circ} \mathrm{C}$ in $7.9 \%$ of the subjects [126]. Most of the adverse reactions have been mild to moderate and have been resolved within a short time after vaccination [126]. The side effects after the second dose of vaccinations were the same, but a little milder and less common [126]. A total of 28 thromboembolic reports were submitted to the database during the same period, 19 of them $(67 \%)$ were by health professionals. More than half $(n=16 ; 57 \%)$ of these reports were for individuals over the age of $85 ; 13(47 \%)$ were from within the EU. Of the six cases of pulmonary embolism, two were fatal, both in women, one each in the category of 18-64 years and more than 85 years of age. In a male patient between 18-64 years of age as well; there was a fatality following thrombosis [180]. In a case study, [18F] Choline PET/CT has been evaluated for a 75-year-old male with prostate cancer and biochemical recurrence [181]. No malignancy of avid choline could be identified, but avid left axillary nodes were noted. Three days earlier, in the upper left arm, the patient received the Oxford-AstraZeneca Covid-19 vaccination followed by absorption on the left upper arm (deltoid). The nodal uptake reaction of the recent vaccination is supported by a clinical correlation [181]. The current COVID-19 pandemic vaccination scheme on [18F] Choline in this case introduces a new PET/CT pitfall, which, if not noticed, may lead to the incorrect image interpretation and misrepresentation of the disease [181]. Another case study shows after 8 days of administration of COVAZD1222 vaccine, a 26-year-old woman was hospitalized for acute stroke [182]. Right hemiplegia and aphasia occurred quickly during the hospitalization of the patient for persistent nausea and headache that had begun shortly after the vaccination. Initial angiography revealed an occlusion of the left, middle cerebral artery. Dual thrombo-aspiration by using a first pass technique 3.5 hours following the onset of the symptoms resulted in the rechanneling of the left middle cerebral artery following a first pass. Final angiography showed a $2 \mathrm{C}$ thrombolysis recanalization in the cerebral infarction. Significant thrombocytopenia, hypofibrinogenemia, and inflammation were noted in laboratory tests of this patient [182]. Roughly after a month of WHO approval, reports regarding thrombotic issues like blood clotting began to circulate after administration of ChAdOx1nCoV-19. However, following EMA, MHRA, and TGA, WHO on 22 April 2021 in an update stated that the benefits of the vaccine outweigh the risk of blood clots. In June 2021, EMA confirmed capillary leak syndrome as a potential side effect of ChAdOx1nCoV-19. In July 2021, EMA has recommended the insertion of a warning on Guillian-Barre syndrome in the product information.

In a phase 1-2a trial with Ad26.COV2.S involving 805 participants, local side effects like fatigue, headache, myalgia, injection site pain were reported after vaccination while fever was the most reported systemic adverse effect at the primary endpoint [130]. Adverse events were more common in participants receiving a two-dose schedule than those receiving single-dose and less common in participants receiving the high dose $\left(1 \times 10^{11}\right.$ viral particles per $\mathrm{ml})$ than those receiving a low dose $\left(5 \times 10^{10}\right.$ viral particles per $\left.\mathrm{ml}\right)$. In Cleveland, USA, a woman aged 62 years complained of altered mental status 37 days after vaccination and was ultimately diagnosed with thrombotic thrombocytopenic purpura [183]. Tests revealed elevated white blood cell count of $19.25 \mathrm{k} / \mu \mathrm{L}$, absolute neutrophils $15.59 \mathrm{k} / \mu \mathrm{L}$, lactate $4 \mathrm{mmol} / \mathrm{L}$, procalcitonin $13.21 \mathrm{ng} / \mathrm{ml}$, C-reactive protein $6.4 \mathrm{mg} / \mathrm{dl}$, low fibrinogen $120 \mathrm{mg} / \mathrm{dl}$ and platelets $29 \mathrm{k} / \mu \mathrm{L}$. Urinalysis revealed large hemoglobin and 11- 
25 red blood cells per high-powered field. Nishizawa and colleagues [184] reported a case of House-Brackmann score 4 Bell's palsy (near-complete paralysis of the right lower face and significant paralysis of the right upper face with incomplete eye closure) after 20 days of vaccination. The 62 years old Pilipino woman had a history of type 2 diabetes mellitus, hypertension, and hyperlipidemia but no previous record of any neurological symptoms. Vaccine-induced thrombosis and thrombocytopenia have been reported from the USA and UK, (6 and 23 cases, respectively) between 6 to 13 days post-vaccination [183]. EMA has expressed concerns regarding the coming up of unusual blood clots as very rare side effect of Ad26.COV2.S; however potential benefits seem to outweigh the risks [185]. Cases of vaccine-induced thrombotic thrombocytopenia have also been reported from South Africa, Canada, and many European countries [186]. Responding to such reported cases of thrombosis with thrombocytopenia syndrome, USFDA has included a new warning in April 2021 regarding rare clotting events among women aged 18-49 years; however, they are also of the opinion that potential benefits outweigh the risks [187]. A 74 years old male having known allergies to sulpha drugs and amoxicillin-clavulanic acid combinations from Virginia presented with severe cutaneous adverse reaction in the form of new-onset rash along with ipsilateral arm discomfort within 3 days of vaccination [113]. Further examination revealed erythematous plaques with acral swelling, small, non-follicular pustules spreading to face, genitals, and mucosae without palpable lymphadenopathy. Situations improved with topical steroids and oral prednisone $20 \mathrm{mg}$. Multiple queries have been raised on the development of unusual blood clots in patients with low platelet count after vaccination with Ad26.COV2.S, however on 7th May 2021, EMA confirmed that benefits outweigh the risks. Considering later developments, in July 2021 EMA enlisted capillary leak syndrome and Guillain-Barre syndrome as very rare side effects of Ad26.COV2.S in the product information sheet.

Adverse reactions were mostly mild to moderate and more common after the $2^{\text {nd }}$ dose in a phase I study with mRNA-1273 [135]. Trial subjects reported severe adverse events at doses $\geq 100 \mu \mathrm{g}$ in another phase I study [136]. Reactogenicity symptoms like pain, redness, swelling, fever, fatigue, etc. were mild to moderate and appeared more frequently after $2^{\text {nd }}$ dose than after $1^{\text {st }}$ dose in the phase III trial [69]. Local and systemic reactions after vaccination were more common in subjects aged 18-64 years than in the older subjects and disappeared within 4-5 days of vaccination in most cases. Local injection site reactions (pain, redness, swelling, axillary tenderness) and systemic adverse reactions (fever, fatigue, myalgia, headache, arthralgia, nausea, chills) of grade 3 and above were reported by $9.1 \%$ and $16.5 \%$ of the vaccine recipients, respectively. GRADE analysis showed moderate certainty towards serious adverse events and high certainty of reactogenicity [67]. In the USA, 4041396 persons were injected with the first dose of the vaccine between $21^{\text {st }}$ December 2020 and 10th January 2021, among which 1266 persons (0.03\%) faced adverse events [188]. Among the 108 suspected cases of anaphylaxis, only 10 were confirmed as anaphylactic reactions (interestingly, all were females aged between 31-63 years), 5 of which had the previous history of anaphylaxis, and 9 had a history of allergic reactions. While symptoms of anaphylactic shock appeared within 45 minutes, no anaphylactic death was recorded. 47 of the remaining suspected cases were concluded to be non-allergic reactions while 47 were allergic reactions not related to anaphylaxis and 4 cases were abandoned due to lack of sufficient information. Occurrence rate of anaphylaxis was found to be 2.5 per million vaccinations which is higher than the rate $(1.3$ per million vaccinations) with other similar vaccines [189]. In the phase III coronavirus efficacy trial of this vaccine, out of 15185 recipients of the first dose, 228 (1.5\%) reported hypersensitivity associated adverse events [190]. Among them, 4 cases had very specific symptoms of localized erythematous rash surrounding the injection site within few days of the first dose, often referred to as 'COVID arm'. However, the 'COVID arm' has been perceived as a harmless side effect by physicians [162]. All 4 reported cases were in females, which is in conjunction with findings by [187] fuelling the possibility of further clinical analysis regarding any relationship between sex and occurrence of hypersensitivity reactions after 
administration of the mRNA-1273 vaccine. A 22 years old myopic female in the USA experienced bilateral retinal detachment after vaccination with mRNA-1273 [191]. In July 2021, EMA confirmed myocarditis and pericarditis as side effects of mRNA-1273.

Xia et al [143] reported only mild pain at the injection site and fever as adverse events after phase I and phase II trials with BBIBP-Cor-V in China. Adverse events were mostly mild to moderate among recipients of BBIBP-CorV, the most common reaction being fever as reported from phase I and phase II clinical trials conducted by the Beijing Institute of Biological Products [192]. Jordanian healthcare workers receiving BBIBP-CorV reported mild side effects like injection site pain, fatigue, fever, myalgia, headache, dizziness, arm numbness, and ear symptoms within 0-5 days [193]. Occurrence of side effects was more after $2^{\text {nd }}$ dose while no statistically significant relationship could be established between severity of side effects and sex or age group.

In a phase I/II trial of CoronaVac, while most of the adverse effects were categorized as mild to moderate with pain at the injection site being most frequent, $2 \%$ of the recipients reported serious adverse events which were judged to be unrelated to vaccination [135]. One serious adverse event recorded was pneumonia in the placebo (alum only) group in a China-based trial on the juvenile population [139]. An independent cross-sectional study was undertaken for CoronaVac side effects among Turkish healthcare workers in February 2021 [194]. Pain at the injection site was the most frequent side effect (41.5\%) within 4 weeks of vaccination while fatigue, headache, muscle pain, and joint pain followed later. Females were more prone to side effects than males. The study concluded CoronaVac to be safe overall, however, younger age, previous infection history, and compromised health status seemed to enhance the risk of side effects. A case report stated the development of SDRIFE like eruptions and itchy rashes 4 days after CoronaVac in an 87-year-old patient, though the specific allergen could not be identified yet [195]. In a 45-year-old female healthcare worker of Turkey, pityriasis rosea (skin rashes, herald patch, multiple plaques in chest region), generally caused by the herpes virus and rarely caused after vaccination developed 4 days after both the $1^{\text {st }}$ and the $2^{\text {nd }}$ dose of CoronaVac which cured within few weeks on treatment[196]. Though compared to life threats, skin eruptions are somewhat acceptable, close monitoring may be recommended as the mechanism behind the development of this side effect is not clear yet. A Thailand-based clinical trial (ictrpTCTR20210610004) has reported neurological complications after CoronaVac injection. Type I Kounis syndrome, pustular psoriasis, petechial skin rash, and reactive arthritis are among other adverse effects reported after CoronaVac administration [197-200].

In May 2021, a Brazilian health regulatory agency alleged contamination of Sputnik $\mathrm{V}$; claiming the $2^{\text {nd }}$ dose contains adenovirus capable of replication and a posing potential risk for the recipients [201]. An Argentine cohort study supported short-term safety from early serious events but displayed high rates of local and systemic reactions [163]. Muscle pain, injection site pain, fever, redness, swelling, and diarrhea were the highest reported local and systemic adverse events. Occurrences of adverse events were higher in females and in the age groups below 55 years. A recent infodemiology study by Jarynowski et al [202] claims Sputnik V to cause mild to moderate adverse effects in females compared to males and increasing in number with increaseing age $(0.05 /$ year, $\mathrm{p}<0.001)$. Reported adverse events were in line with other vector vaccines including fever, pain, fatigue, and headache. A cohort study by Montalti et al [203] in the Republic of San Marino analyzed data of 2558 persons (between 18-89 years); 7 days after $1^{\text {st }}$ dose and 1288 people after 7 days of $2^{\text {nd }}$ dose. After the first dose, vaccine recipients described both local and systemic reactions in $16.4 \%$ cases, $25.8 \%$ reported systemic reactions only and $10.2 \%$ reported local symptoms only whereas after the second dose, both local and systemic reactions were reported in $31.9 \%$ cases, $18.5 \%$ reported systemic reactions only and $16.1 \%$ reported local symptoms: only chief complaints being injection site pain, asthenia, headache, and joint pain. $81.8 \%$ of the people experienced adverse events after both the $1^{\text {st }}$ and the $2^{\text {nd }}$ dose. Ryzhikov and colleagues reported mild pain at the injection site as the only adverse effect of EpiVacCorona [85]. 
In a randomized control trial of BBV152 with 375 participants, three groups were formed with 100 participants in each of them randomly selected for all three vaccine groups and 75 were allocated randomly for the control group receiving Algel only [167]. After injection of both the doses, $17(17 \%$; 95\% CI 10.5\%-26.1\%) participants in the $3 \mu \mathrm{g}$ group with Algel-IMDG, 21 (21\%; 95\% CI 13.8-30.5) in a $6 \mu$ group with Algel-IMDG, $14(14 \% ; 95 \%$ CI 8.1-22.7) in the $6 \mu \mathrm{g}$ group with Algel Group, and 10 (10\%; 95\% CI 6.9-23.6) in the Algel only group reported local or systemic adverse reactions [167]. Injection site pain $(5 \%$ of total participants), headache $(3 \%)$, fatigue $(3 \%)$, fever $(2 \%)$, and nausea or vomiting (2\%) were the most reported adverse events out of which $69 \%$ were mild and $31 \%$ were moderate [167]. Srivastava et al [170] claimed that at a particular tertiary care center in India, only 15 candidates out of 1322 were found to have minor adverse effects after the first dose of BBV152 between $16^{\text {th }}$ January 2021 and $16^{\text {th }}$ February 2021 . The adverse effects included pain at the injection site, chest pain, fever, headache, etc.

As reported by Zhu and colleagues regarding Ad5-nCoV, 83\% of the low dose group ( 1 vial of $5 \times 10^{10}$ viral particles per $0.5 \mathrm{ml}$ ), $83 \%$ of the middle dose group ( 2 vials of $5 \times$ $10^{10}$ viral particles per $0.5 \mathrm{ml}$ ) and $75 \%$ of the high dose group ( 3 vials of $5 \times 10^{10}$ viral particles per $0.5 \mathrm{ml}$ ) reported at least one adverse reaction within 7 days of vaccination [171]. Most common local and systemic adverse effects included pain at the injection site, fever, fatigue, headache, and muscle pain all with mild to moderate severity while no serious adverse events were recorded within 28 days of vaccination. However narrow age range of the volunteers, short follow-up period, and absence of any randomized control pose doubts on the acceptability of the outcomes. A placebo-controlled, randomized, double-blind phase II clinical trial was also conducted by Zhu and colleagues on 508 adult volunteers divided into three groups viz. Low dose $\left(1 \times 10^{11} \mathrm{VP}\right.$ per $\left.\mathrm{ml}\right)$, middle-dose $(5 \mathrm{x}$ $10^{10} \mathrm{VP}$ per $\mathrm{ml}$ ) and placebo [173]. 14 days post-vaccination, significantly higher reports of adverse events were reported from low and middle dose populations $(74 \%$ and $72 \%$ respectively) than placebo recipients. Adverse events were similar to those reported in the phase I trial and the joint pain being the lone additional symptom [171, 173]. 9\% of the middle dose group reported severe adverse events.

\section{Vaccines under development: a brief overview of current forerunners}

The global pandemic has already affected innumerable lives in many ways. Vaccines are the need of the hour to prevent the loss of human resources and the economy. Coalition for economic preparedness innovations, global alliance for vaccines and immunization, and WHO are collaboratively leading COVAX, in partnership with UNICEF. CO$\mathrm{VAX}$ is a global sharing platform aiming to accelerate the development and manufacture of COVID-19 vaccines worldwide and subsequently ensuring equitable distribution of vaccines worldwide. Operation warp speed, a public-private venture led by the US government was announced in May 2020 to speed up the development, manufacturing, and distribution of COVID-19 vaccines. These two initiatives have played havoc towards the release of many of the vaccine candidates. Table 3 enlists the current frontrunners in clinical trials likely to get approval in near future. 
Table 3. Forerunners in clinical trials: possible candidates for future.

\begin{tabular}{|c|c|c|c|c|c|}
\hline S. No. & Vaccines & Country of origin & Trial phase & Types & Potential promises \\
\hline 1 & Vidprevtyn & USA & 3 & Recombinant protein with adjuvant & $\begin{array}{c}\text { Interim phase } 2 \text { result reported } 95-100 \% \\
\text { seroconversion, } 3^{\text {rd }} \text { phase trial started in } \\
\text { May } 2021\end{array}$ \\
\hline 2 & CVnCoV (CureVac) & Germany and Belgium & $2 b / 3$ & $\begin{array}{l}\text { Non-chemically modified mRNA } \\
\qquad(\mathrm{CBnCOV})\end{array}$ & $\begin{array}{l}\text { Protection against B.1.951 variant in } \\
\text { mice, } 48 \% \text { efficacy in phase } 2 b / 3 \text { trial }\end{array}$ \\
\hline 3 & $\begin{array}{l}\text { BCG vaccine } \\
\text { (repurposing) }\end{array}$ & Australia, Netherlands & $2 / 3$ & Live attenuated virus & $\begin{array}{l}\text { Reduced COVID-19 related clinical } \\
\text { symptoms, not impressive enough for } \\
\text { confirmatory decision }\end{array}$ \\
\hline 4 & NVX-CoV2373 & Australia & 3 & Protein nanoparticle & $\begin{array}{c}\text { About } 90 \% \text { efficacy reported in various } \\
\text { trials, approval sought in Australia, } \\
\text { USA, Canada, Europe }\end{array}$ \\
\hline 5 & ARCoV & China & 3 & $\begin{array}{l}\text { mRNA (encoding receptor binding } \\
\text { domain) lipid nanoparticle }\end{array}$ & Phase 3 trial on the way \\
\hline 6 & $\begin{array}{l}\text { Unnamed } \\
\text { (Medicago) }\end{array}$ & Canada & 3 & $\begin{array}{l}\text { Virus like particle along with plant } \\
\text { based adjuvants }\end{array}$ & $\begin{array}{l}\text { High antibody titers with tolerable safety } \\
\text { profile }\end{array}$ \\
\hline 7 & VLA2001 & UK & 3 & Inactivated vaccine & $\begin{array}{l}\text { Safe, well tolerated as per phase } 1 / 2 \text { trial } \\
\text { reports in April } 2021\end{array}$ \\
\hline 8 & Corbevax & India & 3 & $\begin{array}{c}\text { Protein subunit with CpG1018 as } \\
\text { adjuvant }\end{array}$ & $\begin{array}{l}\text { Very positive results from phase } 1 / 2,3^{\text {rd }} \\
\text { phase announced on April } 2021 \text {. }\end{array}$ \\
\hline 9 & Nanocovax & Vietnam & 3 & $\begin{array}{l}\text { Glycosylated recombinant spike } \\
\text { protein }\end{array}$ & $\begin{array}{c}\text { Displayed in vitro neutralizing activity, } \\
\text { in phase } 2 \text {, all non-placebo recipients } \\
\text { developed antibodies }\end{array}$ \\
\hline 10 & BNT162 & USA & $1 / 2 / 3$ & mRNA vaccine & $\begin{array}{l}\text { BNT162b2 already approved by WHO, } \\
\text { BNT162b1 displayed similar efficacy } \\
\text { with altered adverse reaction profile }\end{array}$ \\
\hline
\end{tabular}




\begin{tabular}{|c|c|c|c|c|c|}
\hline 11 & INO-4800 & USA & $2 / 3$ & Intradermal DNA vaccine (plasmid) & $\begin{array}{l}\text { Phase } 2 \text { portion declared INO-4800 as } \\
\text { safe and well tolerated in May } 2021\end{array}$ \\
\hline 12 & $\begin{array}{l}\text { Unnamed (Immunity } \\
\text { Bio) }\end{array}$ & USA & $2 / 3$ & $\begin{array}{c}\text { Adenovirus based vaccine targeting } \\
\text { spike protein and nucleocapsid } \\
\text { DNA }\end{array}$ & $\begin{array}{l}\text { Reported CD4+ and CD8+ antigen } \\
\text { specific } \mathrm{T} \text { cell response in mice, no } \\
\text { serious adverse events reported in } \\
\text { humen receiving low dose }\end{array}$ \\
\hline 13 & UB612 & Taiwan & $2 / 3$ & Multitope peptide vaccine & $\begin{array}{l}\text { Well tolerated, } \mathrm{CD} 4+/ \mathrm{CD} 8+\mathrm{T} \text { cell } \\
\text { response }\end{array}$ \\
\hline 15 & SCB-2019 & China & $2 / 3$ & Protein subunit with adjuvants & $\begin{array}{c}\text { Adjuvant optimized for formulation, } \\
\text { robust cellular and humoral immune } \\
\text { response reported along with strong } \\
\text { neutralizing activity }\end{array}$ \\
\hline
\end{tabular}


US phase I trial comprising of persons of age groups 18-55 years and 65-85 years recommended BNT162b2 over BNT162b1 for further trials based mainly on lesser systemic reactogenicity among the older population $[204,205]$. BNT162b1 is still in the final phases of the clinical trial while BNT162b2 is already approved by WHO. A recombinant vaccine using Sf9 cells developed in China is showing promise in clinical trials (currently in phase III, NCT04904471). A lipid nanoparticle encapsulated mRNA vaccine coding for the RDB developed by Walvax Biotechnology Co. Ltd. is all set to start a phase III clinical trial (NCT04847102). A prefusion stabilized protein nanoparticle vaccine candidate, NVXCoV2373 has already been granted provisional determination by TGA and fast track designation by USFDA. NVX-CoV23, reportedly demonstrated 51.0\% efficacy against B.1.351 variant of coronavirus in HIV-negative subjects [207]. Medicago has developed a plantbased adjuvant vaccine belonging to virus-like particles currently undergoing phase III clinical trial (NCT04636697). The vaccine candidate has displayed high antibody titers compared to natural infection according to phase II results made public on 18 May 2021 through a press release. USFDA has granted fast track designation for the vaccine candidate in February 2021. Valneva has developed an inactivated vaccine candidate VLA2001 claimed to be safe and well-tolerated to human subjects in a press release dated 06 April 2021. A phase III study (NCT04864561) comprising of about 4000 participants aimed to compare VLA2001 with AZD1222 is on the way starting from April 2021. Biological E, India in collaboration with Dynavax and Baylor College of Medicine has developed a protein subunit-adjuvant complex vaccine candidate specifically aimed at children. The candidate is all set to enter into the $3 \mathrm{rd}$ phase of the clinical trial after very positive results in earlier phases (CTRI/2020/11/029032) in India. Sanofi and GSK have announced 95-100\% seroconversion in interim phase 2 results on 17 May 2021 with their vaccine candidate combining recombinant protein and adjuvant. Phase III trial has begun on May 2021 and EMA has started a rolling review for the candidate in July 2021. Nanogen Pharmaceuticals, Vietnam has developed a glycosylated recombinant spike protein vaccine candidate against SARS-CoV-2. The vaccine candidate demonstrated in vitro neutralizing activity 7 days after two doses according to a press release dated 08 February 2021. Phase III study (NCT04922788) has begun in June 2021 with the candidate. Attempts are also being made towards passive acquired immunity by the use of plasma therapy, monoclonal antibodies, and cocktail antibodies $[55,206]$.

\section{Possibility of reinfection: what goes around, can come back around?}

All vaccines approved by regulators for public use have proven themselves to protect the vaccinated subject from COVID-19 in clinical trial setups. Vaccination is expected to prevent severe illness, hospitalization, and death resulting from SARS-CoV-2 infection. But, from a bird's eye viewpoint, no one is completely protected until everyone is protected. Vaccination is a very important tool to deal with the current pandemic. While the vaccines in use are effective, no vaccine is able to prevent infection $100 \%$ of the time. However, there is a fine delineation among reinfection, relapse and positivity which should not be misinterpreted. The emergence of new mutant strains of coronavirus makes the situation more complicated. How frequently vaccine breakthrough cases are coming up is an indication of the safety of the vaccinated population from SARS-CoV-2. Edridge and peers [208] reported reinfection by seasonal human coronaviruses as early as within 6 to 12 months of the first infection.

A person could be infected just before or just after vaccination and get sick. It typically takes few weeks for the human immune system to build up protection after vaccination, hence a person may get sick if the vaccine has not had enough time to provide protection. However, the severity of the disease would be low in a vaccinated individual. In 
most cases of reinfection, the first episode of the disease was mild or asymptomatic [209]. The greater magnitude of antibody responses and T-cell responses generated during severe COVID-19 may confer more robust and long-lasting protection.

Researchers are trying to extract a pattern or trend from the breakthrough cases based on age, sex, health condition, race, vaccine type, viral strain etc. Vaccines can either block new infections or can halt the progression of symptoms after infection by stimulating the immune system. Protection seems to be dependent upon antibody response along with important contributions from CD4+ T cells [210]. Neutralizing antibodies generated after infection or vaccination last for months to years but are not lifelong [211,212]. There still exist remote chances of infection of coronavirus back from humans to animals, which may potentially induce vaccine failure [213]. Neutralizing antibody titer seems to decrease 8 folds within 144 days of natural infection in a patient reinfected with COVID-19 [13]. During the second infection, antibody response increased continuously from day 3 to day 8 of hospitalization while Ig M response was absent.

\section{Discussions: Lessons learned towards future directions}

Many vaccines have been developed against COVID-19 so far using different platforms. Probably for the first time in history, companies have started scaling up the production capacity even before getting approval foreseeing the huge demand post-approval. The requirement of a cold chain is proving to be a key factor towards mass vaccination in a multicentric mode. Exact antibody titers or defined $\mathrm{T}$ cell responses are yet to be arrived at to guarantee protection from SARS-CoV-2. There are no set international standards regarding these parameters also, which might result in different interpretation and approval in different countries from similar outcomes. The durability of the induced immunity is still under research [214]. Till now, very little data is available on the effect of vaccines on vulnerable populations like pregnant ladies, children, infants through lactating women, pre-existing disease conditions, immunodeficiency, etc. Success of vaccination largely depends on virus variants and host immunity. It is also to be made clear that, the 'best' COVID-19 vaccine is nothing but a utopian maxim since different vaccines use different technologies and different platforms, each of which might suit the appropriate population under proper contexts.

Though the fast-tracking of the vaccine candidates seems justified under the current pandemic emergency, it is to be taken care that no aspect of potential risks gets overlooked in undue haste. The viral genome is prone to mutations by antigenic shift and antigenic drift while spreading through different populations in different environmental conditions [215]. This may in turn give rise to a resistant strain with time. Too much stress on the $S$ protein as the target antigen may generate a mutation force. Vaccine might then become seasonal protection like in the case of influenza. Apart from vaccine development, the success of strategic herd immunity through vaccination is largely dependent on the proper distribution of the vaccines throughout the globe also.

Results and data regarding COVID-19 vaccines are mostly available from the manufacturers and from governments of various countries, rather than from peer-reviewed publications now. BNT162 and mRNA-1273 possess the unique advantage of possible quick re-engineering if need to cope up with new mutations of coronavirus [216]. There exist multiple evidences that mRNA COVID-19 vaccines (Pfizer-BioNTech, Moderna) offer similar protection in real-world conditions [217-219]. Some vaccines, particularly the inactivated vaccines and subunit vaccines suffer from very short immune memory [48]. From the safety point of view, clinicians are actively considering the possibility of recommending mRNA vaccines instead of viral vector vaccines for those at substantially higher risks of TTS [220]. Interestingly, capillary leak syndrome and Guillain-Barre syndrome have been reported as very rare side effects of both AstraZeneca and Janssen as listed by EMA. Interestingly, Guillian-Barre syndrome is also enlisted as a post-infection complication related to CNS [221,222]. In a comparative survey on Pfizer-BioNTech and Moderna vaccines (both mRNA vaccines), both of them presented with almost identical efficacy 
profiles regarding protection against COVID-19 while the former one came up with a lesser number of reported adverse effects, whereas the latter one seemed more convenient regarding transport and storage conditions [223]. Statistical analysis of results concluded that Sinopharm, Oxford-AstraZeneca and Pfizer-BioNTech vaccines provided a similar level of protection from COVID-19 [148]. Wang and colleagues have described both BBIBP-CorV and CoronaVac to be more or less equally effective against B.1.1.7 (alpha) variant, but they might be less effective against B.1.351 (beta) variant local to South Africa [224]. Variants with mutations in the RDB were effectively neutralized by CoronaVac (inactivated virus vaccine) but variants with $\mathrm{E} 484 \mathrm{~K}$ mutation were resistant to CoronaVac [152]. Comparatively low efficacy of the two-dose schedule of CoronaVac than single dose was doubted to be the result of some non-pharmaceutical interventions or bias in the setting [153]. Two doses of CoronaVac have been observed to boost longer-lasting neutralizing antibody responses in previously seropositive patients possibly via inducing B cell memory responses [225]. However, this boosting effect was absent in three patients, obesity being the common factor among them. In the same study, it was also noted that both CoronaVac (2 doses) and BNT162b2 (single dose) yielded similar neutralizing antibody responses to naturally infected patients between 4.2 and 13.3 months of vaccination. In Indonesia, COVID-19 symptoms developed 40 days post-vaccination with CoronaVac in a patient (female, 41 years) on 19 March 2021 [226]. Though the patient likely had a limited amount of humoral immune response to the vaccine, no history of immunodeficiency disorders has been found. Moreover, antibody level in this patient was much lower than those previously infected with COVID-19. Interestingly, a high titer of the antibody was present 20 days after the development of symptoms. Observations hint towards either lack of immune response elicited by the vaccine and subsequent infection with the variant virus or involvement of a different variant of the virus resistant to CoronaVac. It has been observed that rAd26 and rAd5 successfully neutralized spike protein of B.1.1.7, showed moderate efficacy against variants with E484K mutation (also resistant to CoronaVac), and failed to neutralize spike protein of B.1.351 [164, 165]. A network meta-analysis provided the order of effectiveness as BNT162b2 $\simeq$ mRNA-1273 > Sputnik V >> AZD1222 [227]. Concerning the untoward effects arising from vaccination, the risk-benefit balance must favour the latter. Table 4 enlists the reported adverse reactions of the vaccines currently in use. The majority of the approved vaccines are represented by viral vector vaccines while among the frontrunners in the pipeline, protein subunit vaccines gained an overwhelming majority (Figure 3). The mRNA vaccines have displayed very high efficacy against symptomatic COVID-19 infection, while inactivated vaccines and viral vector vaccines perform better to prevent COVID-associated hospitalization (Figure 4).

Table 4. Reported adverse effects of approved vaccines with respect to vaccine types.

\begin{tabular}{|c|c|c|c|c|}
\hline \multirow[t]{2}{*}{ S. No. } & \multirow{2}{*}{$\begin{array}{c}\text { Vaccine } \\
\text { types }\end{array}$} & \multirow{2}{*}{$\begin{array}{l}\text { Approved } \\
\text { vaccines }\end{array}$} & \multicolumn{2}{|c|}{ Adverse events } \\
\hline & & & Mild & Severe \\
\hline 1 & $\begin{array}{c}\text { mRNA } \\
\text { vaccines }\end{array}$ & $\begin{array}{l}\text { BNT162b2, } \\
\text { mRNA-1273 }\end{array}$ & $\begin{array}{l}\text { Pain, tenderness, redness } \\
\text { and swelling at injection } \\
\text { site, fatigue, headache, } \\
\text { fever, nausea, chills, } \\
\text { COVID arm, }\end{array}$ & $\begin{array}{l}\text { Allergy-like reactions, Bell's } \\
\text { palsy, acute myocarditis, } \\
\text { pericarditis, arthralgia (grade } 3 \\
\text { and above), anaphylactic } \\
\text { reactions, bilateral retinal } \\
\text { detachment }\end{array}$ \\
\hline 2 & $\begin{array}{l}\text { Protein } \\
\text { subunit } \\
\text { vaccines }\end{array}$ & EpiVacCorona & Pain at injection site & - \\
\hline
\end{tabular}




\begin{tabular}{|c|c|c|c|c|}
\hline 3 & $\begin{array}{l}\text { Recombinant } \\
\text { viral vector } \\
\text { vaccines }\end{array}$ & $\begin{array}{c}\text { AZD1222, } \\
\text { Ad26.COV2.S, } \\
\text { Sputnik V, } \\
\text { Convidicea }\end{array}$ & $\begin{array}{l}\text { Pain and tenderness at } \\
\text { injection site, exhaustion, } \\
\text { discomfort, headache, } \\
\text { pyrexia, fatigue, muscle } \\
\text { pain, diarrhoea, asthenia, } \\
\text { joint pain }\end{array}$ & $\begin{array}{l}\text { Clotting events, venous and } \\
\text { arterial thromboembolism, } \\
\text { cerebral venous thrombosis, } \\
\text { pulmonary thromboembolism, } \\
\text { acute stroke, capillary leak } \\
\text { syndrome, Guillian-Barre } \\
\text { syndrome, thrombotic } \\
\text { thrombocytopenic purpura, } \\
\text { cutaneous rash }\end{array}$ \\
\hline 4 & $\begin{array}{c}\text { Whole killed } \\
\text { vaccines }\end{array}$ & $\begin{array}{l}\text { BBIBP-CorV, } \\
\text { CoronaVac, } \\
\text { BBV152 }\end{array}$ & $\begin{array}{l}\text { Pain at injection site, fever, } \\
\text { fatigue, myalgia, dizziness, } \\
\text { arm numbness, headache, } \\
\text { ear symptoms, joint pain, } \\
\text { itchy rash, pityriasis rosea, } \\
\text { pustular psoriasis, nausea, } \\
\text { chest pain }\end{array}$ & $\begin{array}{l}\text { Neurological complications, } \\
\text { type I Kounis syndrome, } \\
\text { reactive arthritis }\end{array}$ \\
\hline 5 & $\begin{array}{c}\text { DNA } \\
\text { vaccines }\end{array}$ & ZyCoV-D & $\begin{array}{c}\text { Tenderness at injection site, } \\
\text { fever, itching, joint pain, } \\
\text { diarrhoea }\end{array}$ & Enteric fever \\
\hline
\end{tabular}

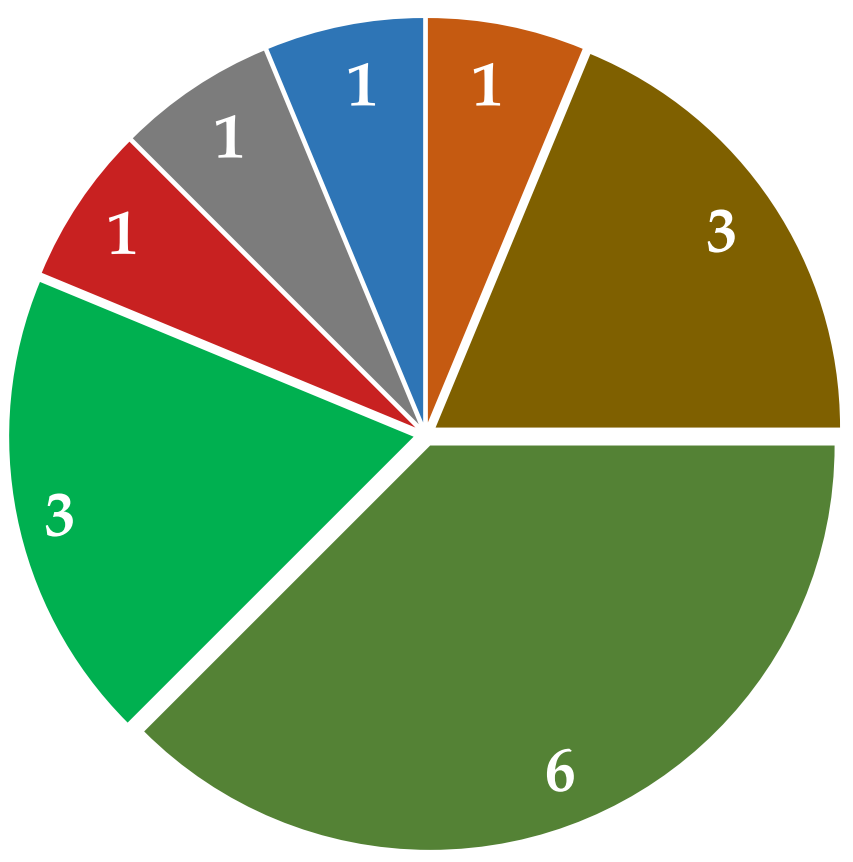

DNA vaccine

mRNA vaccine

- Protein subunit

Recombinant viral vector

Live attenuated vaccine

Inactivated vaccine

- Virus like particles

Figure 3. Vaccines currently in the final phase of clinical trial. Protein subunit vaccines (6) dominate the list followed by mRNA vaccine \& recombinant viral vector (3 each). Each of live attenuated, inactivated, virus like particles and DNA vaccines are in the final phase trial. 


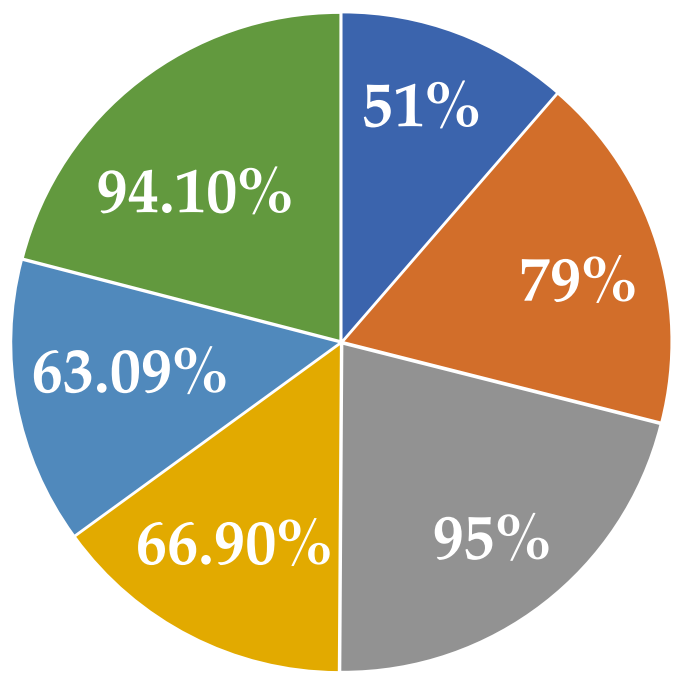

\section{CoronaVac inactivated vaccine}

BBIBP inactivated vaccine

BNT162b2 mRNAvaccine

Ad26.COV.2S viral vector vaccine

AZD1222 vector vaccine

mRNA-1273 vaccine

Figure 4. Percentage efficacy of WHO approved vaccines against symptomatic COVID-19.

The temporary lack of peer review is somewhat posing doubts on some questionable results being presented among the scientific fraternity. On January 18, 2021 in an open letter to the health ministry of Russia, many of the trial participants stated that independent testing had revealed a much lower level of antibody generation among them than declared by vaccine developers. The scientific community worldwide is still divided on whether or not the peptides used in EpiVacCorona are detectable to the human immune system to generate B cell response [228-230]. A report published in Lancet claims that the vaccine BBV152 has been rolling out even though there are several trial allegations made against them [231]. The allegations included participants claiming that they were unable to read the consent form and they were unable to report adverse events. Participants also claimed that they did not know it was a trial and they can refuse to take the vaccine [231].

In a study to compare two vaccines AZD1222 and BBV152, the first dose of vaccines was injected into 552 healthcare workers, where 456 received AZD1222 and 96 received BBV152 [232]. In total, seropositivity after the first dose was found to be $79.3 \%$. In AZD1222, responder rate and median (IQR) rise in anti-spike protein, antibody was significantly higher compared to BBV152 (86.8\% vs. $43.8 \%$; $61.5 \mathrm{AU} / \mathrm{ml}$ vs. $6 \mathrm{AU} / \mathrm{ml}$; both $\mathrm{p}<0.001)$ [232]. No differences were observed with respect to age, gender, and BMI. There was a lesser response rate in the subjects with a history of hypertension $(65.7 \%$ vs. $82.3 \%$, $\mathrm{p}=0.001)$. The recipient of AZD1222 had more negative effects compared to recipients of BBV152 (46.7\% vs. 32.4\%, p = 0.006). In a randomized controlled study, of the 515 healthcare workers, $95.0 \%$ showed seropositivity following both doses of the AZD1222 and BBV152 [233]. The $98.1 \%$ and $80.0 \%$, of the participants, showed seropositivity among the 425 AZD1222 and 90 BBV152 recipients respectively. In line with the observations after first-dose, the seropositivity rate and median rise in anti-spike antibody were higher in AD1222 compared to those in BBV152 (98.1\% vs. 80.0\%; $127.0 \mathrm{AU} / \mathrm{ml}$ vs. $53 \mathrm{AU} / \mathrm{ml}$; both cases $\mathrm{p}<0.001)$. Though there was no definitive agreement observed with regard to sex, $\mathrm{BMI}$, and blood group, there were significantly lower seropositive rates for either people $>60$ years of age or people with type 2 diabetes [233]. Recipients irrespective of the vaccine type received had mild to moderate adverse effects which were similar and expected, and neither had any serious unwanted effects [233]. In June 2020 China's Central Military Commission approved the use of $\mathrm{Ad} 5-\mathrm{nCoV}$ by the military for 1 year - arguably the equivalent of a Phase III trial. Both Oxford/Astrazeneca and CanSino utilize adenovirus 
as a vector for their COVID-19 vaccine. Adenoviruses are common and can cause a variety of illnesses in humans ranging from a cold to conjunctivitis. When comparing the neutralizing antibody response between the two-adenoviral vector-based vaccine candidates, it was shown that while Oxford/AstraZeneca's AZD1222 has demonstrated a high neutralizing antibody level in $91 \%$ of individuals following the first dose, and in all individuals following a booster dose, only 59\% of individuals in CanSino's vaccine demonstrated neutralizing antibody $[124,170]$. This indicates that a good proportion of participants did not develop an effective immune response due to the presence of pre-existing immunity against human adenoviruses. Oxford/AstraZeneca was able to prevent this outcome by utilizing a genetically modified chimpanzee-derived adenovirus against which humans do not have pre-existing immunity [68]. However, CanSino's vaccine at a lower cost combined with its moderate efficacy may prove advantageous for some countries.

\section{Conclusion}

Ideally, the vaccine needs to be made available to nearly 8 billion people worldwide. Safe and equitable distribution is a challenge, especially in developing and under-developed countries. It takes around 2-4 weeks post-vaccination to develop immunity. Initially, the healthcare workers, susceptible aged population with co-morbidities and potential super spreaders had been prioritized for vaccination. Currently, entire world is racing to get to the end of the pandemic. The durability of the elicited immune response is a critical player to generate sustainable herd immunity worldwide. To further mobilize people towards vaccination, the principle of vaccine passport is being actively considered by some countries. Different technologies, platforms, and routes have been utilized to develop safe and effective vaccines. Choice of optimum vaccine for a population sub-group depends on factors like race, environmental conditions, prevalent immunity, health conditions, etc. Ideal interval and dose for vaccination to naturally infected person post-infection are also matters of concern. Also, mutation of the highly contagious retrovirus is a headache. All approved vaccines are more than 50\% efficacious in preventing COVID-19. Some are displaying promise against newer strains also. The delta strain (B.1.617.2) has been in discussion for quite a bit now regarding the future third wave. Sputnik $V$ has displayed high efficacy against B.1.617.2. BBIBP-CorV has also demonstrated a similar antibody response against B.1.617.2 compared to natural infection. Ad26.COV2.S and BNT162b2 have also demonstrated some efficacy against B.1.617.2. Many candidates are showing promises in clinical trials which are likely to be approved in the future. As soon as the world population becomes vaccinated, the pandemic will start to fade out as no one is safe until everyone is safe.

Author Contributions: SD: VDF and RK contributed to the conceptualization and designing the manuscript. PC, JV, AC, SS, and PHR edited and corrected the manuscript. The final correction and editing were done by SD, VDF, PHR, and RK.

Funding: VDF provided APC for publishing this manuscript and all the authors acknowledged the same.

Institutional Review Board Statement: Not applicable.

Informed Consent Statement: Not applicable.

Acknowledgments: The authors are thankful to the Jadavpur University, India for awarding research fellowship to Pratik Chakraborty (reference no. R-11/13/20 dated 22.01.2020), CSIR-India for awarding research project to Saikat Dewanjee (grant number 02(0275)/16/EMR-II), and DBT-India for providing Ramalingaswami Re-entry Fellowship to Ramesh Kandimalla (No. BT/RLF/Re-entry/22/2016 and SAN.No. 102/IFD/SAN/1117/2018-19) for the period of 2018-2023.

Conflicts of Interest: The authors declare no conflict of interest. 


\section{References}

1. Kalra, R.S.; Tomar, D.; Meena, A.S.; Kandimalla, R. SARS-CoV-2, ACE2, andhydroxychloroquine: cardiovascular complications, therapeutics, and clinical readoutsin the current settings. Pathogens 2020, 9, 546, doi:10.3390/pathogens9070546.

2. Kandimalla, R.; Dewanjee, S.; Kalra, R.S.; Valupadas, C.; Vallamkondu, J.; Kolli, V.;Reddy, P.A.; Reddy, P.H. COVID-19 and Rheumatoid Arthritis Crosstalk: Emerging association, therapeutic options, and challenges. 2021, doi:10.31219/osf.io/pzehv

3. Kalra, R.S.; Kandimalla, R. Engaging the spikes: heparan sulfate facilitates SARS- CoV-2 spike protein binding to ACE2 and potentiates viral infection. Signal Transduction and Targeted Therapy 2021, 6, 39, doi:10.1038/s41392-021-00470-1

4. Agrawal, L.; Poullikkas, T.; Eisenhower, S.; Monsanto, C.; Bakku, R.K.; Chen, M.- H.; Kalra, R.S. Viroinformatics-based analysis of SARS-CoV-2 core proteins forpotential therapeutic targets. Antibodies 2021, 10, 3, doi: 10.3390/antib10010003.

5. Dhanjal, J.K.; Kumar, V.; Garg, S.; Subramani, C.; Agarwal, S.; Wang, J.; Zhang, H.; Kaul, A.; Kalra, R.S.; Kaul, S.C. Molecular mechanism of anti-SARS-CoV2 activity of Ashwagandha-derived withanolides. International Journal of Biological Macromolecules 2021, 184, 297-312, doi:10.1016/j.ijbiomac.2021.06.015.

6. Kalra, R.S.; Kumar, V.; Dhanjal, J.K.; Garg, S.; Li, X.; Kaul, S.C.; Sundar, D.; Wadhwa, R. COVID19-inhibitory activity of withanolides involves targeting of the host cell surface receptor ACE2: insights from computational and biochemical assays.Journal of Biomolecular Structure and Dynamics 2021, doi:10.1080/07391102.2021.1902858.

7. Asselah, T.; Durantel, D.; Pasmant, E.; Lau, G.; Schinazi, R.F. COVID-19: Discovery, diagnostics and drug development. J Hepatol 2021, 74, 168-184, doi:10.1016/j.jhep.2020.09.031.

8. Elrashdy, F.; Redwan, E.M.; Uversky, V.N. Why COVID-19 Transmission Is More Efficient and Aggressive Than Viral Transmission in Previous Coronavirus Epidemics? Biomolecules 2020, 10, 1312, doi:10.3390/biom10091312.

9. Xia, S.; Liu, M.; Wang, C.; Xu, W.; Lan, Q.; Feng, S.; Qi, F.; Bao, L.; Du, L.; Liu, S.;et al. Inhibition of SARS-CoV-2 (previously 2019-nCoV) infection by a highly potentpan-coronavirus fusion inhibitor targeting its spike protein that harbors a high capacity to mediate membrane fusion. Cell Res 2020, 30, 343-355, doi:10.1038/s41422-020-0305-x.

10. Lee, J.S.; Shin, E.C. The type I interferon response in COVID-19: implications for treatment. Nat Rev Immunol 2020, 20, 585-586, doi:10.1038/s41577-020-00429-3.

11. Dos Santos, W.G. Impact of virus genetic variability and host immunity for the success of COVID-19 vaccines. Biomed Pharmacother 2021, 136, 111272, doi:10.1016/j.biopha.2021.111272.

12. Penna, C.; Mercurio, V.; Tocchetti, C.G.; Pagliaro, P. Sex-related differences inCOVID-19 lethality. Br J Pharmacol 2020, 177, 43754385, doi:10.1111/bph.15207.

13. To, K.K.; Hung, I.F.; Chan, K.H.; Yuan, S.; To, W.K.; Tsang, D.N.; Cheng, V.C.; Chen, Z.; Kok, K.H.; Yuen, K.Y. Serum Antibody Profile of a Patient With Coronavirus Disease 2019 Reinfection. Clin Infect Dis 2021, 72, e659-e662, doi:10.1093/cid/ciaa1368.

14. Wu, A.; Peng, Y.; Huang, B.; Ding, X.; Wang, X.; Niu, P.; Meng, J.; Zhu, Z.; Zhang, Z.; Wang, J.; et al. Genome Composition and Divergence of the Novel Coronavirus (2019-nCoV) Originating in China. Cell Host Microbe 2020, 27, 325-328, doi:10.1016/j.chom.2020.02.001.

15. Wan, Y.; Shang, J.; Graham, R.; Baric, R.S.; Li, F. Receptor Recognition by theNovel Coronavirus from Wuhan: an Analysis Based on Decade-Long Structural Studies of SARS Coronavirus. J Virol 2020, 94, doi:10.1128/JVI.00127-20.

16. Wrapp, D.; Wang, N.; Corbett, K.S.; Goldsmith, J.A.; Hsieh, C.L.; Abiona, O.; Graham, B.S.; McLellan, J.S. Cryo-EM structure of the 2019-nCoV spike in the prefusion conformation. Science 2020, 367, 1260-1263, doi:10.1126/science.abb2507.

17. Casalino, L.; Gaieb, Z.; Goldsmith, J.A.; Hjorth, C.K.; Dommer, A.C.; Harbison, A.M.; Fogarty, C.A.; Barros, E.P.; Taylor, B.C.; McLellan, J.S.; et al. Beyond Shielding: The Roles of Glycans in the SARS-CoV-2 Spike Protein. ACS Cent Sci 2020, 6, 1722-1734, doi:10.1021/acscentsci.0c01056.

18. Masihi, K.N. Fighting infection using immunomodulatory agents. Expert Opin Biol Ther 2001, 1, 641-653, doi:10.1517/14712598.1.4.641.

19. Kumar, R.; Verma, H.; Singhvi, N.; Sood, U.; Gupta, V.; Singh, M.; Kumari, R.; Hira,P.; Nagar, S.; Talwar, C.; et al. Comparative Genomic Analysis of Rapidly Evolving SARS-CoV-2 Reveals Mosaic Pattern of Phylogeographical Distribution. mSystems 2020, 5, e00505-e00520.doi:10.1128/mSystems.00505-20.

20. Liu, Y.; Gayle, A.A.; Wilder-Smith, A.; Rocklov, J. The reproductive number of COVID-19 is higher compared to SARS coronavirus. J Travel Med 2020, 27, taaa02, doi:10.1093/jtm/taaa021.

21. Broder, S. The development of antiretroviral therapy and its impact on the HIV-1/AIDS pandemic. Antiviral Res 2010, 85, 1-18, doi:10.1016/j.antiviral.2009.10.002.

22. Forni, G.; Mantovani, A. Covid-19 Commission of Accademia Nazionale dei Lincei, R. COVID-19 vaccines: where we stand and challenges ahead. Cell Death Differ 2021, 28, 626-639, doi:10.1038/s41418-020-00720-9.

23. Awasthi, A.; Vishwas, S.; Corrie, L.; Kumar, R.; Khursheed, R.; Kaur, J.; Kumar, R.; Arya, K.R.; Gulati, M.; Kumar, B.; et al. OUTBREAK of novel corona virus disease (COVID-19): Antecedence and aftermath. Eur J Pharmacol 2020, 884, 173381, doi:10.1016/j.ejphar.2020.173381.

24. Yang, Z.Y.; Kong, W.P.; Huang, Y.; Roberts, A.; Murphy, B.R.; Subbarao, K.; Nabel, G.J. A DNA vaccine induces SARS coronavirus neutralization and protective immunity in mice. Nature 2004, 428, 561-564, doi:10.1038/nature02463.

25. Hobernik, D.; Bros, M. DNA Vaccines-How Far From Clinical Use? Int J Mol Sci 2018, 19, 3605, doi:10.3390/ijms19113605.

26. Chakraborty, C.; Sharma, A.R.; Bhattacharya, M.; Lee, S.S. From COVID-19 to Cancer mRNA Vaccines: Moving From Bench to Clinic in the Vaccine Landscape. Front Immunol 2021, 12, 679344, doi:10.3389/fimmu.2021.679344. 
27. Li, Y.; Ma, M.L.; Lei, Q.; Wang, F.; Hong, W.; Lai, D.Y.; Hou, H.; Xu, Z.W.; Zhang,B.; Chen, H.; et al. Linear epitope landscape of the SARS-CoV-2 Spike protein constructed from 1,051 COVID-19 patients. Cell Rep 2021, 34, 108915, doi:10.1016/j.celrep.2021.108915.

28. Bisht, H.; Roberts, A.; Vogel, L.; Bukreyev, A.; Collins, P.L.; Murphy, B.R.; Subbarao, K.; Moss, B. Severe acute respiratory syndrome coronavirus spike protein expressed by attenuated vaccinia virus protectively immunizes mice. Proc Natl Acad Sci U S A 2004, 101, 6641-6646, doi:10.1073/pnas.0401939101.

29. Sahin, U.; Muik, A.; Vogler, I.; Derhovanessian, E.; Kranz, L.M.; Vormehr, M.; Quandt, J.; Bidmon, N.; Ulges, A.; Baum, A.; et al. BNT162b2 vaccine induces neutralizing antibodies and poly-specific T cells in humans. Nature 2021, 595, 572- 577, doi:10.1038/s41586-021-03653-6.

30. Tai, W.; Zhang, X.; He, Y.; Jiang, S.; Du, L. Identification of SARS-CoV RBD- targeting monoclonal antibodies with cross-reactive or neutralizing activity against SARS-CoV-2. Antiviral Res 2020, 179, 104820, doi:10.1016/j.antiviral.2020.104820.

31. Krammer, F. SARS-CoV-2 vaccines in development. Nature 2020, 586, 516-527, doi:10.1038/s41586-020-2798-3.

32. Pang, H.; Liu, Y.; Han, X.; Xu, Y.; Jiang, F.; Wu, D.; Kong, X.; Bartlam, M.; Rao, Z. Protective humoral responses to severe acute respiratory syndrome-associated coronavirus: implications for the design of an effective protein-based vaccine. J Gen Virol 2004, 85, 3109-3113, doi:10.1099/vir.0.80111-0.

33. Gralinski, L.E.; Menachery, V.D. Return of the Coronavirus: 2019-nCoV. Viruses 2020, 12, 135, doi:10.3390/v12020135.

34. Collisson, E.W.; Pei, J.; Dzielawa, J.; Seo, S.H. Cytotoxic T lymphocytes are critical in the control of infectious bronchitis virus in poultry. Dev Comp Immunol 2000, 24, 187-200, doi:10.1016/s0145-305x(99)00072-5.

35. Graham, B.S. Rapid COVID-19 vaccine development. Science 2020, 368, 945-946, doi:10.1126/science.abb8923.

36. Humphreys, I.R.; Sebastian, S. Novel viral vectors in infectious diseases. Immunology 2018, 153, 1-9, doi:10.1111/imm.12829.

37. Pan, C.; Yue, H.; Zhu, L.; Ma, G.H.; Wang, H.L. Prophylactic vaccine delivery systems against epidemic infectious diseases. Adv Drug Deliv Rev 2021, 176, 113867, doi:10.1016/j.addr.2021.113867.

38. Jiang, S.; Hillyer, C.; Du, L. Neutralizing Antibodies against SARS-CoV-2 and Other Human Coronaviruses. Trends Immunol 2020, 41, 355-359,doi:10.1016/j.it.2020.03.007.

39. Gao, W.; Tamin, A.; Soloff, A.; D'Aiuto, L.; Nwanegbo, E.; Robbins, P.D.; Bellini, W.J.; Barratt-Boyes, S.; Gambotto, A. Effects of a SARS-associated coronavirusvaccine in monkeys. Lancet 2003, 362, 1895-1896, doi:10.1016/S0140- 6736(03)14962-8.

40. O'Connell, A.K.; Douam, F. Humanized Mice for Live-Attenuated Vaccine Research:From Unmet Potential to New Promises. Vaccines (Basel) 2020, 8, 36, doi:10.3390/vaccines8010036.

41. DeDiego, M.L.; Alvarez, E.; Almazan, F.; Rejas, M.T.; Lamirande, E.; Roberts, A.; Shieh, W.J.; Zaki, S.R.; Subbarao, K.; Enjuanes, L. A severe acute respiratory syndrome coronavirus that lacks the E gene is attenuated in vitro and in vivo. J Virol 2007, 81, 1701-1713, doi:10.1128/JVI.01467-06.

42. Dediego, M.L.; Pewe, L.; Alvarez, E.; Rejas, M.T.; Perlman, S.; Enjuanes, L. Pathogenicity of severe acute respiratory coronavirus deletion mutants in hACE-2 transgenic mice. Virology 2008, 376, 379-389, doi:10.1016/j.virol.2008.03.005.

43. Lamirande, E.W.; DeDiego, M.L.; Roberts, A.; Jackson, J.P.; Alvarez, E.; Sheahan, T.; Shieh, W.J.; Zaki, S.R.; Baric, R.; Enjuanes, L.; et al. A live attenuated severe acute respiratory syndrome coronavirus is immunogenic and efficacious in golden Syrian hamsters. J Virol 2008, 82, 7721-7724, doi:10.1128/JVI.00304-08.

44. Pandey, S.C.; Pande, V.; Sati, D.; Upreti, S.; Samant, M. Vaccination strategies to combat novel corona virus SARS-CoV-2. Life Sci 2020, 256, 117956, doi:10.1016/j.lfs.2020.117956.

45. Tsunetsugu-Yokota, Y. Large-scale preparation of UV-inactivated SARS coronavirus virions for vaccine antigen. Methods Mol Biol 2008, 454, 119-126, doi:10.1007/978-1-59745-181-9_11.

46. Zhang, C.H.; Lu, J.H.; Wang, Y.F.; Zheng, H.Y.; Xiong, S.; Zhang, M.Y.; Liu, X.J.; Li, J.X.; Wan, Z.Y.; Yan, X.G.; et al. Immune responses in Balb/c mice induced by acandidate SARS-CoV inactivated vaccine prepared from F69 strain. Vaccine 2005, 23, 3196-3201, doi:10.1016/j.vaccine.2004.11.073.

47. Kyriakidis, N.C.; Lopez-Cortes, A.; Gonzalez, E.V.; Grimaldos, A.B.; Prado, E.O. SARS-CoV-2 vaccines strategies: a comprehensive review of phase 3 candidates. NPJVaccines 2021, 6, 28, doi:10.1038/s41541-021-00292-w.

48. Strizova, Z.; Smetanova, J.; Bartunkova, J.; Milota, T. Principles and Challenges in anti-COVID-19 Vaccine Development. Int Arch Allergy Immunol 2021, 182, 339- 349, doi:10.1159/000514225.

49. WHO. The Pfizer BioNTech (BNT162b2) COVID-19 vaccine: What you need to know. 2021. https://www.who.int/newsroom/feature-stories/detail/who-can-take-the-pfizer-biontech-covid-19--vaccine (accessed on September 9, 2021)

50. Lustig, Y.; Sapir, E.; Regev-Yochay, G.; Cohen, C.; Fluss, R.; Olmer, L.; Indenbaum, V.; Mandelboim, M.; Doolman, R.; Amit, S.; Mendelson, E. 2021. BNT162b2 COVID-19 vaccine and correlates of humoral immune responses and dynamics: a prospective, single-centre, longitudinal cohort study in health-care workers. The Lancet Respiratory Medicine 2021, 9, 999-1009, doi: 10.1016/S2213-2600(21)00220-4.

51. Salvagno, G.L.; Henry, B.M.; Pighi, L.; De Nitto, S.; Gianfilippi, G.L.; Lippi, G. Three-month analysis of total humoral response to Pfizer BNT162b2 mRNA COVID-19 vaccination in healthcare workers. J Infect 2021, 83, e4-e5, doi:10.1016/j.jinf.2021.06.024.

52. Prendecki, M.; Clarke, C.; Brown, J.; Cox, A.; Gleeson, S.; Guckian, M.; Randell, P.; Pria, A.D.; Lightstone, L.; Xu, X.N.; et al. Effect of previous SARS-CoV-2 infection on humoral and T-cell responses to single-dose BNT162b2 vaccine. Lancet 2021, 397, 1178-1181, doi:10.1016/S0140-6736(21)00502-X.

53. Zimmermann, P.; Curtis, N. Factors That Influence the Immune Response to Vaccination. Clin Microbiol Rev 2019, 32, e0008418. doi:10.1128/CMR.00084-18. 
54. Connors, M.; Graham, B.S.; Lane, H.C.; Fauci, A.S. SARS-CoV-2 Vaccines: Much Accomplished, Much to Learn. Ann Intern Med 2021, 174, 687-690, doi:10.7326/M21-0111.

55. Kaur, S.P.; Gupta, V. COVID-19 Vaccine: A comprehensive status report. Virus Res 2020, 288, 198114, doi:10.1016/j.virusres.2020.198114

56. Angeli, F.; Spanevello, A.; Reboldi, G.; Visca, D.; Verdecchia, P. SARS-CoV-2vaccines: Lights and shadows. Eur J Intern Med 2021, 88, 1-8, doi:10.1016/j.ejim.2021.04.019.

57. Wise, J. Covid-19: New data on Oxford AstraZeneca vaccine backs 12 week dosing interval. BMJ 2021, 372, n326, doi:10.1136/bmj.n326.

58. Voysey, M.; Costa Clemens, S.A.; Madhi, S.A.; Weckx, L.Y.; Folegatti, P.M.; Aley, P.K.; Angus, B.; Baillie, V.L.; Barnabas, S.L.; Bhorat, Q.E.; et al. Single-dose administration and the influence of the timing of the booster dose on immunogenicity and efficacy of ChAdOx1 nCoV-19 (AZD1222) vaccine: a pooled analysis of four randomised trials. Lancet 2021, 397, 881-891, doi:10.1016/S0140-6736(21)00432-3.

59. Mahase, E. Covid-19: South Africa pauses use of Oxford vaccine after study casts doubt on efficacy against variant. BMJ 2021, 372, n372, doi:10.1136/bmj.n372.

60. Lumley, S.F.; Rodger, G.; Constantinides, B.; Sanderson, N.; Chau, K.K.; Street, T.L.; O'Donnell, D.; Howarth, A.; Hatch, S.B.; Marsden, B.D.; et al. An observationalcohort study on the incidence of SARS-CoV-2 infection and B.1.1.7 variant infection in healthcare workers by antibody and vaccination status. Clin Infect Dis 2021, ciab608, doi:10.1093/cid/ciab608.

61. WHO. The Janssen Ad26.COV2.S COVID-19 vaccine: What you need to know. 2021. https://www.who.int/news-room/featurestories/detail/the-j-j-covid-19-vaccine-what-you-need-to-know (Accessed on September 11, 2021)

62. Bos, R.; Rutten, L.; van der Lubbe, J.E.M.; Bakkers, M.J.G.; Hardenberg, G.; Wegmann, F.; Zuijdgeest, D.; de Wilde, A.H.; Koornneef, A.; Verwilligen, A.; et al. Ad26 vector-based COVID-19 vaccine encoding a prefusion-stabilized SARS-CoV-2 Spike immunogen induces potent humoral and cellular immune responses. NPJ Vaccines 2020, 5, 91, doi:10.1038/s41541-020-00243-X.

63. Mukhopadhyay, L.; Yadav, P.D.; Gupta, N.; Mohandas, S.; Patil, D.Y.; Shete-Aich, A.; Panda, S.; and Bhargava, B. Comparison of the immunogenicity \& protective efficacy of various SARS-CoV-2 vaccine candidates in non-human primates. The Indian journal of medical research 2021, 153(1-2), 93-114, doi: 10.4103/ijmr.IJMR_4431_20.

64. Mercado, N.B.; Zahn, R.; Wegmann, F.; Loos, C.; Chandrashekar, A.; Yu, J.; Liu, J.; Peter, L.; McMahan, K.; Tostanoski, L.H.; et al. Single-shot Ad26 vaccine protects against SARS-CoV-2 in rhesus macaques. Nature 2020, 586, 583-588, doi:10.1038/s41586020-2607-z.

65. van der Lubbe, J.E.M.; Rosendahl Huber, S.K.; Vijayan, A.; Dekking, L.; van Huizen,E.; Vreugdenhil, J.; Choi, Y.; Baert, M.R.M.; Feddes-de Boer, K.; Izquierdo Gil, A.;et al. Ad26.COV2.S protects Syrian hamsters against G614 spike variant SARS-CoV-2 and does not enhance respiratory disease. NPJ Vaccines 2021, 6, 39, doi:10.1038/s41541-021-00301-y.

66. He, X.; Chandrashekar, A.; Zahn, R.; Wegmann, F.; Yu, J.; Mercado, N.B.; McMahan, K.; Martinot, A.J.; Piedra-Mora, C.; Beecy, S.; et al. Low-dose Ad26.COV2.S protection against SARS-CoV-2 challenge in rhesus macaques. Cell 2021, 184, 3467-3473 e3411, doi:10.1016/j.cell.2021.05.040.

67. Oliver, S.E.; Gargano, J.W.; Marin, M.; Wallace, M.; Curran, K.G.; Chamberland,M.; McClung, N.; Campos-Outcalt, D.; Morgan, R.L.; Mbaeyi, S.; et al. The AdvisoryCommittee on Immunization Practices' Interim Recommendation for Use of Moderna COVID-19 Vaccine - United States, December 2020. MMWR Morb Mortal Wkly Rep 2021, 69, 1653-1656, doi:10.15585/mmwr.mm695152e1.

68. Sharma, O.; Sultan, A.A.; Ding, H.; Triggle, C.R. A Review of the Progress and Challenges of Developing a Vaccine for COVID19. Front Immunol 2020, 11, 585354, doi:10.3389/fimmu.2020.585354.

69. Baden, L.R.; El Sahly, H.M.; Essink, B.; Kotloff, K.; Frey, S.; Novak, R.; Diemert,D.; Spector, S.A.; Rouphael, N.; Creech, C.B.; et al. Efficacy and Safety of the mRNA-1273 SARS-CoV-2 Vaccine. N Engl J Med 2021, 384, 403-416, doi:10.1056/NEJMoa2035389.

70. Mahase, E. Covid-19: Moderna vaccine is nearly 95\% effective, trial involving high risk and elderly people shows. BMJ 2020, 371, m4471, doi:10.1136/bmj.m4471.

71. Corbett, K.S.; Flynn, B.; Foulds, K.E.; Francica, J.R.; Boyoglu-Barnum, S.; Werner, A.P.; Flach, B.; O'Connell, S.; Bock, K.W.; Minai, M.; et al. Evaluation of themRNA-1273 Vaccine against SARS-CoV-2 in Nonhuman Primates. N Engl J Med 2020, 383, 1544-1555, doi:10.1056/NEJMoa2024671.

72. Corbett, K.S.; Edwards, D.K.; Leist, S.R.; Abiona, O.M.; Boyoglu-Barnum, S.,; Gillespie, R.A.; Himansu, S.; Schäfer, A.; Ziwawo, C.T.; DiPiazza, A.T; Dinnon, K.H., SARS-CoV-2 mRNA vaccine design enabled by prototype pathogen preparedness. Nature 2020, 586, 567-571, doi: 10.1038/s41586-020-2622-0.

73. WHO. The Sinovac-CoronaVac COVID-19 vaccine: What you need to know. 2021. https://www.who.int/news-room/featurestories/detail/the-sinovac-covid-19-vaccine-what-you-need-to-know (Access on September 9, 2021)

74. BBIBP-CorV, Sinopharm COVID-19 vaccine. New Drug Approvals. 2021. https://newdrugapprovals.org/2021/03/23/bbibpcorv-sinopharm-covid-19-vaccine/ (Access on September 1, 2021)

75. Wang, H.; Zhang, Y.; Huang, B.; Deng, W.; Quan, Y.; Wang, W.; Xu, W.; Zhao, Y.; Li, N.; Zhang, J.; et al. Development of an Inactivated Vaccine Candidate, BBIBP- CorV, with Potent Protection against SARS-CoV-2. Cell 2020, 182, 713-721, doi:10.1016/j.cell.2020.06.008.

76. Palacios, R.; Batista, A.P.; Albuquerque, C.S.N.; Patiño, E.G.; Santos, J.P.; Conde, M.T.R.P.; Piorelli, R.O.; Júnior, L.C.P.; Raboni, S.M.; Ramos, P.; et al. Efficacy and Safety of a COVID-19 Inactivated Vaccine inHealthcare Professionals in Brazil: The PROFISCOV Study. Preprint (SSRN) 2021, doi: https://doi.org/10.2139/ssrn.3822780 
77. Zhang, Y.; Zeng, G.; Pan, H.; Li, C.; Hu, Y.; Chu, K.; Han, W.; Chen, Z.; Tang, R.; Yin, W.; et al. Safety, tolerability, and immunogenicity of an inactivated SARS-CoV- 2 vaccine in healthy adults aged 18-59 years: a randomised, double-blind, placebocontrolled, phase 1/2 clinical trial. Lancet Infect Dis 2021, 21, 181-192, doi:10.1016/S1473-3099(20)30843-4.

78. Logunov, D.Y.; Dolzhikova, I.V.; Shcheblyakov, D.V.; Tukhvatulin, A.I.; Zubkova, O.V.; Dzharullaeva, A.S.; Kovyrshina, A.V.; Lubenets, N.L.; Grousova, D.M.; Erokhova, A.S.; et al. Safety and efficacy of an rAd26 and rAd5 vector-based heterologous prime-boost COVID-19 vaccine: an interim analysis of a randomised controlled phase 3 trial in Russia. Lancet 2021, 397, 671681, doi:10.1016/S0140- 6736(21)00234-8.

79. Barouch, D.H.; Kik, S.V.; Weverling, G.J.; Dilan, R.; King, S.L.; Maxfield, L.F.; Clark, S.; Ng'ang'a, D.; Brandariz, K.L.; Abbink, P.; et al. International seroepidemiology of adenovirus serotypes 5, 26, 35, and 48 in pediatric and adult populations. Vaccine 2011, 29, 5203-5209, doi:10.1016/j.vaccine.2011.05.025.

80. Jones, I.; Roy, P. Sputnik V COVID-19 vaccine candidate appears safe and effective. Lancet 2021, 397, 642-643, doi:10.1016/S01406736(21)00191-4.

81. Lawton, G. Sputnik V vaccine goes global. New Sci 2021, 250, 10-11, doi:10.1016/S0262-4079(21)00671-0.

82. Balakrishnan, V.S. The arrival of Sputnik V. Lancet Infect Dis 2020, 20, 1128,doi:10.1016/S1473-3099(20)30709-X.

83. Burki, T.K. The Russian vaccine for COVID-19. Lancet Respir Med 2020, 8, e85- e86, doi:10.1016/S2213-2600(20)30402-1.

84. Logunov, D.Y.; Dolzhikova, I.V.; Zubkova, O.V.; Tukhvatulin, A.I.; Shcheblyakov, D.V.; Dzharullaeva, A.S.; Grousova, D.M.; Erokhova, A.S.; Kovyrshina, A.V.; Botikov, A.G.; et al. Safety and immunogenicity of an rAd26 and rAd5 vector-based heterologous prime-boost COVID-19 vaccine in two formulations: two open, non- randomised phase 1/2 studies from Russia. Lancet 2020, 396, 887-897, doi:10.1016/S0140-6736(20)31866-3.

85. Ryzhikov, A.B.; Ryzhikov, E.A.; Bogryantseva, M.P.; Danilenko, E.D.; Imatdinov, I.R.; Nechaeva, E.A.; Pyankov, O.V.; Pyankova, O.G.; Susloparov, I.M.; Taranov, O.S. et al. Immunogenicity and protectivity of the peptide vaccineagainst SARSCoV-2. Annals of the Russian academy of medical sciences 2021, 76, 5-19.

86. Thiagarajan, K. What do we know about India's Covaxin vaccine? BMJ 2021, 373, n997, doi:10.1136/bmj.n997.

87. Ganneru, B.; Jogdand, H.; Dharam, V.K.; Molugu, N.R.; Prasad, S.D.; Vellimudu, S.; Ella, K.M.; Ravikrishnan, R.; Awasthi, A.; Jose, J.; et al. Evaluation of Safety and Immunogenicity of an Adjuvanted, TH-1 Skewed,Whole Virion InactivatedSARS-CoV2 Vaccine - BBV152. bioRxiv 2020.09.09.285445 2020, doi:https://doi.org/10.1101/2020.09.09.285445.

88. Peshimam, G.N.; Farooq, U. CanSinoBIO's COVID-19 vaccine 65.7\% effective in global trials, Pakistan official says; Reuters Healthcare \& Pharma, February 8, 2021.

89. Wu, S.; Zhong, G.; Zhang, J.; Shuai, L.; Zhang, Z.; Wen, Z.; Wang, B.; Zhao, Z.; Song, X.; Chen, Y.; et al. A single dose of an adenovirus-vectored vaccine provides protection against SARS-CoV-2 challenge. Nat Commun 2020, 11, 4081, doi:10.1038/s41467-020-17972-1.

90. Kumar, V.M.; Pandi-Perumal, S.R.; Trakht, I.; Thyagarajan, S.P. Strategy for COVID-19 vaccination in India: the country with the second highest population and number of cases. npj Vaccines 2021, 6, 1-7.

91. Dey, A.; Chozhavel Rajanathan, T.M.; Chandra, H.; Pericherla, H.P.R.; Kumar, S.; Choonia, H.S.; Bajpai, M.; Singh, A.K.; Sinha, A.; Saini, G.; et al. Immunogenic potential of DNA vaccine candidate, ZyCoV-D against SARS-CoV-2 in animal models. Vaccine 2021, 39, 4108-4116, doi:10.1016/j.vaccine.2021.05.098.

92. Yadav, P.; Kumar, S.; Agarwal, K.; Jain, M.; Patil, D.; Maithal, K.; Mathapati, B.; Giri, S.; Mohandas, S.; Shete, A. Assessment of immunogenicity and protectiveefficacy of ZyCoV-D DNA vaccine candidates in Rhesus macaques against SARS- CoV-2 infection. BioRxiv 2021. doi:10.1101/2021.02.02.429480

93. Momin, T.; Kansagra, K.; Patel, H.; Sharma, S.; Sharma, B.; Patel, J.; Mittal, R.; Sanmukhani, J.; Maithal, K.; Dey, A. Safety and Immunogenicity of a DNA SARS- CoV-2 vaccine (ZyCoV-D): Results of an open-label, non-randomized phase I part of phase I/II clinical study by intradermal route in healthy subjects in India. EClinicalMedicine 2021, 38, 101020, doi:10.1016/j.eclinm.2021.101020

94. Polack, F.P.; Thomas, S.J.; Kitchin, N.; Absalon, J.; Gurtman, A.; Lockhart, S.; Perez,J.L.; Perez Marc, G.; Moreira, E.D.; Zerbini, C.; et al. Safety and Efficacy of the BNT162b2 mRNA Covid-19 Vaccine. N Engl J Med 2020, 383, 2603-2615, doi:10.1056/NEJMoa2034577.

95. Shi, P.-Y.; Xie, X.; Zou, J.; Fontes-Garfias, C.; Xia, H.; Swanson, K.; Cutler, M.; Cooper, D.; Menachery, V.; Weaver, S.; et al. Neutralization of N501Y mutant SARS-CoV-2 by BNT162b2 vaccine-elicited sera. 2021, rs.3.rs-143532, doi:10.21203/rs.3.rs$143532 / \mathrm{v} 1$

96. Xie, X.; Zou, J.; Fontes-Garfias, C.R.; Xia, H.; Swanson, K.A.; Cutler, M.; Cooper, D.; Menachery, V.D.; Weaver, S.; Dormitzer, P.R.; et al. Neutralization of N501Y mutant SARS-CoV-2 by BNT162b2 vaccine-elicited sera. BioRxiv 2021, 2021.01.07.425740, doi: doi:10.1101/2021.01.07.425740.

97. Amit, S.; Regev-Yochay, G.; Afek, A.; Kreiss, Y.; Leshem, E. Early rate reductionsof SARS-CoV-2 infection and COVID-19 in BNT162b2 vaccine recipients. Lancet 2021, 397, 875-877, doi:10.1016/S0140-6736(21)00448-7.

98. Levine-Tiefenbrun, M.; Yelin, I.; Katz, R.; Herzel, E.; Golan, Z.; Schreiber, L.; Wolf, T.; Nadler, V.; Ben-Tov, A.; Kuint, J.; et al. Initial report of decreased SARS-CoV-2 viral load after inoculation with the BNT162b2 vaccine. Nat Med 2021, 27, 790-792, doi:10.1038/s41591-021-01316-7.

99. Chodick, G.; Tene, L.; Patalon, T.; Gazit, S.; Ben Tov, A.; Cohen, D.; Muhsen, K. Assessment of Effectiveness of 1 Dose of BNT162b2 Vaccine for SARS-CoV-2 Infection 13 to 24 Days After Immunization. JAMA Netw Open 2021, 4, e2115985, doi:10.1001/jamanetworkopen.2021.15985. 
100. Xie, X.; Liu, Y.; Liu, J.; Zhang, X.; Zou, J.; Fontes-Garfias, C.R.; Xia, H.; Swanson, K.A.; Cutler, M.; Cooper, D.; et al. Neutralization of SARS-CoV-2 spike 69/70 deletion, E484K and N501Y variants by BNT162b2 vaccine-elicited sera. Nature Medicine 2021, 27, 620-621, doi:10.1038/s41591-021-01270-4.

101. Muik, A.; Wallisch, A.K.; Sanger, B.; Swanson, K.A.; Muhl, J.; Chen, W.; Cai, H.; Maurus, D.; Sarkar, R.; Tureci, O.; et al. Neutralization of SARS-CoV-2 lineage B.1.1.7 pseudovirus by BNT162b2 vaccine-elicited human sera. Science 2021, 371, 11521153, doi:10.1126/science.abg6105.

102. Kustin, T.; Harel, N.; Finkel, U.; Perchik, S.; Harari, S.; Tahor, M.; Caspi, I.; Levy, R.; Leshchinsky, M.; Ken Dror, S.; et al. Evidence for increased breakthrough rates of SARS-CoV-2 variants of concern in BNT162b2-mRNA-vaccinated individuals. Nature Medicine 2021, 27, 1379-1384, doi:10.1038/s41591-021-01413-7.

103. Ducloux, D.; Colladant, M.; Chabannes, M.; Yannaraki, M.; Courivaud, C. Humoral response after 3 doses of the BNT162b2 mRNA COVID-19 vaccine in patients on hemodialysis. Kidney Int 2021, 100, 702-704, doi:10.1016/j.kint.2021.06.025.

104. Morales-Núñez, J.J.; Muñoz-Valle, J.F.; Meza-López, C.; Wang, L.-F.; Machado Sulbarán, A.C.; Torres-Hernández, P.C.; BedollaBarajas, M.; De la O-Gómez, B.; Balcázar-Félix, P.; Hernández-Bello, J. Neutralizing Antibodies Titers and Side Effects in Response to BNT162b2 Vaccine in Healthcare Workers with and without Prior SARS-CoV-2 Infection. Vaccines 2021, 9, 742, doi:10.3390/vaccines9070742.

105. Mariani, M.; Acquila, M.; Tripodi, G.; Spiazzi, R.; Castagnola, E. Antibodies against Receptor Binding Domain of SARS-CoV2 spike protein induced by BNT162b2 vaccine: results from a pragmatic, real-life study. J Infect Public Health 2021, S18760341(21)00186-6, doi:10.1016/j.jiph.2021.06.020.

106. Rosman, Y.; Lavi, N.; Meir-Shafrir, K.; Lachover-Roth, I.; Cohen-Engler, A.; Mekori, Y.A.; Confino-Cohen, R. Safety of BNT162b2 mRNA COVID-19 vaccine inpatients with mast cell disorders. J Allergy Clin Immunol Pract 2021, 9, $3487-3489$. doi:10.1016/j.jaip.2021.06.032.

107. Ramos, A.; Cardoso, M.J.; Norton, P.; Sarmento, A.; Guimarães, J.T. Serological response to a single dose of a SARS-CoV-2 mRNA vaccine. J Virol Methods 2021, 296, 114223, doi:10.1016/j.jviromet.2021.114223.

108. Ben-Tov, A.; Banon, T.; Chodick, G.; Kariv, R.; Assa, A.; Gazit, S.; Collaborators of the Maccabi Institute for, Research \& Innovation COVID-19 Task Force. Messenger RNA COVID-19 Vaccine Effectiveness in Patients With Inflammatory Bowel Disease: Preliminary Real-World Data During Mass Vaccination Campaign. Gastroenterology 2021, S0016-5085(21)03233-9, doi:10.1053/j.gastro.2021.06.076.

109. Pottegard, A.; Lund, L.C.; Karlstad, O.; Dahl, J.; Andersen, M.; Hallas, J.; Lidegaard, O.; Tapia, G.; Gulseth, H.L.; Ruiz, P.L.; et al. Arterial events, venous thromboembolism, thrombocytopenia, and bleeding after vaccination with Oxford- AstraZeneca ChAdOx1-S in Denmark and Norway: population based cohort study. BMJ 2021, 373, n1114, doi:10.1136/bmj.n1114.

110. Ram, R.; Hagin, D.; Kikozashvilli, N.; Freund, T.; Amit, O.; Bar-On, Y.; Beyar-Katz, O.; Shefer, G.; Moshiashvili, M.M.; Karni, C.; et al. Safety and Immunogenicity of the BNT162b2 mRNA COVID-19 Vaccine in Patients after Allogeneic HCT or CD19based CART therapy-A Single-Center Prospective Cohort Study. Cell Ther Transplant 2021, 27, 788-794, doi:10.1016/j.jtct.2021.06.024.

111. Liu, Y.; Liu, J.; Xia, H.; Zhang, X.; Zou, J.; Fontes-Garfias, C.R.; Weaver, S.C.; Swanson, K.A.; Cai, H.; Sarkar, R.; et al. BNT162b2Elicited Neutralization against New SARS-CoV-2 Spike Variants. N Engl J Med 2021, 385, 472-474, doi:10.1056/NEJMc2106083.

112. Lopez Bernal, J.; Andrews, N.; Gower, C.; Gallagher, E.; Simmons, R.; Thelwall, S.; Stowe, J.; Tessier, E.; Groves, N.; Dabrera, G.; et al. Effectiveness of Covid-19 Vaccines against the B.1.617.2 (Delta) Variant. $N$ Engl J Med 2021, 385, 585-594, doi:10.1056/NEJMoa2108891.

113. Lospinoso, K.; Nichols, C.S.; Malachowski, S.J.; Mochel, M.C.; Nutan, F. A case of severe cutaneous adverse reaction following administration of the Janssen Ad26.COV2.S COVID-19 vaccine. JAAD Case Rep 2021, 13, 134-137, doi:10.1016/j.jdcr.2021.05.010.

114. Rashidi-Alavijeh, J.; Frey, A.; Passenberg, M.; Korth, J.; Zmudzinski, J.; Anastasiou, O.E.; Saner, F.H.; Jahn, M.; Lange, C.M.; Willuweit, K. Humoral Response to SARS-Cov-2 Vaccination in Liver Transplant Recipients-A Single-Center Experience. Vaccines (Basel) 2021, 9, 738, doi:10.3390/vaccines9070738.

115. Jahn, M.; Korth, J.; Dorsch, O.; Anastasiou, O.E.; Sorge-Hadicke, B.; Tyczynski, B.; Gackler, A.; Witzke, O.; Dittmer, U.; Dolff, S.; et al. Humoral Response to SARS- CoV-2-Vaccination with BNT162b2 (Pfizer-BioNTech) in Patients on Hemodialysis. Vaccines (Basel) 2021, 9, 360, doi:10.3390/vaccines9040360.

116. Strengert, M.; Becker, M.; Morilla Ramos, G.; Dulovic, A.; Gruber, J.; Juengling, J.; Luerken, K.; Beigel, A.; Wrenger, E.; Lonnemann, G.; et al. Cellular and humoral immunogenicity of a SARS-CoV-2 mRNA vaccine in patients on hemodialysis. medRxiv 2021, doi:10.1101/2021.05.26.21257860.

117. Maneikis, K.; Sablauskas, K.; Ringeleviciute, U.; Vaitekenaite, V.; Cekauskiene, R.; Kryzauskaite, L.; Naumovas, D.; Banys, V.; Peceliunas, V.; Beinortas, T.; et al.Immunogenicity of the BNT162b2 COVID-19 mRNA vaccine and early clinicaloutcomes in patients with haematological malignancies in Lithuania: a national prospective cohort study. Lancet Haematol 2021, 8, e583e592, doi:10.1016/S2352- 3026(21)00169-1.

118. Terpos, E.; Trougakos, I.P.; Gavriatopoulou, M.; Papassotiriou, I.; Sklirou, A.D.; Ntanasis-Stathopoulos, I.; Papanagnou, E.D.; Fotiou, D.; Kastritis, E.; Dimopoulos, M.A. Low neutralizing antibody responses against SARS-CoV-2 in older patients with myeloma after the first BNT162b2 vaccine dose. Blood 2021, 137, 3674-3676, doi:10.1182/blood.2021011904.

119. Azzi, L., Dalla Gasperina, D., Veronesi, G., Shallak, M., Ietto, G., Iovino, D., Baj, A.,Gianfagna, F., Focosi, D., Maggi, F. and Ferrario, M.M. Mucosal Immune Responsein BNT162b2 COVID-19 Vaccine Recipients. Available at SSRN Preprint, 2021, doi:http://dx.doi.org/10.2139/ssrn.3871718. 
120. Knoll, M.D., and Wonodi, C. . Oxford-AstraZeneca COVID-19 vaccine efficacy.

The Lancet 2020, 397, P72-74, doi:https://doi.org/10.1016/S0140-6736(20)32623-4.

121. Ostergaard, S.D.; Schmidt, M.; Horvath-Puho, E.; Thomsen, R.W.; Sorensen, H.T. Thromboembolism and the Oxford-AstraZeneca COVID-19 vaccine: side-effect or coincidence? Lancet 2021, 397, 1441-1443, doi:10.1016/S0140-6736(21)00762-5.

122. Lopez Bernal, J.; Andrews, N.; Gower, C.; Robertson, C.; Stowe, J.; Tessier, E.; Simmons, R.; Cottrell, S.; Roberts, R.; O'Doherty, M.; et al. Effectiveness of the Pfizer-BioNTech and Oxford-AstraZeneca vaccines on covid-19 related symptoms, hospital admissions, and mortality in older adults in England: test negative case- control study. BMJ 2021, 373, n1088, doi:10.1136/bmj.n1088.

123. Iacobucci, G. Covid-19: Single dose of Pfizer and Oxford vaccines cuts risk ofhospital admission by $80 \%$ in over 80 s, data suggest. BMJ 2021, 372, n612, doi:10.1136/bmj.n612.

124. Folegatti, P.M.; Ewer, K.J.; Aley, P.K.; Angus, B.; Becker, S.; Belij-Rammerstorfer, S.; Bellamy, D.; Bibi, S.; Bittaye, M.; Clutterbuck, E.A.; et al. Safety and immunogenicity of the ChAdOx1 nCoV-19 vaccine against SARS-CoV-2: a preliminary report of a phase 1/2, single-blind, randomised controlled trial. Lancet 2020, 396, 467-478, doi:10.1016/S0140-6736(20)31604-4.

125. Ramasamy, M.N.; Minassian, A.M.; Ewer, K.J.; Flaxman, A.L.; Folegatti, P.M.; Owens, D.R.; Voysey, M.; Aley, P.K.; Angus, B.; Babbage, G.; et al. Safety and immunogenicity of ChAdOx1 nCoV-19 vaccine administered in a prime-boost regimen in young and old adults (COV002): a single-blind, randomised, controlled, phase 2/3 trial. The Lancet 2020, 396, 1979-1993, doi:10.1016/S0140-6736(20)32466-1.

126. Voysey, M.; Clemens, S.A.C.; Madhi, S.A.; Weckx, L.Y.; Folegatti, P.M.; Aley, P.K.; Angus, B.; Baillie, V.L.; Barnabas, S.L.; Bhorat, Q.E.; et al. Safety and efficacy of the ChAdOx1 nCoV-19 vaccine (AZD1222) against SARS-CoV-2: an interim analysis of four randomised controlled trials in Brazil, South Africa, and the UK. The Lancet 2020, 397, 99-111, doi:10.1016/s0140-6736(20)326611.

127. Hung, I.F.N.; Poland, G.A. Single-dose Oxford-AstraZeneca COVID-19 vaccine followed by a 12-week booster. Lancet 2021, 397, 854-855, doi:10.1016/S0140-6736(21)00528-6.

128. Eyre, D.W.; Lumley, S.F.; Wei, J.; Cox, S.; James, T.; Justice, A.; Jesuthasan, G.; O'Donnell, D.; Howarth, A.; Hatch, S.B.; et al. Quantitative SARS-CoV-2 anti-spike responses to Pfizer-BioNTech and Oxford-AstraZeneca vaccines by previousinfection status. Clin Microbiol Infect 2021, S1198-743X(21)00289-5, doi:10.1016/j.cmi.2021.05.041.

129. Griffin, S. Covid-19: AstraZeneca vaccine prevents $79 \%$ of symptomatic disease and $100 \%$ of severe disease, US study finds. BMJ 2021, 372, n793, doi:10.1136/bmj.n793.

130. Sadoff, J.; Le Gars, M.; Shukarev, G.; Heerwegh, D.; Truyers, C.; de Groot, A.M.; Stoop, J.; Tete, S.; Van Damme, W.; LerouxRoels, I.; et al. Interim Results of aPhase 1-2a Trial of Ad26.COV2.S Covid-19 Vaccine. N Engl J Med 2021, 384, 1824-1835, doi:10.1056/NEJMoa2034201.

131. Stephenson, K.E.; Le Gars, M.; Sadoff, J.; de Groot, A.M.; Heerwegh, D.; Truyers, C.; Atyeo, C.; Loos, C.; Chandrashekar, A.; McMahan, K.; et al. Immunogenicity of the Ad26.COV2.S Vaccine for COVID-19. JAMA 2021, 325, 1535-1544, doi:10.1001/jama.2021.3645.

132. Yu, J.; Tostanoski, L.H.; Mercado, N.B.; McMahan, K.; Liu, J.; Jacob-Dolan, C.; Chandrashekar, A.; Atyeo, C.; Martinez, D.R.; Anioke, T.; et al. Protective efficacy ofAd26.COV2.S against SARS-CoV-2 B.1.351 in macaques. Nature 2021, 596, 423- 427, doi:10.1038/s41586-021-03732-8.

133. Jongeneelen, M.; Kaszas, K.; Veldman, D.; Huizingh, J.; van der Vlugt, R.; Schouten, T.; Zuijdgeest, D.; Uil, T.; van Roey, G.; Guimera, N.; et al. Ad26. COV2. S elicited neutralizing activity against Delta and other SARS-CoV-2 variants of concern. bioRxiv 2021, 2021.07.01.450707, doi:10.1101/2021.07.01.450707.

134. Moore, P.; Moyo, T.; Hermanus, T.; Kgagudi, P.; Ayres, F.; Makhado, Z.; Sadoff, J.; Le Gars, M.; van Roey, G.; Crowther, C.; et al. Neutralizing antibodies elicited by the Ad26.COV2.S COVID-19 vaccine show reduced activity against 501Y.V2 (B.1.351), despite protection against severe disease by this variant. bioRxiv 2021, 2021.06.09.447722, doi:10.1101/2021.06.09.447722.

135. Anderson, E.J.; Rouphael, N.G.; Widge, A.T.; Jackson, L.A.; Roberts, P.C.; Makhene,M.; Chappell, J.D.; Denison, M.R.; Stevens, L.J.; Pruijssers, A.J.; et al. Safety and Immunogenicity of SARS-CoV-2 mRNA-1273 Vaccine in Older Adults. N Engl J Med 2020, 383, 2427-2438, doi:10.1056/NEJMoa2028436.

136. Jackson, L.A.; Anderson, E.J.; Rouphael, N.G.; Roberts, P.C.; Makhene, M.; Coler, R.N.; McCullough, M.P.; Chappell, J.D.; Denison, M.R.; Stevens, L.J.; et al. An mRNA Vaccine against SARS-CoV-2 - Preliminary Report. N Engl J Med 2020, 383, 1920-1931, doi:10.1056/NEJMoa2022483.

137. USFDA. Vaccines and Related Biological Products Advisory Committee Meeting. 2021. https://www.fda.gov/advisory-committees/advisory-committee-calendar/vaccines-and-related-biological-products-advisory-committee-february-26-2021-meetingannouncement (Accessed on August 15, 2021)

138. Tré-Hardy, M.; Cupaiolo, R.; Wilmet, A.; Beukinga, I.; Blairon, L. Waning antibodies in SARS-CoV-2 naïve vaccinees: Results of a three-month interim analysis of ongoing immunogenicity and efficacy surveillance of the mRNA-1273 vaccine in healthcare workers. J Infect 2021, 83, 381-412. doi:10.1016/j.jinf.2021.06.017.

139. Mustafa, S.S.; Ramsey, A.; Staicu, M.L. Administration of a Second Dose of the Moderna COVID-19 Vaccine After an Immediate Hypersensitivity Reaction With the First Dose: Two Case Reports. Ann Intern Med 2021, 174, 1177-1178, doi:10.7326/121-0104. 
140. Banerji, A.; Wickner, P.G.; Saff, R.; Stone, C.A.; Robinson, L.B.; Long, A.A.; Wolfson, A.R.; Williams, P.; Khan, D.A.; Phillips, E.; et al. mRNA Vaccines to Prevent COVID-19 Disease and Reported Allergic Reactions: Current Evidence and Suggested Approach. The Journal of Allergy and Clinical Immunology. In Practice J Allergy Clin Immunol Pract 2021, 9, 1423-1437, doi:10.1016/j.jaip.2020.12.047.

141. Widge, A.T.; Rouphael, N.G.; Jackson, L.A.; Anderson, E.J.; Roberts, P.C.; Makhene,M.; Chappell, J.D.; Denison, M.R.; Stevens, L.J.; Pruijssers, A.J.; et al. Durability of Responses after SARS-CoV-2 mRNA-1273 Vaccination. N Engl J Med 2021, 384, 80-82, doi:10.1056/NEJMc2032195.

142. Krammer, F.; Srivastava, K.; Alshammary, H.; Amoako, A.A.; Awawda, M.H.; Beach, K.F.; Bermúdez-González, M.C.; Bielak, D.A.; Carreño, J.M.; Chernet, R.L.; et al. Antibody Responses in Seropositive Persons after a Single Dose of SARS-CoV-2 mRNA Vaccine. N Engl J Med 2021, 384, 1372-1374, doi:10.1056/nejmc2101667.

143. Xia, S.; Duan, K.; Zhang, Y.; Zhao, D.; Zhang, H.; Xie, Z.; Li, X.; Peng, C.; Zhang, Y.; Zhang, W.; et al. Effect of an Inactivated Vaccine Against SARS-CoV-2 on Safety and Immunogenicity Outcomes. JAMA 2020, 324, 951-960, doi:10.1001/jama.2020.15543.

144. Xie, X.; Liu, Y.; Liu, J.; Zhang, X.; Zou, J.; Fontes-Garfias, C.R.; Xia, H.; Swanson, K.A.; Cutler, M.; Cooper, D.; et al. Neutralization of SARS-CoV-2 spike 69/70deletion, E484K and N501Y variants by BNT162b2 vaccine-elicited sera. Nat Med 2021, 27, 620-621, doi:10.1038/s41591-021-01270-4.

145. Kerr, S.; Shepherd, C. Covid vaccine from China's Sinopharm is 86\% effective, says UAE. Financial Times December 9, 2020.

146. Baraniuk, C. What do we know about China's covid-19 vaccines? BMJ 2021, 373, n912, doi:10.1136/bmj.n912.

147. Loo, K.Y.; Letchumanan, V.; Ser, H.L.; Teoh, S.L.; Law, J.W.F.; Tan, L.T.H.; Ab Mutalib, N.S.; Chan, K.G.; Lee, L.H. COVID-19: Insights into potential vaccines. Microorganisms 2021, 9(3), 605, doi: 10.3390/microorganisms9030605.

148. Hatmal, M.M.; Al-Hatamleh, M.A.I.; Olaimat, A.N.; Hatmal, M.; Alhaj-Qasem, D.M.; Olaimat, T.M.; Mohamud, R. Side Effects and Perceptions Following COVID-19 Vaccination in Jordan: A Randomized, Cross-Sectional Study Implementing Machine Learning for Predicting Severity of Side Effects. Vaccines (Basel) 2021, 9, 556, doi:10.3390/vaccines9060556.

149. Huang, B.; Dai, L.; Wang, H.; Hu, Z.; Yang, X.; Tan, W.; Gao, G.F. Neutralization of SARS-CoV-2 VOC $501 Y . V 2$ by human antisera elicited by both inactivated BBIBP-CorV and recombinant dimeric RBD ZF2001 vaccines. bioRxiv 2021, 2021.02.01.429069, doi:10.1101/2021.02.01.429069.

150. Jeewandara, C.; Aberathna, I.S.; Pushpakumara, P.D.; Kamaladasa, A.; Guruge, D.; Jayathilaka, D.; Gunesekara, B.; Tanussiya, S.; Kuruppu, H.; Ranasinghe, T.; et al. Antibody and T cell responses to Sinopharm/BBIBP-CorV in naïve and previously infected individuals in Sri Lanka. . medRxiv 2021, 2021.07.15.21260621, doi:https://doi.org/10.1101/2021.07.15.21260621.

151. Wu, Z.; Hu, Y.; Xu, M.; Chen, Z.; Yang, W.; Jiang, Z.; Li, M.; Jin, H.; Cui, G.; Chen, P.; et al. Safety, tolerability, and immunogenicity of an inactivated SARS-CoV-2 vaccine (CoronaVac) in healthy adults aged 60 years and older: a randomised, double-blind, placebo-controlled, phase 1/2 clinical trial. Lancet Infect Dis 2021, 21, 803-812, doi:10.1016/S1473-3099(20)30987-7.

152. Chen, Y.; Shen, H.; Huang, R.; Tong, X.; Wu, C. Serum neutralising activity against SARS-CoV-2 variants elicited by CoronaVac. Lancet Infect Dis 2021, 21, 1071-1072,doi:10.1016/S1473-3099(21)00287-5.

153. Hitchings, M.D.T.; Ranzani, O.T.; Torres, M.S.S.; de Oliveira, S.B.; Almiron, M.; Said, R.; Borg, R.; Schulz, W.L.; de Oliveira, R.D.; da Silva, P.V.; et al. Effectivenessof CoronaVac among healthcare workers in the setting of high SARS-CoV-2 Gamma variant transmission in Manaus, Brazil: A test-negative case-control study. Lancet Reg Health Am 2021, 1, 100025, doi:10.1016/j.lana.2021.100025.

154. Ranzani, O.T.; Hitchings, M.D.T.; Dorion, M.; D'Agostini, T.L.; de Paula, R.C.; de Paula, O.F.P.; Villela, E.F.M.; Torres, M.S.S.; de Oliveira, S.B.; Schulz, W.; et al. Effectiveness of the CoronaVac vaccine in older adults during a gamma variant associated epidemic of covid-19 in Brazil: test negative case-control study. BMJ 2021, 374, n2015, doi:10.1136/bmj.n2015.

155. Han, B.; Song, Y.; Li, C.; Yang, W.; Ma, Q.; Jiang, Z.; Li, M.; Lian, X.; Jiao, W.; Wang, L.; et al. Safety, tolerability, and immunogenicity of an inactivated SARS- CoV-2 vaccine (CoronaVac) in healthy children and adolescents: a double-blind, randomised, controlled, phase 1/2 clinical trial. Lancet Infect Dis 2021, doi:10.1016/S1473-3099(21)00319-4.

156. Faria, E.; Guedes, A.R.; Oliveira, M.S.; Moreira, M.V.G.; Maia, F.L.; Barboza, A.S.; Leme, M.D.; Letaif, L.S.H.; Miethke-Morais, A.; Bonfa, E.; et al. Performance of vaccination with CoronaVac in a cohort of healthcare workers (HCW)-preliminary report. medRxiv 2021, 2021.04.12.21255308 doi:https://doi.org/10.1101/2021.04.12.21255308.

157. Bayram, A.; Demirbakan, H.; Gunel Karadeniz, P.; Erdogan, M.; Kocer, I. Quantitation of antibodies against SARS-CoV-2 spike protein after two doses of CoronaVac in healthcare workers. J Med Virol 2021, 93, 5560-5567, doi:10.1002/jmv.27098.

158. Estofolete, C.F.; Banho, C.A.; Campos, G.R.F.; Marques, B.C.; Sacchetto, L.; Ullmann, L.S.; Possebon, F.S.; Machado, L.F.; Syrio, J.D.; Araujo Junior, J.P.; et al. Case Study of Two Post Vaccination SARS-CoV-2 Infections with P1 Variants in CoronaVac Vaccinees in Brazil. Viruses 2021, 13, 1237, doi:10.3390/v13071237.

159. Kemal, R.A.S., D. K.; Paulin, A. J. Antibody Response to CoronaVac Vaccine in Indonesian COVID-19 Survivor. medRxiv 2021, 2021.05.28.2125461, doi:https://doi.org/10.1101/2021.05.28.21254613.

160. Calil, V.M.L.T.; Palmeira, P.; Zheng, Y.; Krebs, V.L.J.; Carvalho, W.B. de; Carneiro-Sampaio, M. CoronaVac can induce the production of anti-SARS-CoV-2 IgA antibodies in human milk. Clinics 2021, 76, doi:10.6061/clinics/2021/e3185.

161. Akpolat, T.; Uzun, O. Reduced mortality rate after coronavac vaccine among healthcare workers. J Infect 2021, 83, e20-e21, doi:10.1016/j.jinf.2021.06.005.

162. Tanriover, M.D.; Doğanay, H.L.; Akova, M.; Güner, H.R.; Azap, A.; Akhan, S.; Köse, Ş.; Erdinç, F.Ş.; Akalın, E.H.; Tabak, Ö.F.; et al. Efficacy and safety of an inactivated whole-virion SARS-CoV-2 vaccine (CoronaVac): interim results of a double-blind, randomised, placebo-controlled, phase 3 trial in Turkey. The Lancet 2021 398, 213-222, doi: 10.1016/S0140-6736(21)01429-X. 
163. Pagotto, V.; Ferloni, A.; Mercedes Soriano, M.; Diaz, M.; Braguinsky Golde, N.; Gonzalez, M.I.; Asprea, V.; Staneloni, M.I.; Zingoni, P.; Vidal, G.; et al. Active monitoring of early safety of Sputnik V vaccine in Buenos Aires, Argentina. Medicina(B Aires) 2021, 81, 408-414.

164. Ikegame, S.; Siddiquey, M.N.A.; Hung, C.T.; Haas, G.; Brambilla, L.; Oguntuyo, K.Y.; Kowdle, S.; Chiu, H.P.; Stevens, C.S.; Vilardo, A.E.; et al. Neutralizing activityof Sputnik V vaccine sera against SARS-CoV-2 variants. Nat Commun 2021, 12, 4598, doi:10.1038/s41467-021-24909-9.

165. Ikegame, S., Siddiquey, M.N., Hung, C.T., Haas, G., Brambilla, L., Oguntuyo, K.Y., Kowdle, S., Vilardo, A.E., Edelstein, A., Perandones, C. and Kamil, J.P. Qualitativelydistinct modes of Sputnik V vaccine-neutralization escape by SARS-CoV-2 Spike variants. medRxiv 2021， 2021.03.31.21254660 doi:https://doi.org/10.1101/2021.03.31.21254660.

166. Gushchin, V.A.; Dolzhikova, I.V.; Shchetinin, A.M.; Odintsova, A.S.; Siniavin, A.E.; Nikiforova, M.A.; Pochtovyi, A.A.; Shidlovskaya, E.V.; Kuznetsova, N.A.; Burgasova, O.A.; et al. Neutralizing Activity of Sera from Sputnik V-Vaccinated People against Variants of Concern (VOC: B.1.1.7, B.1.351, P.1, B.1.617.2, B.1.617.3) and Moscow Endemic SARS-CoV-2 Variants. Vaccines (Basel) 2021, 9, doi:10.3390/vaccines9070779.

167. Sapkal, G.N.; Yadav, P.D.; Ella, R.; Deshpande, G.R.; Sahay, R.R.; Gupta, N.; Vadrevu, K.M.; Abraham, P.; Panda, S.; Bhargava, B. Inactivated COVID-19 vaccineBBV152/COVAXIN effectively neutralizes recently emerged B.1.1.7 variant of SARS-CoV-2. J Travel Med 2021, 28, taab051, doi:10.1093/jtm/taab051.

168. Ella, R.; Reddy, S.; Jogdand, H.; Sarangi, V.; Ganneru, B.; Prasad, S.; Das, D.; Raju, D.; Praturi, U.; Sapkal, G.; et al. Safety and immunogenicity clinical trial of an inactivated SARS-CoV-2 vaccine, BBV152 (a phase 2, double-blind, randomised controlled trial) and the persistence of immune responses from a phase 1 follow-up report. medRxiv 2020, 2020.12.21.20248643, doi:10.1101/2020.12.21.20248643.

169. Ella, R.; Vadrevu, K.M.; Jogdand, H.; Prasad, S.; Reddy, S.; Sarangi, V.; Ganneru, B.;Sapkal, G.; Yadav, P.; Abraham, P.; et al. Safety and immunogenicity of an inactivated SARS-CoV-2 vaccine, BBV152: a double-blind, randomised, phase 1trial. Lancet Infect Dis 2021, 21, 637-646, doi:10.1016/S1473-3099(20)30942-7.

170. Srivastava, R.K.; Ish, P. Covid-Vaccination Group, S. The initial experience ofCOVID-19 vaccination from a tertiary care centre of India. Monaldi Arch Chest Dis 2021, doi:10.4081/monaldi.2021.1816.

171. Zhu, F.C.; Li, Y.H.; Guan, X.H.; Hou, L.H.; Wang, W.J.; Li, J.X.; Wu, S.P.; Wang, B.S.; Wang, Z.; Wang, L.; et al. Safety, tolerability, and immunogenicity of a recombinant adenovirus type- 5 vectored COVID-19 vaccine: a dose-escalation, open- label, non-randomised, first-in-human trial. Lancet 2020, 395, 1845-1854, doi:10.1016/S0140-6736(20)31208-3.

172. O'Brien, E. Covid Antibodies Endure Over Six Months in China Trial Subjects. 2020, https://www.bloomberg.com/news/articles/2020-09-25/covid-antibodies-endure- over-six-months-in-china-trial-subjects. (Accessed on September 10, 2021)

173. Zhu, F.C.; Guan, X.H.; Li, Y.H.; Huang, J.Y.; Jiang, T.; Hou, L.H.; Li, J.X.; Yang, B.F.; Wang, L.; Wang, W.J.; et al. Immunogenicity and safety of a recombinant adenovirus type-5-vectored COVID-19 vaccine in healthy adults aged 18 years or older: a randomised, double-blind, placebo-controlled, phase 2 trial. Lancet 2020, 396, 479-488, doi:10.1016/S0140-6736(20)31605-6.

174. de Vrieze, J. Pfizer's vaccine raises allergy concerns. Science 2021, 371, 10-11,doi:10.1126/science.371.6524.10.

175. Ortega Rodriguez, N.R.; Audicana Berasategui, M.T.; de la Hoz Caballer, B.; Valero Santiago, A. The Century of mRNA Vaccines: COVID-19 Vaccines and Allergy. J Investig Allergol Clin Immunol 2021, 31, 89-91, doi:10.18176/jiaci.0665.

176. Troelnikov, A.; Perkins, G.; Yuson, C.; Ahamdie, A.; Balouch, S.; Hurtado, P.R.; Hissaria, P. Basophil reactivity to BNT162b2 is mediated by PEGylated lipid nanoparticles in patients with PEG allergy. J Allergy Clin Immunol 2021, 148, 91-95, doi:10.1016/j.jaci.2021.04.032.

177. Shemer, A.; Pras, E.; Einan-Lifshitz, A.; Dubinsky-Pertzov, B.; Hecht, I. Association of COVID-19 Vaccination and Facial Nerve Palsy: A Case-Control Study. JAMA Otolaryngol Head Neck Surg 2021, 147, 739-743, doi:10.1001/jamaoto.2021.1259.

178. Nevet, A. Acute myocarditis associated with anti-COVID-19 vaccination. Clin Exp Vaccine Res 2021, 10, 196-197, doi:10.7774/cevr.2021.10.2.196.

179. Perera, R.; Fletcher, J. Thromboembolism and the Oxford-AstraZeneca vaccine. BMJ 2021, 373, n1159, doi:10.1136/bmj.n1159.

180. Tobaiqy, M.; Elkout, H.; MacLure, K. Analysis of Thrombotic Adverse Reactions of COVID-19 AstraZeneca Vaccine Reported to EudraVigilance Database. Vaccines(Basel) 2021, 9, 393, doi:10.3390/vaccines9040393.

181. Nawwar, A.A.; Searle, J.; Singh, R.; Lyburn, I.D. Oxford-AstraZeneca COVID-19 vaccination induced lymphadenopathy on [18F]Choline PET/CT-not only an FDG finding. Eur J Nucl Med Mol Imaging 2021, 48, 2657-2658, doi:10.1007/s00259-021-052792.

182. Garnier, M.; Curado, A.; Billoir, P.; Barbay, V.; Demeyere, M.; Dacher, J.N. Imaging of Oxford/AstraZeneca(R) COVID-19 vaccine-induced immune thrombotic thrombocytopenia. Diagn Interv Imaging 2021, S2211-5684(21)00107-8, doi:10.1016/j.diii.2021.04.005.

183. Yocum, A.; Simon, E.L. Thrombotic Thrombocytopenic Purpura after Ad26.COV2-S Vaccination. Am J Emerg Med 2021, S07356757(21)00376-4, doi:10.1016/j.ajem.2021.05.001.

184. Nishizawa, Y.; Hoshina, Y.; Baker, V. Bell's palsy following the Ad26. COV2. S COVID-19 vaccination. QJM: An International Journal of Medicine 2021, hcab143, doi: 10.1093/qjmed/hcab143.

185. Mahase, E. Covid-19: Unusual blood clots are "very rare side effect" of Janssen vaccine, says EMA. BMJ 2021, 373, n1046, doi:10.1136/bmj.n1046.

186. Takuva, S.; Takalani, A.; Garrett, N.; Goga, A.; Peter, J.; Louw, V.; Opie, J.; Jacobson, B.; Sanne, I.; Gail-Bekker, L.; et al. Thromboembolic Events in the South African Ad26.COV2.S Vaccine Study. N Engl J Med 2021, 385, 570-571,doi:10.1056/NEJMc2107920. 
187. MacNeil, J.R.; Su, J.R.; Broder, K.R.; Guh, A.Y.; Gargano, J.W.; Wallace, M.; Hadler, S.C.; Scobie, H.M.; Blain, A.E.; Moulia, D.; et al. Updated Recommendationsfrom the Advisory Committee on Immunization Practices for Use of the Janssen (Johnson \& Johnson) COVID-19 Vaccine After Reports of Thrombosis with Thrombocytopenia Syndrome Among Vaccine Recipients United States, April 2021.MMWR Morb Mortal Wkly Rep 2021, 70, 651-656, doi:10.15585/mmwr.mm7017e4.

188. CDC. Allergic reactions including anaphylaxis after receipt of the first dose of Moderna COVID-19 Vaccine-United States. 2021, p.125.

189. McNeil, M.M.; Weintraub, E.S.; Duffy, J.; Sukumaran, L.; Jacobsen, S.J.; Klein,N.P.; Hambidge, S.J.; Lee, G.M.; Jackson, L.A.; Irving, S.A.; et al. Risk of anaphylaxis after vaccination in children and adults. J Allergy Clin Immunol 2016, 137, 868-878, doi:10.1016/j.jaci.2015.07.048.

190. Wei, N.; Fishman, M.; Wattenberg, D.; Gordon, M.; Lebwohl, M. "COVID arm": A reaction to the Moderna vaccine. JAAD Case Rep 2021, 10, 92-95, doi:10.1016/j.jdcr.2021.02.014.

191. Subramony, R.; Lin, L.C.; Knight, D.K.; Aminlari, A.; Belovarski, I. Bilateral Retinal Detachments in a Healthy 22-year-old Female Following Moderna SARS-CoV-2 Vaccination. J Emerg Med 2021, doi:10.1016/j.jemermed.2021.07.034

192. Xia, S.; Zhang, Y.; Wang, Y.; Wang, H.; Yang, Y.; Gao, G.F.; Tan, W.; Wu, G.; Xu, M.; Lou, Z.; et al. Safety and immunogenicity of an inactivated SARS-CoV-2 vaccine, BBIBP-CorV: a randomised, double-blind, placebo-controlled, phase 1/2trial. Lancet Infect Dis 2021, 21, 39-51, doi:10.1016/S1473-3099(20)30831-8.

193. Abu-Hammad, O.; Alduraidi, H.; Abu-Hammad, S.; Alnazzawi, A.; Babkair, H.; Abu-Hammad, A.; Nourwali, I.; Qasem, F.; Dar-Odeh, N. Side Effects Reported by Jordanian Healthcare Workers Who Received COVID-19 Vaccines. Vaccines (Basel) 2021, 9, 577, doi:10.3390/vaccines9060577.

194. Riad, A.; Sagiroglu, D.; Ustun, B.; Pokorna, A.; Klugarova, J.; Attia, S.; Klugar, M. Prevalence and Risk Factors of CoronaVac Side Effects: An Independent Cross-Sectional Study among Healthcare Workers in Turkey. J Clin Med 2021, 10, 2629, doi:10.3390/jcm10122629.

195. Orenay, O.M.; Balta, I.; Yigit, D.; Eksioglu, M. Systemic drug-related intertriginous and flexural exanthema like eruption after CoronaVac vaccine. J Eur Acad Dermatol Venereol 2021, 35, e634-e635, doi:10.1111/jdv.17454.

196. Akdas, E.; Ilter, N.; Ogut, B.; Erdem, O. Pityriasis rosea following CoronaVac COVID-19 vaccination: a case report. J Eur Acad Dermatol Venereol 2021, 35, e491-e493, doi:10.1111/jdv.17316.

197. Cebeci, F.; Kartal, I. Petechial skin rash associated with CoronaVac vaccination: first cutaneous side effect report before phase 3 results. Eur J Hosp Pharm 2021, ejhpharm-2021-002794, doi:10.1136/ejhpharm-2021-002794.

198. Onsun, N.; Kaya, G.; Isik, B.G.; Gunes, B. A generalized pustular psoriasis flare after CoronaVac COVID-19 vaccination: Case report. Health Promot Perspect 2021, 11, 261-262, doi:10.34172/hpp.2021.32.

199. Ozdemir, I.H.; Ozlek, B.; Ozen, M.B.; Gunduz, R.; Bayturan, O. Type 1 Kounis Syndrome Induced by Inactivated SARS-COV-2 Vaccine. J Emerg Med 2021, S0736-4679(21)00391-7, doi:10.1016/j.jemermed.2021.04.018.

200. An, Q.-j.; Qin, D.-a.; Pei, J.-x. Reactive arthritis after COVID-19 vaccination. Hum Vaccin Immunother 2021, 17, 2954-2956, doi:10.1080/21645515.2021.1920274

201. Moutinho, S.; Wadman, M. Brazil and Russia face off over vaccine contamination charge. Science 2021, 372, 554. doi:10.1126/science.372.6542.554-a.

202. Jarynowski, A.; Semenov, A.; Kamiński, M.; Belik, V. Mild Adverse Events of Sputnik V Vaccine Extracted from Russian Language Telegram Posts via BERT Deep Learning Model. medRxiv 2021, 2021.06.14.21258875, doi:10.1101/2021.06.14.21258875.

203. Montalti, M.; Soldà, G.; Di Valerio, Z.; Salussolia, A.; Lenzi, J.; Forcellini, M.; Barvas, E.; Guttman, S.; Messina, R.; Poluzzi, E.; et al. ROCCA study protocol and interim analysis on safety of Sputnik V vaccine (Gam-COVID-Vac) in the Republic of San Marino: an observational study using active surveillance. medRxiv 2021, 2021.05.03.21256509, doi:10.1101/2021.05.03.21256509.

204. Mulligan, M.J.; Lyke, K.E.; Kitchin, N.; Absalon, J.; Gurtman, A.; Lockhart, S.; Neuzil, K.; Raabe, V.; Bailey, R.; Swanson, K.A.; et al. Phase I/II study of COVID-19RNA vaccine BNT162b1 in adults. Nature 2020, 586, 589-593, doi:10.1038/s41586- 020-2639-4.

205. Walsh, E.E.; Frenck, R.W., Jr.; Falsey, A.R.; Kitchin, N.; Absalon, J.; Gurtman, A.; Lockhart, S.; Neuzil, K.; Mulligan, M.J.; Bailey, R.; et al. Safety and Immunogenicityof Two RNA-Based Covid-19 Vaccine Candidates. N Engl J Med 2020, 383, 2439- 2450, doi:10.1056/NEJMoa2027906.

206. Shinde, V.; Bhikha, S.; Hoosain, Z.; Archary, M.; Bhorat, Q.; Fairlie, L.; Lalloo, U.; Masilela, M.S.L.; Moodley, D.; Hanley, S.; et al. Efficacy of NVX-CoV2373 Covid-19 Vaccine against the B.1.351 Variant. $N$ Engl J Med 2021, 384, 1899-1909, doi:10.1056/NEJMoa2103055.

207. Weinreich, D.M.; Sivapalasingam, S.; Norton, T.; Ali, S.; Gao, H.; Bhore, R.; Musser,B.J.; Soo, Y.; Rofail, D.; Im, J.; et al. REGNCOV2, a Neutralizing Antibody Cocktail, in Outpatients with Covid-19. $N$ Engl J Med 2021, 384, 238-251, doi:10.1056/NEJMoa2035002.

208. Edridge, A.W.D; Kaczorowska, J.; Hoste, A.C.R.; Bakker, M.; Klein, M.; Loens, K.; Jebbink, M.F.; Matser, A.; Kinsella, C.M.; Rueda, P.; et al. Seasonal coronavirus protective immunity is short-lasting. Nat Med 2020, 26, 1691-1693, doi:10.1038/s41591-0201083-1.

209. Kim, A.Y.; Gandhi, R.T. Re-infection with SARS-CoV-2: What Goes Around May Come Back Around. Clin Infect Dis 2020, ciaa1541, doi:10.1093/cid/ciaa1541

210. Burton, D.R.; Topol, E.J. Toward superhuman SARS-CoV-2 immunity? Nat Med 2021, 27, 5-6, doi:10.1038/s41591-02001180-x. 
211. Radbruch, A.; Chang, H.D. A long-term perspective on immunity to COVID. Nature 2021, 595, 359-360, doi:10.1038/d41586021-01557-z

212. Kim, D.S.; Rowland-Jones, S.; Gea-Mallorqui, E. Will SARS-CoV-2 Infection Elicit Long-Lasting Protective or Sterilising Immunity? Implications for Vaccine Strategies (2020). Front Immunol 2020, 11, 571481, doi:10.3389/fimmu.2020.571481.

213. He, S.; Han, J.; Lichtfouse, E. Backward transmission of COVID-19 from humans to animals may propagate reinfections and induce vaccine failure. Environ Chem Lett 2021, doi:10.1007/s10311-020-01140-4.

214. Cromer, D.; Juno, J.A.; Khoury, D.; Reynaldi, A.; Wheatley, A.K.; Kent, S.J.; Davenport, M.P. Prospects for durable immune control of SARS-CoV-2 and prevention of reinfection. Nat Rev Immunol 2021, 21, 395-404, doi:10.1038/s41577- 021-00550-x.

215. Harvey, W.T.; Carabelli, A.M.; Jackson, B.; Gupta, R.K.; Thomson, E.C.; Harrison, E.M.; Ludden, C.; Reeve, R.; Rambaut, A.; Consortium, C.-G.U.; et al. SARS-CoV-2 variants, spike mutations and immune escape. Nat Rev Microbiol 2021, 19, 409-424, doi:10.1038/s41579-021-00573-0.

216. Rogliani, P.; Chetta, A.; Cazzola, M.; Calzetta, L. SARS-CoV-2 Neutralizing Antibodies: A Network Meta-Analysis across Vaccines. Vaccines (Basel) 2021, 9, 227, doi:10.3390/vaccines9030227.

217. Britton, A.; Jacobs Slifka, K.M.; Edens, C.; Nanduri, S.A.; Bart, S.M.; Shang, N.; Harizaj, A.; Armstrong, J.; Xu, K.; Ehrlich, H.Y.; et al. Effectiveness of the Pfizer- BioNTech COVID-19 Vaccine Among Residents of Two Skilled Nursing Facilities Experiencing COVID-19 Outbreaks - Connecticut, December 2020-February 2021. MMWR Morb Mortal Wkly Rep 2021, 70, 396-401, doi:10.15585/mmwr.mm7011e3.

218. Tenforde, M.W.; Olson, S.M.; Self, W.H.; Talbot, H.K.; Lindsell, C.J.; Steingrub, J.S.; Shapiro, N.I.; Ginde, A.A.; Douin, D.J.; Prekker, M.E.; et al. Effectiveness of Pfizer-BioNTech and Moderna Vaccines Against COVID-19 Among Hospitalized Adults Aged >/=65 Years - United States, January-March 2021. MMWR Morb Mortal Wkly Rep 2021, 70, 674-679, doi:10.15585/mmwr.mm7018e1.

219. Thompson, M.G.; Burgess, J.L.; Naleway, A.L.; Tyner, H.L.; Yoon, S.K.; Meece, J.; Olsho, L.E.W.; Caban-Martinez, A.J.; Fowlkes, A.; Lutrick, K.; et al. Interim Estimates of Vaccine Effectiveness of BNT162b2 and mRNA-1273 COVID-19 Vaccines in Preventing SARS-CoV-2 Infection Among Health Care Personnel, First Responders, and Other Essential and Frontline Workers - Eight U.S. Locations, December 2020-March 2021. MMWR Morb Mortal Wkly Rep 2021, 70, 495-500, doi:10.15585/mmwr.mm7013e3.

220. Karron, R.A.; Key, N.S.; Sharfstein, J.M. Assessing a Rare and Serious Adverse Event Following Administration of the Ad26.COV2.S Vaccine. JAMA 2021, 325, 2445-2447, doi:10.1001/jama.2021.7637.

221. Dewanjee, S.; Vallamkondu, J.; Kalra, R.S.; Puvvada, N.; Kandimalla, R.; Reddy, P.H. Emerging COVID-19 Neurological Manifestations: Present Outlook and Potential Neurological Challenges in COVID-19 Pandemic. Mol Neurobiol 2021, doi:10.1007/s12035-021-02450-6.

222. Kalra, R.S.; Dhanjal, J.K.; Meena, A.S.; Kalel, V.C.; Dahiya, S.; Singh, B.; Dewanjee, S.; Kandimalla, R. COVID-19, Neuropathology, and Aging: SARS-CoV-2 neurological infection, mechanism, and associated complications. Front Aging Neurosci 2021, 13, 662786, doi:10.3389/fnagi.2021.662786

223. Meo, S.A.; Bukhari, I.A.; Akram, J.; Meo, A.S.; Klonoff, D.C. COVID-19 vaccines: comparison of biological, pharmacological characteristics and adverse effects of Pfizer/BioNTech and Moderna Vaccines. Eur Rev Med Pharmacol Sci 2021, 25, 1663-1669, doi:10.26355/eurrev_202102_24877.

224. Wang, G.L.; Wang, Z.Y.; Duan, L.J.; Meng, Q.C.; Jiang, M.D.; Cao, J.; Yao, L.; Zhu,K.L.; Cao, W.C.; Ma, M.J. Susceptibility of Circulating SARS-CoV-2 Variants to Neutralization. N Engl J Med 2021, 384, 2354-2356, doi:10.1056/NEJMc2103022.

225. Muena, N.A.; García-Salum, T.; Pardo-Roa, C.; Serrano, E.F.; Levican, J.; Avendaño,M.J.; Almonacid, L.I.; Valenzuela, G.; Poblete, E.; Strohmeier, S. Long-lasting neutralizing antibody responses in SARS-CoV-2 seropositive individuals are robustly boosted by immunization with the CoronaVac and BNT162b2 vaccines. medRxiv 2021, 18:2021.05.17.21257197, doi:10.1101/2021.05.17.21257197.

226. Ulhaq, Z.S.; Soraya, G.V.; Indriana, K. Breakthrough COVID-19 case after full-dose administration of CoronaVac vaccine. Indian J Med Microbiol 2021, S0255-0857(21)04119-0, doi:10.1016/j.ijmmb.2021.05.017.

227. Calzetta, L.; Ritondo, B.L.; Coppola, A.; Matera, M.G.; Di Daniele, N.; Rogliani, P. Factors Influencing the Efficacy of COVID-19 Vaccines: A Quantitative Synthesis of Phase III Trials. Vaccines (Basel) 2021, 9, 341, doi:10.3390/vaccines9040341.

228. Dobrovidova, O. Latest Russian vaccine comes with a big dose of mystery. Science 2021, 372, 116-117, doi:10.1126/science.372.6538.116.

229. Li, Y.; Tenchov, R.; Smoot, J.; Liu, C.; Watkins, S.; Zhou, Q. A Comprehensive Review of the Global Efforts on COVID-19 Vaccine Development. ACS Cent Sci 2021, 7, 512-533, doi:10.1021/acscentsci.1c00120.

230. Farrera-Soler, L.; Daguer, J.P.; Barluenga, S.; Vadas, O.; Cohen, P.; Pagano, S.; Yerly, S.; Kaiser, L.; Vuilleumier, N.; Winssinger, N. Identification of immunodominant linear epitopes from SARS-CoV-2 patient plasma. PLoS One 2020, 15, e0238089, doi:10.1371/journal.pone.0238089.

231. Bhuyan, A. India begins COVID-19 vaccination amid trial allegations. Lancet 2021, 397, 264, doi:10.1016/S0140-6736(21)001458.

232. Singh, A.K.; Phatak, S.; Singh, N.K.; Gupta, A.; Sharma, A.; Bhattacharjee, K.;Singh, R. Antibody Response after First-dose of ChAdOx1-nCOV (Covishield) and BBV-152 (Covaxin) amongst Health Care Workers in India: Preliminary Results of Crosssectional Coronavirus Vaccine-induced Antibody Titre (COVAT) study. medRxiv 2021, 2021.04.07.21255078, doi:https://doi.org/10.1101/2021.04.07.21255078 
233. Singh, A.K.; Phatak, S.R.; Singh, R.; Bhattacharjee, K.; Singh, N.K.; Gupta, A.; Sharma, A. Antibody Response after Second-dose of ChAdOx1-nCOV (CovishieldTM) and BBV-152 (CovaxinTM) among Health Care Workers in India: Final Results of Crosssectional Coronavirus Vaccine-induced Antibody Titre (COVAT) study. medRxiv 2021, 2021.06.02.21258242, doi:https://doi.org/10.1101/2021.06.02.21258242 